\title{
Einfluss einer horizontalen Ganzkörpervibration unter verschiedenen Frequenzen auf die Frakturheilung an der osteopenen Rattentibia
}

\author{
INAUGURAL-DISSERTATION \\ zur Erlangung des Doktorgrades \\ der Medizinischen Fakultät der \\ Georg-August-Universität zu Göttingen
}

vorgelegt von

Peggy Lieberwirth

aus

Karl-Marx-Stadt, jetzt Chemnitz

Göttingen 2018 
Dekan:

Referentin:

Ko-Referent/in:

Drittrefrent/in:
Prof. Dr. rer. nat. H. K. Kroemer

Prof. Dr. med. E. K. Stürmer

Datum der mündlichen Prüfung: 
Hiermit erkläre ich, die Dissertation mit dem Titel „Einfluss einer horizontalen Ganzkörpervibration unter verschiedenen Frequenzen auf die Frakturheilung an der osteopenen Rattentibia" eigenständig angefertigt und keine anderen als die von mir angegebenen Quellen und Hilfsmittel verwendet zu haben.

Göttingen, den 


\section{Inhaltsverzeichnis}

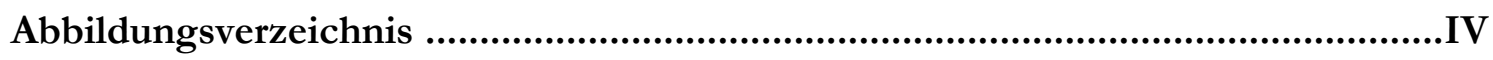

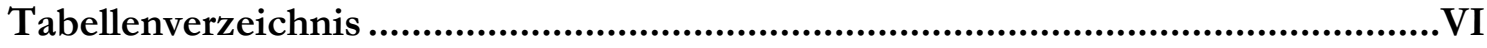

Abkürzungsverzeichnis.................................................................................... VII

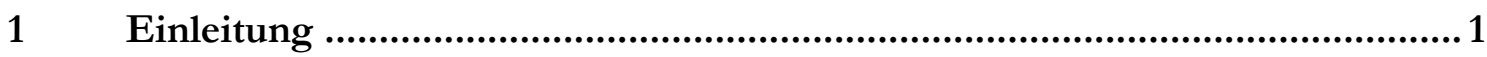

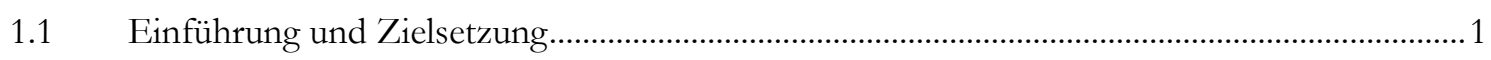

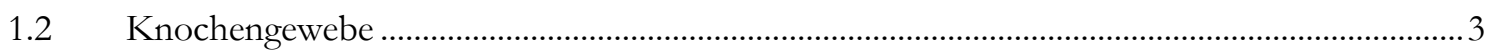

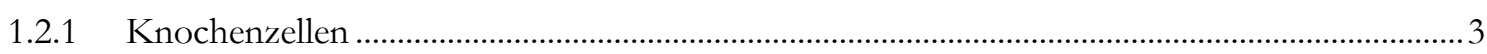

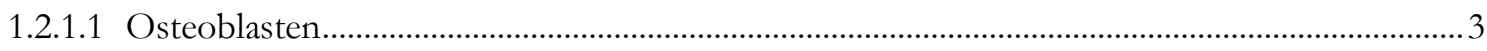

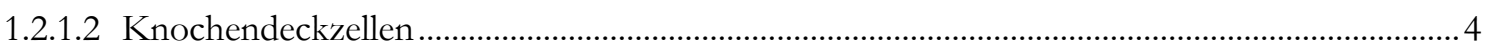

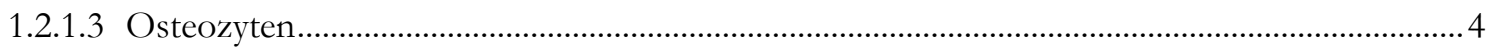

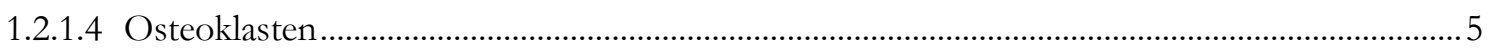

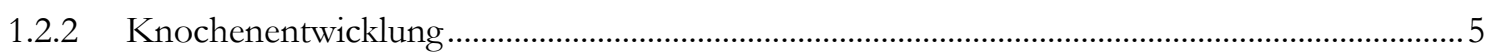

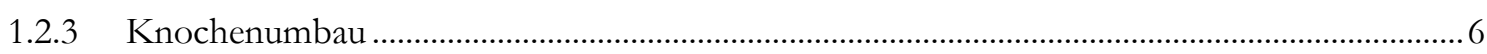

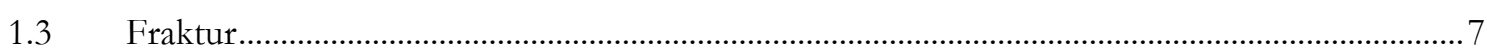

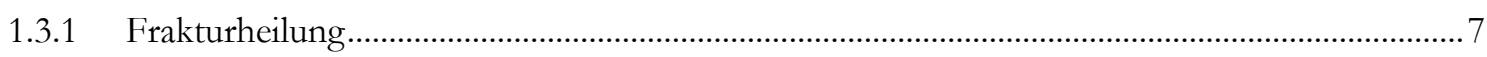

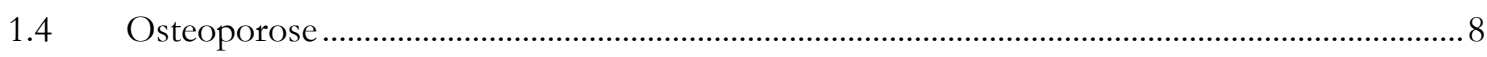

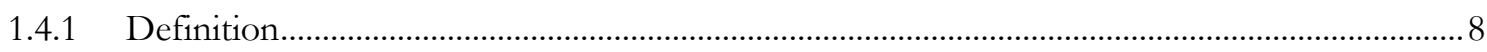

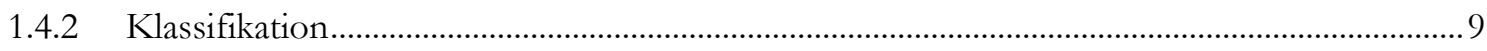

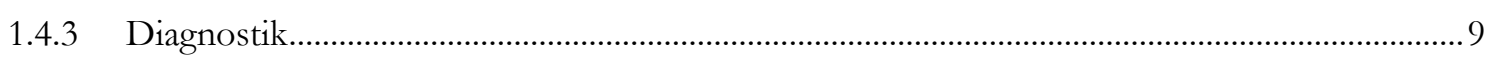

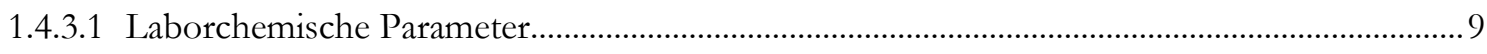

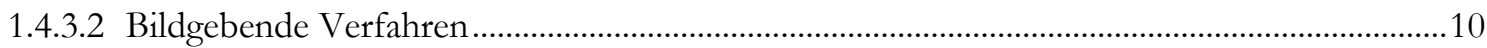

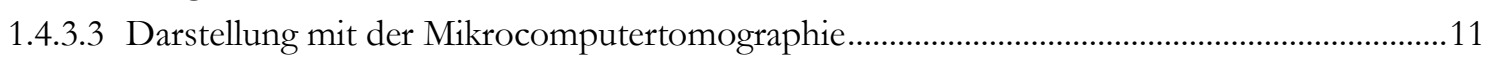

1.4.4 Auswirkungen eines Östrogenmangels auf das Knochengewebe .............................................11

1.4.5 Besonderheiten der Frakturheilung am osteoporotischen Knochen ........................................12

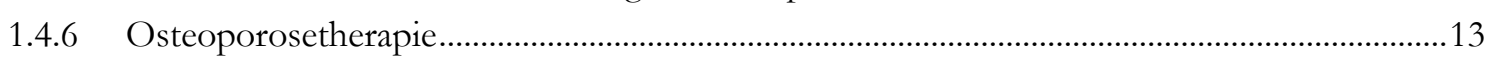

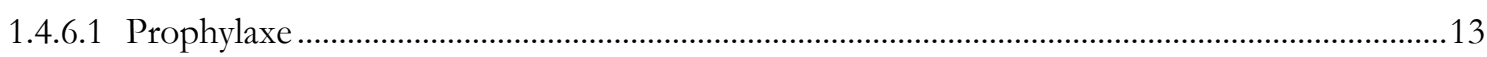

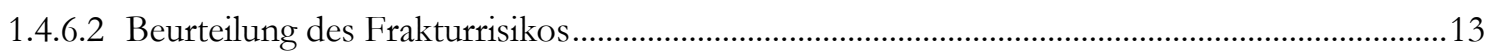

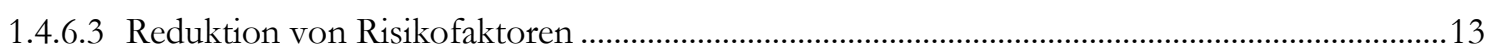

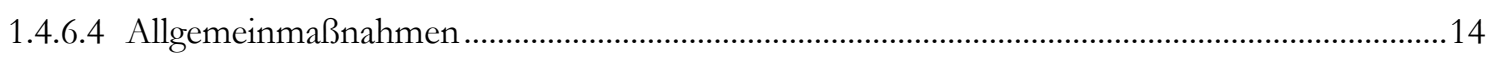

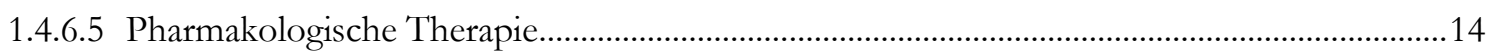

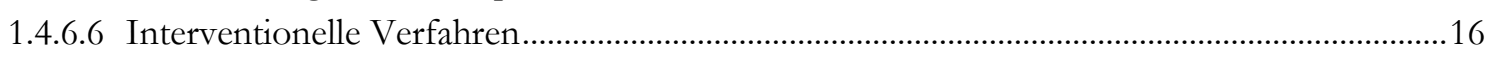

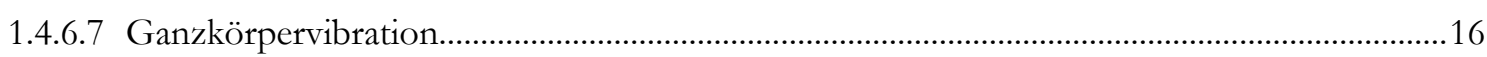

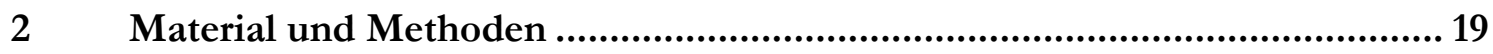

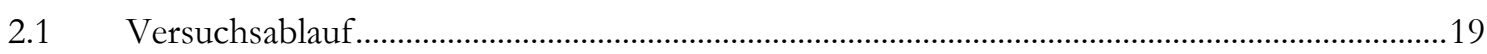

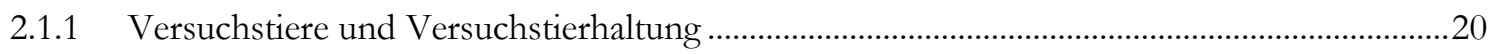

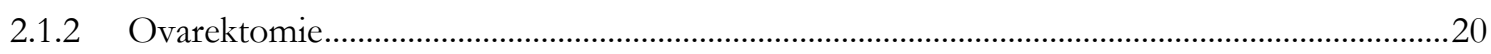

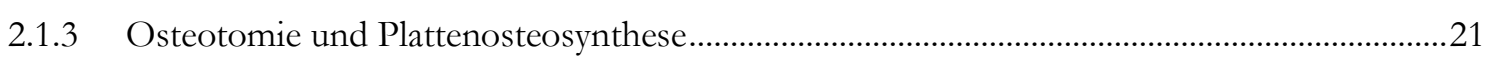

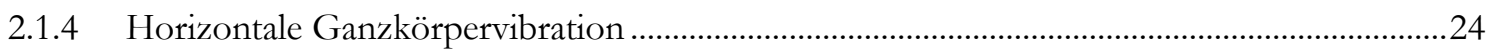




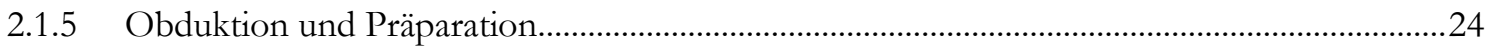

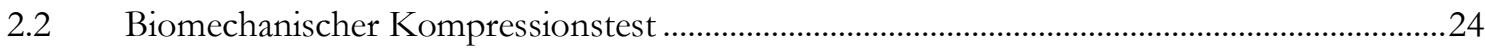

2.2.1 Durchführung des biomechanischen Kompressionstests ...................................................24

2.2.2 Auswertung des biomechanischen Kompressionstests.............................................................26

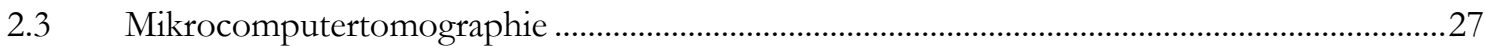

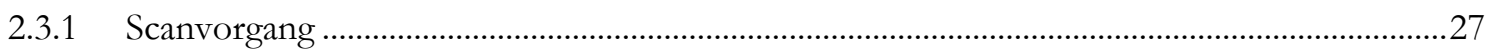

2.3.2 Auswertung der Mikrocomputertomographien.................................................................28

2.3.3 Umrechnung der Bone Mineral Density............................................................................... 30

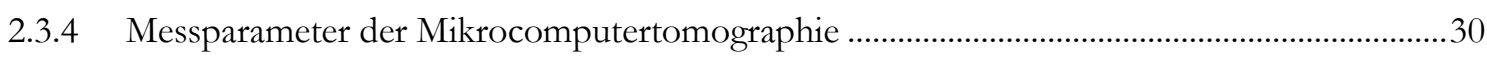

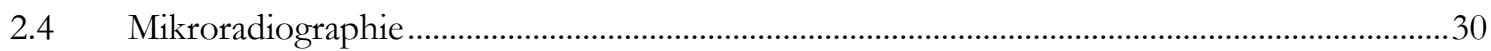

2.4.1 Histologische Aufarbeitung und Erstellen der Mikroradiographien........................................30

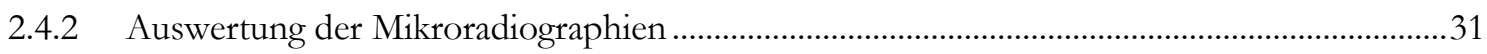

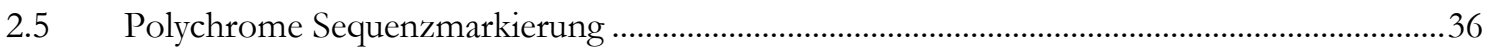

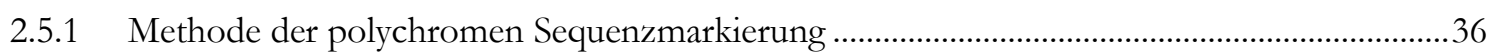

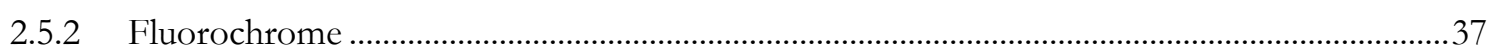

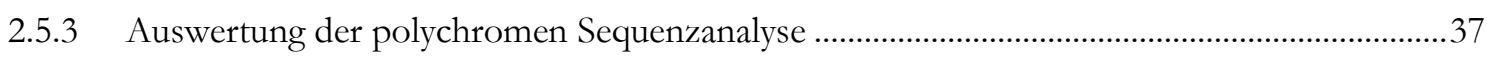

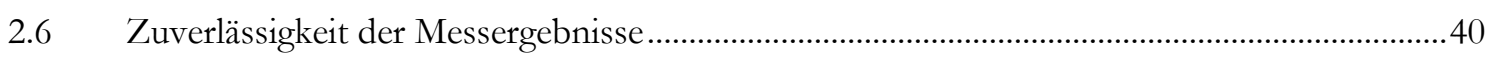

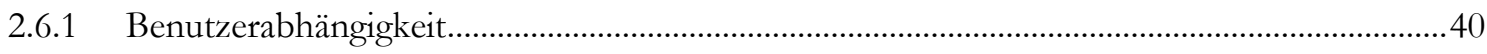

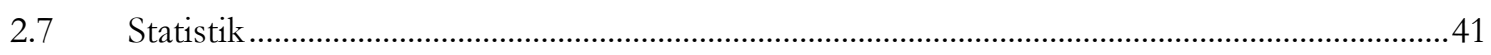

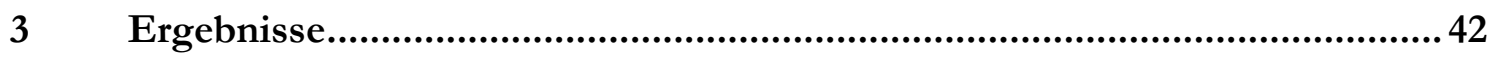

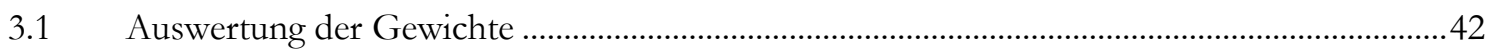

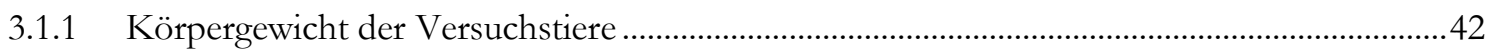

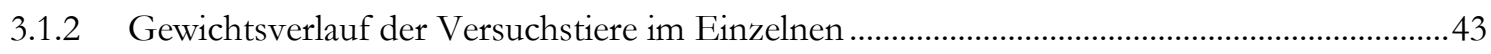

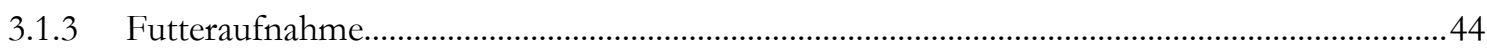

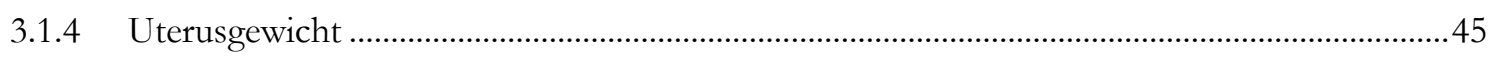

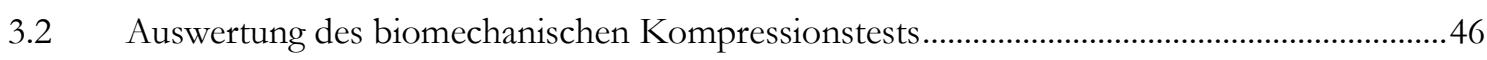

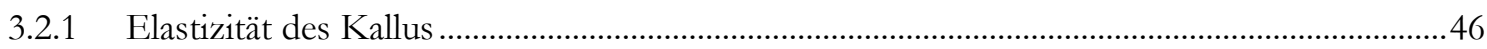

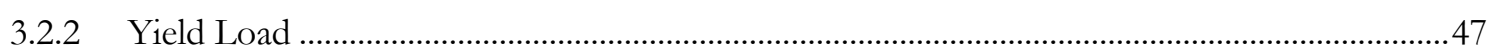

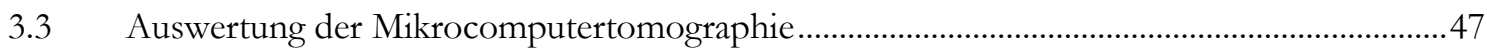

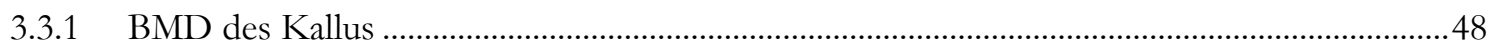

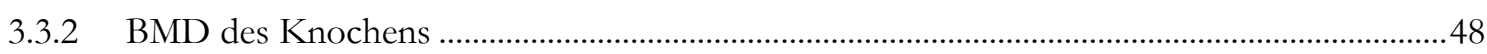

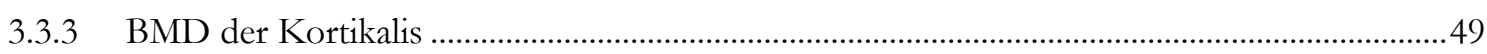

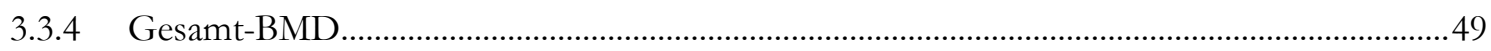

3.3.5 Anteil des Knochenvolumens am Gesamtvolumen .................................................................50

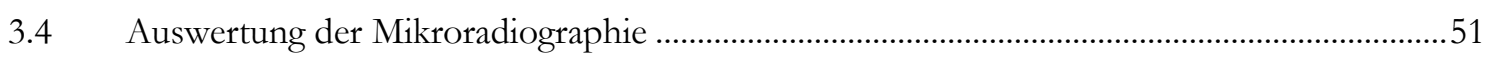

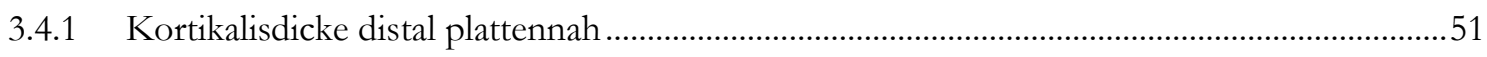

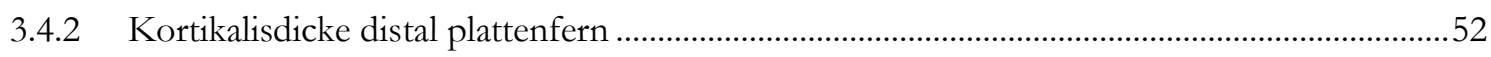

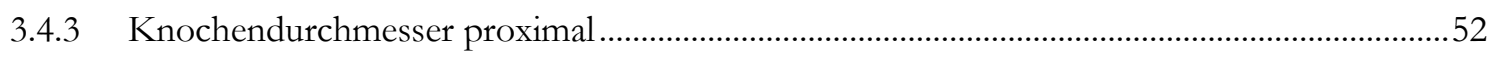

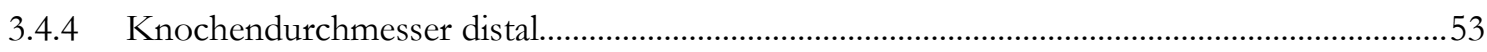

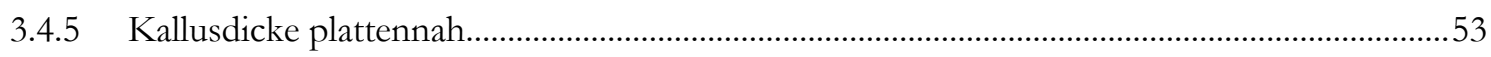

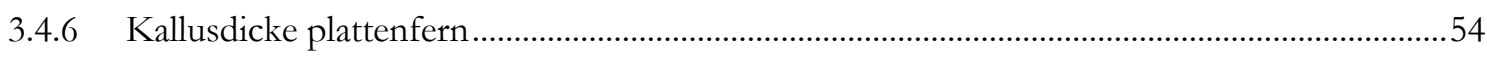

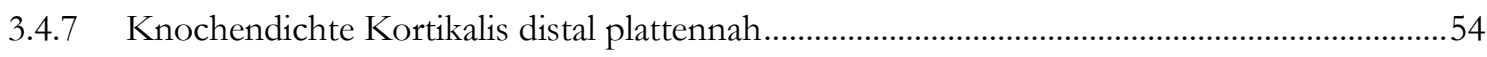

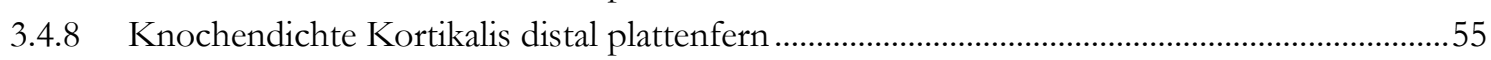

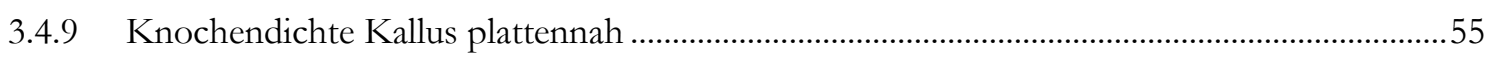




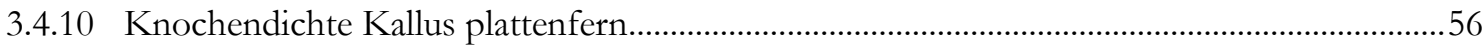

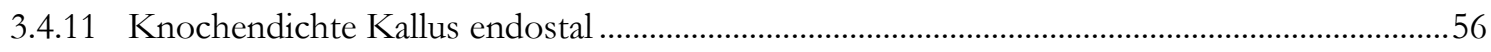

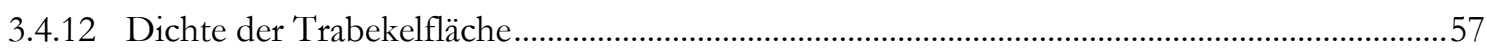

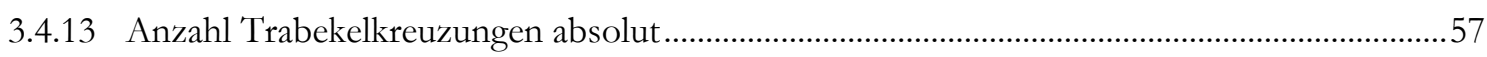

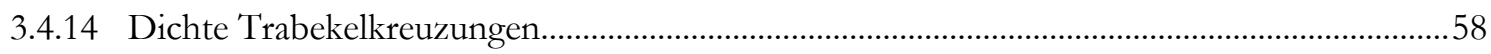

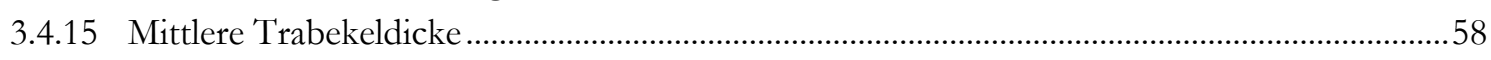

3.5 Auswertung der polychromen Sequenzmarkierung...................................................................60

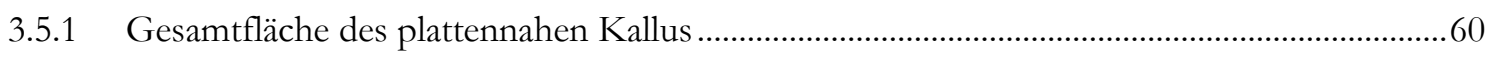

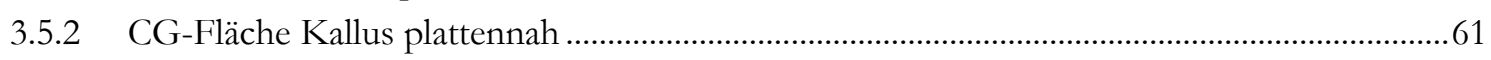

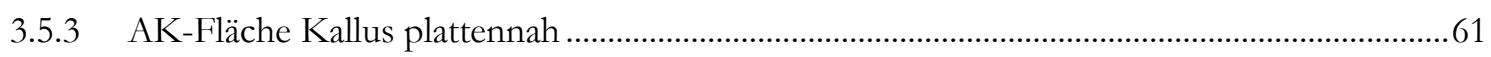

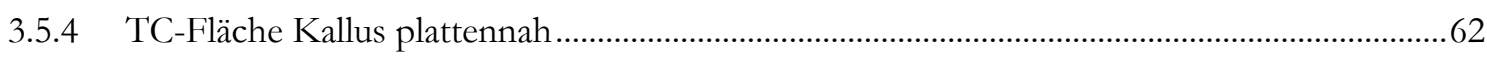

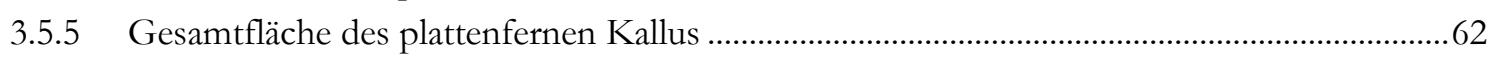

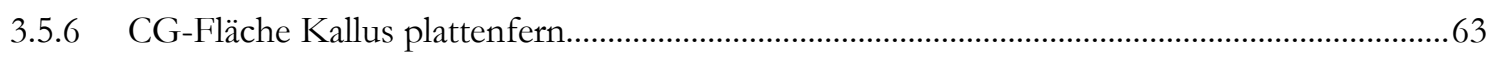

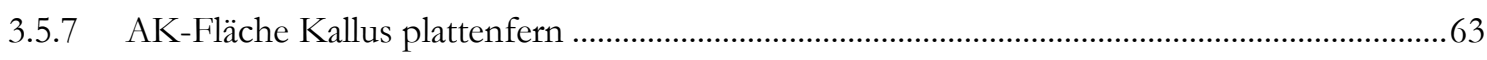

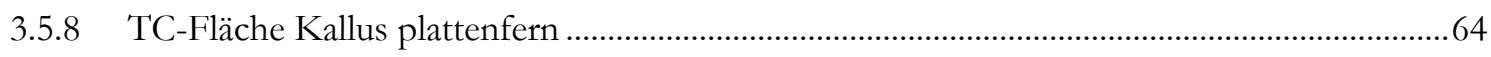

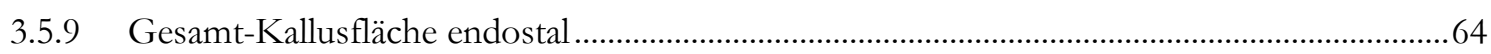

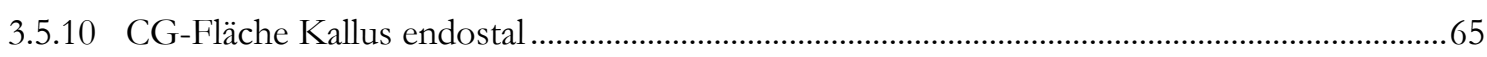

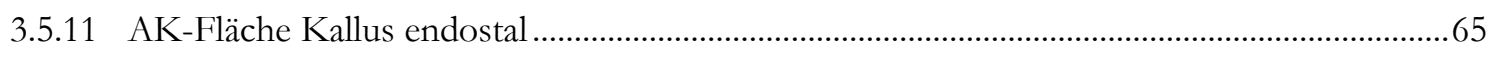

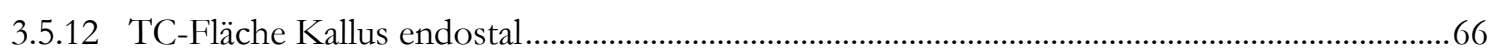

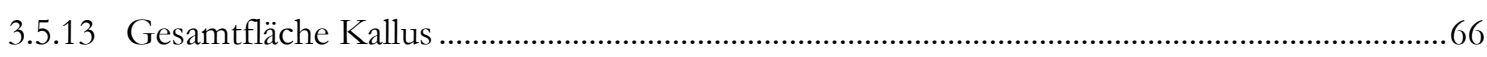

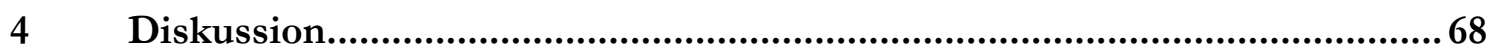

4.1 Die ovarektomierte Ratte als Tiermodell für postmenopausale Knochenveränderung.........69

4.2 Diskussion des metaphysären Frakturmodells .......................................................................70

4.3 Diskussion der Gewichte und der Futteraufnahme der Versuchstiere...................................70

4.4 Diskussion der Ergebnisse des biomechanischen Kompressionstests ....................................72

4.5 Diskussion der Ergebnisse der Mikrocomputertomographie ...................................................73

4.6 Diskussion der Ergebnisse der Mikroradiographie ...............................................................74

4.7 Diskussion der Ergebnisse der polychromen Sequenzmarkierung .......................................76

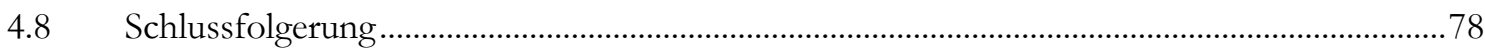

$5 \quad$ Zusammenfassung............................................................................8 80

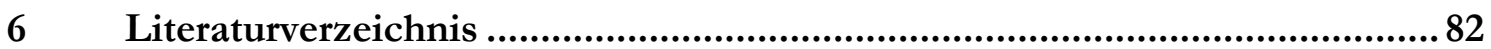




\section{Abbildungsverzeichnis}

Abbildung 1: 5-Loch-Leibinger-Titanplatte mit Schrauben

Abbildung 2: Schablone zur Definition der Osteotomiehöhe in $7 \mathrm{~mm}$ Abstand zum

Tibiaplateau.

Abbildung 3: Schematische Darstellung der Sägeschablone ..........................................................23

Abbildung 4: Röntgendarstellung einer Tibia inklusive Osteotomiematerial. ....................................23

Abbildung 5: Prüfvorrichtung mit aufliegender Tibia .......................................................................25

Abbildung 6: Werkstoffprüfmaschine mit Prüfvorrichtung ............................................................26

Abbildung 7: Kraft-Weg-Diagramm aus dem Programm ,test Xpert“‘............................................26

Abbildung 8: Messrahmen zur Erfassung des Kallusbereiches ..............................................................28

Abbildung 9: Grauwerthistogramm der metaphysären Rattentibia..................................................29

Abbildung 10: Schematische Darstellung der Flächenzuordnung am Beispiel eines mikroradiographischen Bildes

Abbildung 11: Polychrome Sequenzanalyse des Osteotomiekallus der Rattentibia ............................39

Abbildung 12: Abbildung der Messwerte für die Elastizität des Kallus [N/mm] der Gruppen ermittelt aus den Kraft-Weg-Diagrammen..........................................................................46

Abbildung 13: Abbildung der Messwerte für den Yield Load [N] ermittelt aus den Kraft-Weg-

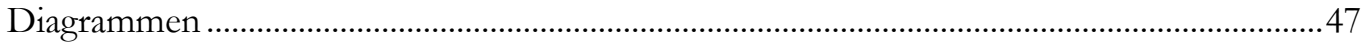

Abbildung 14: Abbildung der im $\mu$ CT ermittelten BMD $\left[\mathrm{g} / \mathrm{cm}^{3}\right]$ des Kallus der Versuchstiergruppen

Abbildung 15: Abbildung der im $\mu$ CT ermittelten BMD $\left[\mathrm{g} / \mathrm{cm}^{3}\right]$ des Knochens außerhalb des Kallus der Versuchstiergruppen

Abbildung 16: Abbildung der im $\mu$ CT ermittelten BMD $\left[\mathrm{g} / \mathrm{cm}^{3}\right]$ der Kortikalis der Versuchstiergruppen

Abbildung 17: Abbildung der im $\mu$ CT ermittelten Gesamt-BMD $\left[\mathrm{g} / \mathrm{cm}^{3}\right]$.....................................49

Abbildung 18: Abbildung des im $\mu$ CT ermittelten Anteils des Knochenvolumens am Gesamtvolumen.....

Abbildung 19: Abbildung der Messwerte der Mikroradiographie für den Parameter „Kortikalisdicke distal plattennah““

Abbildung 20: Abbildung der Messwerte der Mikroradiographie für den Parameter „Kortikalisdicke distal plattenfern“

Abbildung 21: Abbildung der Messwerte der Mikroradiographie für den Parameter „Knochendurchmesser proximal““

Abbildung 22: Abbildung der Messwerte der Mikroradiographie für den Parameter „Knochendurchmesser distal““

Abbildung 23: Abbildung der Messwerte der Mikroradiographie für den Parameter „Kallusdicke plattennah““.

Abbildung 24: Abbildung der Messwerte der Mikroradiographie für den Parameter „Kallusdicke plattenfern“

Abbildung 25: Abbildung der Messwerte der Mikroradiographie für den Parameter „Knochendichte Kortikalis distal plattennah“.

Abbildung 26: Abbildung der Messwerte der Mikroradiographie für den Parameter „Knochendichte Kortikalis distal plattenfern“

Abbildung 27: Abbildung der Messwerte der Mikroradiographie für den Parameter „Knochendichte Kallus plattennah““....

Abbildung 28: Abbildung der Messwerte der Mikroradiographie für den Parameter „Knochendichte Kallus plattenfern“ 
Abbildung 29: Abbildung der Messwerte der Mikroradiographie für den Parameter

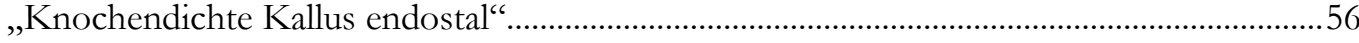

Abbildung 30: Abbildung der Messwerte der Mikroradiographie für den Parameter „Dichte der Trabekelfläche“

Abbildung 31: Abbildung der Messwerte der Mikroradiographie für den Parameter „Anzahl Trabekelkreuzungen absolut"

Abbildung 32: Abbildung der Messwerte der Mikroradiographie für den Parameter „Dichte Trabekelkreuzungen“.

Abbildung 33: Abbildung der Messwerte der Mikroradiographie für den Parameter „mittlere Trabekeldicke“"

Abbildung 34: Abbildung der Messwerte der Gesamtfläche des plattennahen Kallus der polychromen Sequenzmarkierung nach horizontaler WBV

Abbildung 35: Abbildung der Messwerte der CG-Fläche Kallus plattennah der polychromen Sequenzmarkierung nach horizontaler WBV

Abbildung 36: Abbildung der Messwerte der AK-Fläche Kallus plattennah der polychromen Sequenzmarkierung nach horizontaler WBV

Abbildung 37: Abbildung der Messwerte der TC-Fläche Kallus plattennah der polychromen Sequenzmarkierung nach horizontaler WBV

Abbildung 38: Abbildung der Messwerte der Gesamtfläche des plattenfernen Kallus der polychromen Sequenzmarkierung nach horizontaler WBV

Abbildung 39: Abbildung der Messwerte der CG-Fläche Kallus plattenfern der polychromen Sequenzmarkierung nach horizontaler WBV

Abbildung 40: Abbildung der Messwerte der AK-Fläche Kallus plattenfern der polychromen Sequenzmarkierung nach horizontaler WBV

Abbildung 41: Abbildung der Messwerte der TC-Fläche Kallus plattenfern der polychromen Sequenzmarkierung nach horizontaler WBV

Abbildung 42: Abbildung der Messwerte der Gesamt-Kallusfläche endostal der polychromen Sequenzmarkierung nach horizontaler WBV

Abbildung 43: Abbildung der Messwerte der CG-Fläche Kallus endostal der polychromen Sequenzmarkierung nach horizontaler WBV

Abbildung 44: Abbildung der Messwerte der AK-Fläche Kallus endostal der polychromen Sequenzmarkierung nach horizontaler WBV

Abbildung 45: Abbildung der Messwerte der TC-Fläche Kallus endostal der polychromen Sequenzmarkierung nach horizontaler WBV

Abbildung 46: Abbildung der Messwerte der Gesamtfläche Kallus der polychromen Sequenzmarkierung nach horizontaler WBV 


\section{Tabellenverzeichnis}

Tabelle 1: Geschlechtsabhängiges Frakturrisiko für das Auftreten einer osteoporotischen Fraktur (ab dem 50. Lebensjahr) im Bereich der Wirbelkörper, des Unterschenkels und des Oberschenkelhalses in Prozent [\%] 2

Tabelle 2: Gruppeneinteilung und Behandlung der Versuchstiere.........................................................20

Tabelle 3: Scanparameter für die Erstellung der Mikrocomputertomographien......................................27

Tabelle 4: Messparameter der Mikrocomputertomographie .....................................................................30

Tabelle 5: Messparameter der mikroradiographischen Auswertung und deren Berechnungsgrundlage

Tabelle 6: Einteilung der Fluorochrome nach verwendetem Farbstoff, Dosierung, Applikationstag, Markierungszeitraum und Fluoreszenz ……………………………….............37

Tabelle 7: Messparameter der polychromen Sequenzmarkierung und deren Berechnungsgrundlage

Tabelle 8: Durchschnittliches Körpergewicht [g] einer Ratte (MW $\pm S D$ ) eingeteilt nach shamoperierten und ovarektomierten Versuchstieren ohne oder mit einer horizontalen Vibrationsbehandlung bei 30, 50, 70 oder 90 Hertz

Tabelle 9: Durchschnittliche Gewichtszu- oder -abnahme pro Ratte $[\mathrm{g}](\mathrm{MW} \pm \mathrm{SD})$ pro Woche eingeteilt nach sham-operierten und ovarektomierten Versuchstieren ohne oder mit einer horizontalen Vibrationsbehandlung bei 30, 50, 70 oder 90 Hertz.

Tabelle 10: Durchschnittliche Futteraufnahme [g]/Ratte/Tag (MW \pm SD) eingeteilt nach sham-operierten und ovarektomierten Versuchstieren ohne oder mit einer horizontalen Vibrationsbehandlung bei 30, 50, 70 oder 90 Hertz

Tabelle 11: Uterusgewicht [mg] (MW $\pm \mathrm{SD}$ ) eingeteilt nach sham-operierten und ovarektomierten Versuchstieren ohne oder mit einer horizontalen Vibrationsbehandlung bei 30, 50, 70 oder 90 Hertz .

Tabelle 12: Tabellarische Zusammenfassung der Parameter des biomechanischen Kompressionstests (MW $\pm \mathrm{SD}$ ) eingeteilt nach sham-operierten und ovarektomierten Versuchstieren ohne oder mit einer horizontalen Vibrationsbehandlung bei 30, 50, 70 oder 90 Hertz.

Tabelle 13: Tabellarische Zusammenfassung der Messwerte für die BMD der verschiedenen Knochenstrukturen in Gramm pro Kubikzentimeter (MW \pm SD) eingeteilt nach sham-operierten und ovarektomierten Versuchstieren ohne oder mit einer horizontalen Vibrationsbehandlung bei 30, 50, 70 oder 90 Hertz

Tabelle 14: Tabellarische Zusammenfassung der Messparameter der Mikroradiographie $(\mathrm{MW} \pm \mathrm{SD}$ ) eingeteilt nach sham-operierten und ovarektomierten Versuchstieren ohne oder mit einer horizontalen Vibrationsbehandlung bei 30, 50, 70 oder 90 Hertz

Tabelle 15: Tabellarische Zusammenfassung der Messparameter der polychromen Sequenzmarkierung (MW $\pm \mathrm{SD}$ ) eingeteilt nach sham-operierten und ovarektomierten Versuchstieren ohne oder mit einer horizontalen Vibrationsbehandlung bei 30, 50, 70 oder 90 Hertz. 


\section{Abkürzungsverzeichnis}

${ }^{\circ} \mathrm{C}$

2-D

3-D

$\mu \mathrm{A}$

$\mu \mathrm{CT}$

$\mu \mathrm{m}$

AK

a.p.

AP

BMD

BMP

BMU

BV

CG

$\mathrm{cm}$

$\mathrm{cm}^{3}$

$\mathrm{CO}_{2}$

CT

DXA

et al.

g

GVal

hWBV

$\mathrm{Hz}$

I.E.

ISO

KG

$\mathrm{kV}$

$\mathrm{kVp}$

M-CSF

$\mathrm{mA}$

$\mathrm{mg}$

$\min$

$\mathrm{ml}$

$\mathrm{mm}$

$\mathrm{mm}^{2}$

$\mathrm{mm}^{3}$

MMA
Grad Celsius

zweidimensional

dreidimensional

Mikroampere

Mikrocomputertomographie

Mikrometer

Alizarin-Komplexon

anterior-posterior

alkalische Phosphatase

bone mineral density

bone morphogenetic protein

bone (re)modelling unit

bone volume

Calcein-Grün

Zentimeter

Kubikzentimeter

Kohlenstoffdioxid

Computertomographie

dual-energy-x-ray-absorptionmetry

et alii

Gramm

GValues

horizontal whole body vibration

Hertz

Internationale Einheit

International Organization of Standardization

Körpergewicht

Kilovolt

kilo voltage peak

Makrophagen-Koloniestimulierender Faktor

Milliampere

Milligramm

Minute

Milliliter

Millimeter

Quadratmillimeter

Kubikmillimeter

Methylmethacrylsäure 
ms

MW

$\mathrm{N}$

$\mathrm{NaCl}$

$\mathrm{NIH}$

$\mathrm{nm}$

NSAR

OPG

OVX

$\mathrm{p}$

PTH

QCT

RANK

RANKL

SD

SERMs

SHAM

TC

TGF- $\beta$

TSH

TV

vs.

vWBV

W

WBV

WHO

$\mathrm{XO}$
Millisekunde

Mittelwert

Newton

Natriumchlorid

National Institutes of Health

Nanometer

nichtsteroidale Antirheumatika

Osteoprotegerin

ovarektomiert

Signifikanzniveau

Parathormon

quantitative Computertomographie

receptor activator of nuclear factor kappa- $B$

receptor activator of nuclear factor kappa-B ligand

Standardabweichung

selective estrogen receptor modulators

scheinoperiert

Tetracyclin

transforming growth factor-beta

Thyreoidea-stimulierendes Hormon

total volume

versus

vertical whole body vibration

Watt

whole body vibration

World Health Organization

Xylenol-Orange 


\section{$1 \quad$ Einleitung}

\subsection{Einführung und Zielsetzung}

Die Osteoporose ist eine der am häufigsten auftretenden Erkrankungen des Skelettsystems (Kluba 2010). Dabei zeigt sich eine höhere Inzidenz für das fortgeschrittene Lebensalter. Sie gewinnt durch den demografischen Wandel zunehmend an Bedeutung. Jedoch bestätigt sich auch in der jüngeren Bevölkerung ein steigender Anteil an einem medikamentös oder toxisch induzierten Knochenstrukturverlust (Kohn 2011).

Aktuell sind in den Industrienationen (Nordamerika, Europa, Japan und Australien) bis zu 49 Millionen Personen betroffen (Wade et al. 2014). Davon leben circa acht Millionen Patienten in Deutschland (Bartl 2011). Die Erkrankungshäufigkeit ist geschlechtsspezifisch unterschiedlich. Etwa jede dritte Frau und jeder fünfte Mann erkrankt im Verlauf des Lebens an Osteoporose (Kluba 2010). Die höhere Erkrankungswahrscheinlichkeit von Frauen ist begründet durch den sich in der Menopause ausbildenden Östrogenmangel, welcher einen zunehmenden Verlust an Knochensubstanz bedingt. Dadurch steigt das Risiko der weiblichen Bevölkerung, nach dem fünfzigsten Lebensjahr eine osteoporotische Fraktur zu erleiden, auf bis zu 40 Prozent. Das Risiko der männlichen Bevölkerung liegt in diesem Alter bei circa 13 Prozent (Tabelle 1). Das Frakturrisiko steigt dabei exponentiell zum Abfall der Knochendichte, sodass sich bei einem Verlust von 10 bis 15 Prozent der Knochensubstanz das Frakturrisiko verdoppelt. Eine manifeste Osteoporose ist charakterisiert durch atraumatische (osteoporotische) Frakturen. Nach dem ersten Auftreten einer Fraktur steigt das Risiko für weitere pathologische Knochenbrüche auf fünf bis zehn Prozent an (Bartl 2011). Häufig bleibt die Erkrankung bis zum Auftreten erster Frakturen unerkannt, sodass sich ein adäquater Therapiebeginn verzögert (Mikosch und Gosch 2013). Die Kosten zur Versorgung der Osteoporoseerkrankung und ihrer Folgen belaufen sich in Deutschland auf circa fünf Milliarden Euro jährlich. Dabei könnten jedoch mit einer konsequenten und leitliniengerechten Therapie bis zu drei Milliarden Euro eingespart werden (Bartl 2011). In diesem Rahmen stellt die Früherkennung und Prophylaxe einen entscheidenden Faktor dar, um die volkswirtschaftliche Belastung zu reduzieren (Lauritzen 2005). Neben der Reduktion von Risikofaktoren und einer medikamentösen Therapie nimmt vor allem eine regelmäßige adäquate körperliche Betätigung einen wichtigen Stellenwert in der Behandlung der Osteoporose ein. 
Bereits 1892 postulierte Julius Wolff, dass die Festigkeit des Knochens unter Belastung zunimmt und sich der Knochenbau stabilisiert (Wolff 1892). Das Knochengewebe kann sich in seiner Struktur an die auf ihn wirkenden Kräfte anpassen. Neben aktiver Belastung zeigte sich auch eine passive Stimulation mit einer niedrig intensiven Ganzkörpervibration (whole body vibration, WBV) geeignet, einen östrogenmangelinduzierten, Knochenverlust zu reduzieren (Flieger et al. 1998). Dieser Effekt hat sich in verschiedenen Tierversuchen und auch am humanen Skelett bestätigt. Aufgrund der heterogenen Ergebnisse kann eine Abhängigkeit der Resultate vom gewählten Vibrationsmuster, der verwendeten Frequenz und der Anwendungsdauer vermutet werden. Aktuell ist noch keine Empfehlung bezüglich eines optimalen Vibrationsregimes möglich.

In Vorarbeiten unserer Arbeitsgruppe konnte bereits für die vertikale Ganzkörpervibration (vWBV) eine gesteigerte Knochendichte und verbesserte Festigkeit der Knochenstrukturen gezeigt werden (Sehmisch et al. 2009; Tezval et al. 2011). Ebenso konnte auch eine Zunahme an Muskelfasern nachgewiesen werden (Stuermer et al. 2010a). Insbesondere die vertikale Vibration mit Frequenzen von 35 Hertz und 50 Hertz zeigte eine deutliche Stimulation zur verbesserten Ausbildung von Kallusgewebe und kortikaler Knochensubstanz (Trautmann 2014; Komrakova et al. 2013).

In den bisherigen Untersuchungen zum Einfluss der WBV auf die Frakturheilung wurde vorrangig eine vertikale Vibration untersucht. Ziel der vorliegenden Arbeit ist es zu analysieren, ob die horizontale Ganzkörpervibration (hWBV) die Frakturheilung am osteopenen Knochen genauso positiv beeinflusst oder diese noch verbessern kann. Dabei ist auch von Interesse, ob die Ergebnisse einer horizontalen Vibration denen einer vertikalen WBV ähneln. Weiterhin soll gezeigt werden, ob die verwendete Frequenz einen Einfluss auf die Frakturheilung zeigt und die Biomechanik die morphologischen Ergebnisse spiegelt.

Tabelle 1: Geschlechtsabhängiges Frakturrisiko für das Auftreten einer osteoporotischen Fraktur (ab dem 50. Lebensjahr) im Bereich der Wirbelkörper, des Unterschenkels und des Oberschenkelhalses in Prozent [\%]

\begin{tabular}{|l|l|l|}
\hline Frakturlokalisation & Frakturrisiko Frauen [\%] & Frakturrisiko Männer [\%] \\
\hline Wirbelkörper & 32 & 5 \\
\hline Tibiakopf & 18 & 6 \\
\hline Femurhals & 15 & 3 \\
\hline
\end{tabular}




\section{$1.2 \quad$ Knochengewebe}

Das menschliche Skelett ist aus circa 220 Knochen aufgebaut. Im Zusammenspiel mit der Muskulatur und den Bindegewebsstrukturen erfüllt es eine entscheidende Stützfunktion in unserem Körper. Es lässt dabei aktive Bewegungen zu und bietet Schutz für das zentrale Nervensystem und innere Organe. Zudem ist es zusammen mit dem Knochenmark der Ort der Blutbildung (Schmidt 2010). Weiterhin sind im Knochen 99 Prozent des gesamten Kalziums, 85 Prozent des Phosphats und 50 Prozent des Magnesiums gespeichert (Bartl 2011). Aufgrund dieser verschiedenen Funktionen ist es von entscheidender Bedeutung, dass sich das Knochengewebe an verändernde, körpereigene und äußere Faktoren anpassen kann.

Strukturell kann man das Knochengewebe in kompakten und spongiösen Knochen unterteilen. Der kompakte Knochen besteht aus einer festen Struktur. Diese ist beispielsweise in der äußeren Schicht der Röhrenknochen zu finden. Im Gegensatz dazu ist der spongiöse Knochen aus einem Netzwerk sich verzweigender kleiner Knochenbälkchen (Trabekel) aufgebaut. Diese können sich an der Druck- und Zugbelastung des Knochens ausrichten und entsprechend den wirkenden Belastungen anordnen. In Bereichen mit einer dichteren Anordnung besteht eine höhere Stabilität (Sobotta 2003; Bartl 2011).

\subsubsection{Knochenzellen}

Um eine Anpassung der Knochenstruktur zu gewährleisten, ist ein enges Zusammenspiel der verschiedenen Knochenzellen (Osteoblasten, Knochendeckzellen, Osteozyten und Osteoklasten) notwendig.

\subsubsection{Osteoblasten}

Osteoblasten differenzieren sich über Osteoprogenitorzellen aus mesenchymalen Vorläuferzellen. Diese Entwicklung kann durch verschiedene Gene aktiviert werden. Durch die Exprimierung der Gene Runx2 und Coll a1 beginnt eine proliferative Phase, in welcher sich Osteoprogenitorzellen über Präosteoblasten zu Osteoblasten differenzieren (Florencio-Silva et al. 2015). Eine frische Fraktur kann die Differenzierung fördern (Sobotta 2003).

Die Hauptaufgabe der Osteoblasten besteht in der Produktion von Bestandteilen der Knochenmatrix. Diese setzt sich zu einem Teil (35 Prozent) aus organischem Material wie Kollagenfasern, insbesondere Kollagen Typ 1, Knochenproteinen (Osteocalcin, Osteopon- 
tin und Osteonektin) und aus Proteoglykanen zusammen. Zum anderen Teil (65 Prozent) beinhaltet sie anorganische Salze. Im Rahmen ihrer Entstehung wird initial die organische Matrix gebildet, welche durch die Einlagerung von Kalziumphosphat in Form von Hydroxylapatit mineralisiert. Dabei kann auch die Einlagerung von Fluor-, Magnesiumoder Natriumionen erfolgen (Sobotta 2003). Die Funktion der Osteoblasten kann durch Hormone und Zytokine beeinflusst werden. Über die Bindung von Östrogen wird der Abbau von Osteoblasten gehemmt, wodurch der Knochenaufbau positiv beeinflusst wird (Bartl 2011; Florencio-Silva et al. 2015). Im Gegensatz dazu wird über die Bindung von Parathormon (PTH) der Knochenabbau über die Bildung von osteoidabbauenden Enzymen beeinflusst (Sobotta 2003).

\subsubsection{Knochendeckzellen}

Die Knochendeckzellen sind inaktive Osteoblasten, welche entsprechend dem physiologischen Knochenstatus aktiviert werden können. Sie bedecken als ein dünner Zellsaum die gesamte Knochenoberfläche und verhindern eine direkte Interaktion der Osteoklasten mit der Knochenmatrix. Durch die Sekretion der Oberflächenproteine RANKL (receptor activator of nuclear factor kappa-B ligand) und Osteoprotegerin (OPG) haben sie Einfluss auf die Differenzierung der Osteoklasten (Bartl 2011; Florencio-Silva et al. 2015).

\subsubsection{Osteozyten}

Etwa jeder zehnte Osteoblast wird in die Lakunen der neugebildeten Knochensubstanz eingebettet und entwickelt sich zu einem Osteozyten. Demnach leiten diese sich ebenfalls von mesenchymalen Stammzellen ab. Untereinander sind sie über zahlreiche Kanälchen miteinander verbunden (Bartl 2011). Ein einzelner Osteozyt kann bis zu 50 Verbindungen zu benachbarten Osteozyten, Osteoblasten und Knochendeckzellen ausbilden. Über das entstandene Netzwerk ist ein zytoplasmatischer Austausch von Mineralien und hormonaktiven Substanzen mit dem arteriovenösen System möglich (Florencio-Silva et al. 2015). Weiterhin kann über die Zilien der Osteozytenfortsätze in den Kanälchen eine Mechanotransduktion vermittelt werden. Entsprechend der Stärke der einwirkenden mechanischen Belastung können Umbauvorgänge im Knochenstoffwechsel reguliert werden (Jakob und Felsenberg 2013). In diesem Zusammenhang wird vermutet, dass während einer stärkeren mechanischen Beanspruchung - durch eine verminderte Sekretion des Hormons Sklerostin - ein stärkerer Knochenaufbau initiiert werden kann. Osteozyten sezernieren ebenfalls OPG sowie RANKL und können dadurch wie die Osteoblasten die Aktivität der knochenabbauenden Osteoklasten beeinflussen (Bellido 2014). 


\subsubsection{Osteoklasten}

Osteoklasten leiten sich von Monozyten und demnach von hämatopoetischen Stammzellen ab. Durch die Bindung des Zytokins RANKL an dem RANK-Rezeptor (receptor activator of nuclear factor kappa-B) und die Ausschüttung des Makrophagen-Koloniestimulierenden Faktors (M-CSF), wird ihre Differenzierung aus den Vorläuferzellen eingeleitet. Die Bindung von RANKL kann durch den konkurrierenden Faktor OPG behindert werden (Florencio-Silva et al. 2015). Im Knochen liegen sie in den sogenannten Howship-Lakunen. Bei Kontakt zu abzubauender Knochenmatrix bilden sie einen abgegrenzten Raum mit einem Faltensaum aus. Hier kann über die Bildung von Salzsäure, nach Aktivierung einer $\mathrm{H}^{+}$-ATPase-Protonenpumpe und über die Freisetzung von Chlorid-Ionen, die bestehende Knochenmatrix aufgelöst werden.

Das freiwerdende Kollagen I wird über weitere Hydrolasen (Kathepsin K, Metalloproteinasen, Kollagenasen) abgebaut (Bellido 2014). Die Aktivität der Osteoklasten kann durch verschiedene Hormone (PTH, Östrogen, Leptin, Thyreoidea-stimulierendes Hormon (TSH)) und Wachstumsfaktoren beeinflusst werden. Unter dem Einfluss von Östrogen wird ihre Aktivität gehemmt (Bartl 2011). Erkrankungen, welche mit einer verminderten Knochendichte und einem erhöhten Frakturrisiko einhergehen, wie auch die Osteoporose, können in einer übermäßigen Aktivität der Osteoklasten begründet sein. In gleicher Weise kann festgestellt werden, dass dies - bei einer reduzierten Aktivität der Osteoklasten - auch für Erkrankungen mit einem zu geringen Knochenabbau, wie beispielsweise der Osteopetrosis, gilt. Hier kommt es durch einen Gendefekt zu einer Funktionseinschränkung der Osteoklasten (Florencio-Silva et al. 2015).

\subsubsection{Knochenentwicklung}

Es gibt zwei Arten der embryonalen Knochenentwicklung. Die direkte (desmale) und die indirekte (chondrale) Knochenbildung. Im Rahmen der Desmalen entwickeln sich direkt aus mesenchymalen Vorläuferzellen Osteoblasten, welche Knochengewebe aufbauen. Dadurch entstehen vor allem schmale Knochen wie die des Schädels und die Klavikula. Im Unterschied dazu wird der Großteil menschlicher Knochen, wie alle Wirbelkörper und die Knochen der Extremitäten, indirekt über eine vorbestehende Knorpelanlage gebildet. Hier bildet sich um ein vorbestehendes Knorpelfragment, eine Knochenmanschette, sodass im Verlauf die vom neugebildeten Knochen umgebenen Knorpelzellen verkalken. Unterstützend können knorpelabbauende Zellen, welche über die eindringenden Blutgefäße transportiert werden, Hohlräume bilden. In diesen lagern sich Mesenchymzellen ein und können nach Differenzierung zu Osteoblasten weitere Knochenmatrix bilden. Die Verknöcherung schreitet von der Mitte des Knorpelfragments nach distal fort. Im Bereich der Epiphysen bleibt in den Wachstumsfugen eine Knorpelschicht erhalten. Erst nach 
deren Verknöcherung ist das Knochenwachstum abgeschlossen (Sobotta 2003). Zwischen dem 25. bis 30. Lebensjahr wird die maximale Knochendichte erreicht, welche danach um circa ein Prozent pro Lebensjahr abnimmt. Im Rahmen der Menopause (45. bis 55. Lebensjahr) und dem fehlenden Östrogeneinfluss steigt diese Rate bei Frauen auf bis zu vier Prozent pro Lebensjahr an (Bartl 2011; Pschyrembel 2002).

\subsubsection{Knochenumbau}

Zur Erfüllung der vielfältigen Funktionen des Knochengewebes ist eine ständige Anpassung an externe und interne Veränderungen des Körpers notwendig. Dabei spielen vor allem mechanische Einflussfaktoren wie Bettlägerigkeit und Lähmungen, aber auch ein erhöhter Knochenumsatz im Rahmen von Entzündungen, malignen Erkrankungen oder die Einnahme von Glukokortikoiden eine entscheidende Rolle (Jakob und Felsenberg 2013). Während der Umbauvorgänge (Remodelling) wird circa zehn Mal mehr spongiöser Knochen als kortikaler Knochen gebildet (Bartl 2011). Der Umbau erfolgt in speziellen Umbaubereichen (bone (re)modelling unit, BMU). Initial wird der defekte Knochen über Osteoklasten abgebaut und im Verlauf die fehlende Substanz durch die Knochenbildung der Osteoblasten ergänzt. Parallel dazu erfolgt eine Anbindung an Blutgefäße und periphere Nerven (Florencio-Silva et al. 2015).

Die Steuerung der Umbauvorgänge ist abhängig vom Zusammenspiel verschiedener Hormone (PTH, Östrogen, TSH, Insulin und Wachstumshormone) und Vitamine (Vitamin $\mathrm{D}$ und $\left.\mathrm{B}_{6+12}\right)$. Ebenso werden von den Knochenzellen selbst direkt Zytokine sezerniert. Dabei spielt die Sekretion von osteokatabolen Zytokinen wie RANKL und M-CSF eine entscheidende Rolle zur Aufrechterhaltung des Gleichgewichts von Knochenauf- und abbau. M-CSF stimuliert und verbessert die Entwicklung und das Überleben von Osteoklastenvorstufen. RANKL leitet nach Bindung an seinem RANK-Rezeptor auf den Osteklastenvorläuferzellen deren Differenzierung ein. Die Ausschüttung von RANKL wird durch den Einfluss von PTH, Vitamin $\mathrm{D}_{3}$ und Glukokortikoiden beeinflusst (Bartl 2011).

Am RANK-Rezeptor konkurriert RANKL mit dem osteoanabolen OPG. Durch die Bindung von OPG wird die Differenzierung von Osteoklasten gehemmt, und ein vermehrter Knochenabbau wird verhindert (Jakob und Felsenberg 2013). OPG und RANKL stellen damit direkte Gegenspieler dar. Die Aktivität von OPG wird durch den transformierenden Wachstumsfaktor Beta (transforming growth factor-beta, TGF- $\beta$ ), Calcitriol, mechanische Belastung und Östrogen gesteigert (Bartl 2011). 
Die Anzahl der Osteoklasten kann durch Erhöhung der Apoptoserate unter dem Einfluss von Östrogen gesenkt werden. Ebenso steuert Östrogen auch die Ausschüttung von OPG, wodurch der Verlust von Osteoblasten und Osteozyten gehemmt und ein vermehrter Knochenaufbau stimuliert werden kann (Florencio-Silva et al. 2015).

Die Osteozyten spielen eine entscheidende Rolle im Rahmen der Knochenhomöostase. Zum einen stellen sie eine Hauptquelle von RANKL dar (Xiong et al. 2015). Sie können aber auch durch die Ausschüttung von dem knochenumbauhemmenden Sklerostin das Remodelling insgesamt reduzieren. Unter zunehmender mechanischer Belastung kann die Expression von Sklerostin verringert werden, sodass weitere Anpassungsvorgänge des Knochens ermöglicht werden (Bellido 2014).

\section{$1.3 \quad$ Fraktur}

Eine Fraktur ist die „Kontinuitätsunterbrechung eines Knochens unter Bildung von Fragmenten“ (Pschyrembel 2002, Seite 545). Nach der Art der Entstehung teilt man diese in traumatische und atraumatische Frakturen ein. Im Rahmen einer atraumatischen Fraktur sollte immer eine Abklärung der zugrundeliegenden Ursache erfolgen. Davon abzugrenzen sind Ermüdungsfrakturen, bei welchen aufgrund einer Fehl- oder Überbelastung, in der Summe mehrerer Mikrotraumata, eine Fraktur entsteht (Bartl 2011).

\subsubsection{Frakturheilung}

Ziel der Frakturheilung ist es, in einer möglichst geringen Zeitspanne eine stabile Verbindung der Knochenfragmente zu erreichen. In Abhängigkeit von der Stellung der Frakturenden wird eine direkte und eine indirekte Frakturheilung unterschieden.

Als Voraussetzung für eine direkte Heilung muss eine stabile Verbindung der Fragmente mit einem maximalen Frakturspalt von 0,5 mm erreicht werden. Dafür kann mit Hilfe von operativen Verfahren eine stabile Osteosynthese erzeugt werden (Bartl 2011). Über die verletzten Haverschen Kanäle kommt es zum Aussprossen von Kapillaren, welche Kontakt mit dem gegenüberliegenden Fragment aufnehmen. Entlang dieser so entstandenen Resorptionskanäle kann durch die Einwanderung von Osteoblasten neues Knochengewebe formiert werden (Marsell und Einhorn 2011; Sobotta 2003). 
Ist eine solche feste Adaption der Knochenenden nicht möglich, kommt es zur sekundären Frakturheilung, wobei minimale Bewegung und eine leichte Gewichtsbelastung förderliche Auswirkungen zeigen (Marsell und Einhorn 2011). Die Knochenbruchheilung erfolgt hier in vier Phasen. In der ersten Phase, der Entzündungsphase, kommt es durch Verletzungen im Bereich der Weichteile und des Knochens, zur Ausbildung eines Hämatoms. In diesem organisieren sich verschiedene Zellen des Blut- und Immunsystems (Makrophagen, Blutplättchen, Lymphozyten und Granulozyten) zu einem festen Hämatom. Durch sezernierte Zytokine und Wachstumsfaktoren bildet sich im weiteren Verlauf Granulationsgewebe aus. In der zweiten Phase entsteht durch die Einwanderung von Chondrozyten ein weicher Kallus, in welchen Kalzium eingelagert wird. Die Chondrozyten hypertrophieren im Verlauf und sterben ab. Die dritte Phase kennzeichnet sich durch eine hohe Aktivität von Osteoblasten. Durch weitere Einlagerung von Kalzium entsteht erstes Knochengewebe, welches in der abschließenden vierten Phase durch Umbauprozesse an seine Belastungen und Funktion angepasst wird (Schindeler et al. 2008; Marsell und Einhorn 2011).

Das Gewebe ist während der Knochenheilung instabil. Durch eine inadäquate Belastung kann eine komplette knöcherne Heilung ausbleiben und sich eine Pseudoarthrose entwickeln (Sobotta 2003). Die Frakturheilung ist abhängig von verschiedenen Einflussfaktoren. Sie wird durch biologische Faktoren, wie Alter oder Erkrankungen (Diabetes mellitus, Osteoporose), behindert. Ebenso kann sie auch durch Medikamente verzögert werden. Dabei wirken sich Zytostatika, Antibiotika, Glukokortikoide und analgetische Therapien mit Cyclooxygenasen Inhibition (nichtsteroidale Antirheumatika (NSAR), Diclofenac) negativ auf die Frakturheilung aus. Durch Knochenmorphogeneseproteine (bone morphogenetic protein, BMP), Sexualhormone, Statine, Beta-Blocker oder der diskontinuierlichen Applikation von Parathormon kann die Knochenheilung positiv beeinflusst werden (Bartl 2011).

\subsection{Osteoporose}

\subsubsection{Definition}

Osteoporose ist durch einen pathologischen Verlust von Knochensubstanz gekennzeichnet. Dabei sind organische und anorganische Bestandteile in der gleichen Weise betroffen (Niethard 2009). Nach der NIH (National Institutes of Health) Konsensuskonferenz wird die Osteoporose als eine Skeletterkrankung definiert, welche durch eine abnehmende Knochenfestigkeit charakterisiert ist und die für eine Person mit einem erhöhten Frakturrisiko einhergeht (übersetzt nach NIH Consensus Development Panel on Osteoporosis) (NIH 2001). Die WHO (World Health Organization) legt der Definition die Knochenmineraldichte (bone mineral density, BMD) zugrunde, welche mittels 
Doppelenergie-Röntgen-Absorptiometrie (dual-energy-x-ray-absorptionmetry, DXA) bestimmt werden kann. Dabei wird eine manifeste Osteoporose ab einer Knochendichte definiert, welche 2,5 Standardabweichungen (SD) unter dem Mittelwert der BMD einer 20-29 Jahre alten Frau liegt (siehe 1.4.3.2) (Kanis et al. 2013).

\subsubsection{Klassifikation}

Entsprechend ihrer Genese wird die Osteoporose in eine primäre und sekundäre Form eingeteilt. Die Ätiologie der primären Osteoporose ist noch nicht vollständig geklärt, wird aber im Knochenstoffwechsel selbst gesehen (Kohn 2011; Kluba 2010). Hierunter kann eine Typ-I-Osteoporose, die postmenopausale Osteoporose, und eine Typ-II-Osteoporose, welche entsprechend des späteren Manifestationsalters als senile Osteoporose bezeichnet wird, unterschieden werden (Schulte 1997).

Die sekundäre Osteoporose ist auf spezifische Ursachen zurückzuführen. Dazu gehören neben Immobilisation, Malabsorption auch Endokrinopathien, maligne Erkrankungen, hereditäre Entwicklungsstörungen und medikamentöse Therapien, welche einen Verlust von Knochensubstanz verursachen (Grifka 2011).

\subsubsection{Diagnostik}

Der schleichende Abbau von Knochensubstanz wird von den Patienten erst wahrgenommen, wenn sich durch die zunehmende mechanische Instabilität Beschwerden zeigen. Die osteoporotischen Umbauvorgänge betreffen insbesondere den spongiösen Knochen. Klinisch kommt es als Korrelat von Mikrofrakturen häufig zu Schmerzen. Bereits im Vorfeld einer klinisch manifesten Fraktur können sich Veränderungen der Wirbelkörper, beispielsweise aufgrund einer Höhenminderung im Rahmen von Deckplatteneinbrüchen in Form einer reduzierten Körpergröße, Kyphose der Brustwirbelsäule und Hyperlordose der Lendenwirbelsäule zeigen. Zur Diagnostik bei einem anamnestischen oder klinischen Verdacht auf eine reduzierte Knochendichte stehen neben laborchemischen Untersuchungen vor allem bildgebende Verfahren im Mittelpunkt (Kluba 2010).

\subsubsection{Laborchemische Parameter}

Durch Laboruntersuchungen sind Rückschlüsse auf den Knochenstoffwechsel möglich. Dabei sollten initial Basisparameter wie ein Differentialblutbild, das Kreatinin sowie der Kalzium- und Phosphatgehalt im Serum bestimmt werden. Außerdem sollte die Kalzium- 
und Eiweißkonzentration im 24-Stunden-Sammelurin gemessen werden. Spezifisch können als Indikatoren für einen Substanzaufbau die alkalische Phosphatase (AP), Osteokalzin und das carboxyterminale Prokollagen Typ I Propeptid analysiert werden. Für die AP lassen sich auch im Rahmen einer frischen osteoporotischen Fraktur kurzzeitig erhöhte Werte registrieren. Die Bestimmung von Desoxypyridinolin im Urin als HydroxypyridiniumDerivate stellt einen spezifischen Marker der Knochenresorption dar und entsteht durch den Abbau von Kollagen (Schulte 1997).

\subsubsection{Bildgebende Verfahren}

Im konventionellen Skelettröntgen werden osteoporotische Strukturveränderungen erst im fortgeschrittenen Stadium ab einem Verlust von circa 40 Prozent Knochenmasse sichtbar. Es ist deshalb für die Primärdiagnostik ungeeignet. Morphologisch finden sich insbesondere Veränderungen wie Fisch-, Keil- oder Plattwirbel an der Wirbelsäule. Auch die Messung der Wirbelhöhe ermöglicht Rückschlüsse auf eine Knochenschädigung (Bartl 2011).

Die Knochendichte kann mittels DXA der Lendenwirbelsäule oder der Hüfte, sowie mit computertomographischen Methoden bestimmt werden (Niethard 2009). Mittels der DXA wird die Abschwächung der Röntgenstrahlung beim Durchgang durch das Knochengewebe bestimmt. Die gemessene BMD in Gramm pro Kubikzentimeter wird im Anschluss mit dem Mittelwert einer weiblichen Population im Alter zwischen 20-29 Jahren verglichen. Dabei entspricht ein Wert kleiner als 1,0 SD einem normalen Knochengehalt, ein Wert zwischen - 1,0 und - 2,5 SD einer Osteopenie und ein Wert größer - 2,5 SD einer Osteoporose (Kanis et al. 2013). Ist der Wert von - 2,5 SD überschritten und bestehen zudem Frakturen, spricht man von einer manifesten oder schweren Osteoporose (Kluba 2010). Die DXA gilt als anerkanntes Messverfahren zur Definition der Osteoporose und ist ein Entscheidungskriterium bei der Wahl der Therapieform. Im Rahmen der quantitativen Computertomographie (QCT) und peripheren quantitativen Computertomographie ist eine Unterscheidung zwischen kortikalen und spongiösen Knochenstrukturen möglich. Die gewonnenen Parameter werden als Masse an Hydroxylapatit angegeben. Hydroxylapatit wird dabei als Kalibrierungsphantom verwendet.

Ohne den Einfluss von Röntgenstrahlung kann der Knochen mittels einer quantitativen Ultraschallmessung über die Schallgeschwindigkeit und Schallabschwächung beurteilt werden. Die Messung sollte an Arealen mit wenig Muskel- und Fettgewebe erfolgen. Die Auswertung der Parameter erfolgt im Vergleich mit einem Vergleichskollektiv. Bei auffälligen Werten ist eine ergänzende DXA-Messung empfehlenswert. 
Mit bekannten bildgebenden Verfahren wie der Spiralcomputertomographie oder der Magnetresonanztomographie lassen sich weitere morphologische Veränderungen beurteilen. In seltenen Fällen oder bei dem Verdacht auf maligne Erkrankungen kann eine Skelettszintigraphie indiziert sein (Lauritzen 2005; Bartl 2011).

\subsubsection{Darstellung mit der Mikrocomputertomographie}

Mit den bisherigen Verfahren, wie der DXA-Messung und der QCT-Bildgebung, kann die Knochendichte zuverlässig bestimmt werden. Jedoch können keine Vorhersagen zum Frakturrisiko gemacht werden, da die ermittelte Knochendichte keine Aussage über den exakten strukturellen Aufbau des Knochens zulässt. Auch die histomorphometrische Schnittbildgebung ermöglicht nur eine zweidimensionale Darstellung. Mit Hilfe der Mikrocomputertomographie $(\mu \mathrm{CT})$ lassen sich dreidimensionale Bilder der Knochenstruktur erstellen. So ist es möglich, eine optimale Darstellung des Trabekelnetzwerkes zu erzielen und damit eine detaillierte Ansicht der Knochenarchitektur zu gewinnen (Engelke et al. 1999). Ein besonderer Vorteil liegt in der hohen Auflösung der Bilder (Johnson et al. 2006). Die gewonnenen Parameter können, nach Kalibrierung an einem Dichtephantom und Umrechnung, den entsprechenden knöchernen Strukturen zugeordnet werden (McNamara et al. 2005). Ebenso können mehrere kleine Proben ohne aufwendige Vorbereitung zur gleichen Zeit untersucht werden und stehen intakt für weitere Untersuchungen zur Verfügung. Nachteilig zeigt sich, dass nur kleine Probendurchmesser untersucht werden können und dass der Prozess neben langen Scanzeiten auch ein umfangreiches Speichervolumen zur Erfassung der Daten benötigt (Engelke et al. 1999). So findet das Verfahren aktuell nur im Rahmen experimenteller Studien am Kleintier oder bei der Analyse von Knochenbiopsien Anwendung.

\subsubsection{Auswirkungen eines Östrogenmangels auf das Knochengewebe}

Eine der Hauptursachen der Ausbildung eines Knochensubstanzverlustes ist das postmenopausale Östrogendefizit. Durch die reduzierte Bindung von Östrogen an den Östrogenrezeptoren der Knochenzellen wird die Osteoklastenfunktion und der damit verbundene Knochenabbau weniger gehemmt. Ebenfalls wird auch die Bildung von Kollagen durch die Osteoblasten, die Aufnahme von Kalzium und die Ausschüttung von Kalzitonin und Parathormon negativ beeinflusst (Bartl 2011). Bereits 1985 bestätigte sich auf histologischer Ebene am Tiermodell der ovarektomierten Ratte neben einer gesteigerten Knochenresorption auch ein deutlicher Verlust von trabekulären Knochen (Wronski et al. 1985). Aufgrund des Mangels von Östrogen kommt es zu einem gesteigerten Knochenumbau (Wronski et al. 1988b). Dieser zeigt sich besonders zu Beginn der Menopause, in welcher es durch den fehlenden Einfluss von Östrogen initial zu einer 
Phase mit einer erhöhten Knochenumbaufrequenz (high turnover) und einer deutlichen Abnahme des trabekulären Knochens kommt (Christiansen und Lindsay 1990; Kalu 1991). Diese Umbauvorgänge werden unter einer kalziumarmen Ernährung verstärkt (Kubo et al. 1999) und manifestieren sich insbesondere in den ersten 10 Jahren nach Ausfall der ovarialen Funktion. Es lassen sich auch Formen mit einem späteren Beginn der Osteoporose aufgrund eines geringeren Remodelling (low turnover) und geringerem Substanzverlustes unterscheiden (Herold 2015). Diese werden als senile Osteoporose bezeichnet.

\subsubsection{Besonderheiten der Frakturheilung am osteoporotischen Knochen}

Im Rahmen des stärkeren Verlustes und der höheren Umbaurate von trabekulärer Knochensubstanz zählen die Wirbelkörperfraktur, die proximale Femurfraktur und die distale Radiusfraktur (siehe Tabelle 1) zu den häufigsten Frakturmanifestationen des osteoporotischen Knochens (Gruber et al. 2006). Im Tierversuch bestätigt sich eine verschlechterte Kallusbildung am osteopenen Rattenfemur nach Ovarektomie (NamkungMatthai et al. 2001). Neben einer geringeren Kallusgröße und herabgesetzten Mineralisierung zeigte sich auch eine schlechtere Vernetzung der neugebildeten Knochenstrukturen mit daraus resultierender erhöhter mechanischer Instabilität (Hao et al. 2007).

Durch die reduzierte Knochenmasse und verschlechterte Knochenstruktur ergeben sich besondere Voraussetzungen für die operative Rekonstruktion der Frakturelemente. In diesem Rahmen kommen verschiedene Osteosyntheseregime (Marknagel-, Platten-, sowie Schraubenosteosynthesen, Zementaugmentation) zur Anwendung. Es wird eine zeitnahe Belastungsstabilität des Knochens angestrebt, um den Zeitraum der Immobilisation und damit auch weiteren Verlust an Muskelmasse und Weichteilgewebe bei den häufig älteren Patienten zu vermeiden (Bartl 2011).

Zur Optimierung der Frakturheilung und Qualität des neugebildeten Knochens im Rahmen einer manifesten Osteoporose werden in verschiedenen Studien gezielt Medikamente, Hormone und verbesserte Interventionstechniken erforscht, um die Knochenheilung positiv zu beeinflussen. 


\subsubsection{Osteoporosetherapie}

\subsubsection{Prophylaxe}

Aufgrund des kontinuierlichen Verlustes an Knochenmasse ist es wichtig, einen optimalen Ausgangswert zu erreichen. Dazu sollte bereits in der Adoleszenz auf eine ausreichende Zufuhr von Kalzium und Vitamin D geachtet werden. Zudem sollte eine Malnutrition vermieden und die Entwicklung der Skelettmuskulatur gezielt durch ausreichende Aktivität gefördert werden (Schulte 1997).

\subsubsection{Beurteilung des Frakturrisikos}

Aufgrund der Tatsache, dass die Entwicklung einer Osteoporose lange unbemerkt bleibt, ist es von besonderem Interesse für einen frühzeitigen Therapiebeginn eine Voraussage über das bestehende Frakturrisiko zu treffen. Neben der mit bildgebenden Messmethoden erhobenen BMD werden unterschiedliche Einflussfaktoren betrachtet, um das Frakturrisiko zu bestimmen. In früheren Behandlungsempfehlungen war alleinig die BMD ab einem T-Score von - 2,5 SD in der DXA Messung (Bartl 2011) oder ab einem T-Score von - 2,0 SD und aufgetretenen Frakturen, als Entscheidungsgrundlage herangezogen worden. Diese wurde erst im Verlauf um bestehende Risikofaktoren modifiziert (Kohn 2011).

Im Jahr 2008 wurde das „Fracture Risk Assessment Tool“ (FRAX ${ }^{\circledR}$ ) entwickelt und ist als Methode zur Prognose des Zehn-Jahres-Risikos einer Hüftfraktur allgemein anerkannt (Aspray 2013; Edwards et al. 2015). In diesen Fragebogen fließen neben dem Alter, dem Geschlecht, vorangegangenen Frakturen, einem Alkohol- oder Nikotinabusus, der Body Mass Index, eine positive Familienanamnese für Hüftfrakturen und die Einnahme von Glukokortikoiden oder eine bestehende rheumatoide Arthritis ein. Im Rahmen eines Gesamtrisikos größer 20\% für eine osteoporotische Fraktur und eines Risikos einer Hüftfraktur von $>3-5 \%$, wird eine Therapieindikation gestellt. Die BMD muss dabei nicht mit in die Berechnung einfließen (Mikosch und Gosch 2013; Aspray 2013; Kanis et al. 2013).

\subsubsection{Reduktion von Risikofaktoren}

Zur Vermeidung von Spätfolgen eines Knochenschwundes steht als primäres Therapieziel die Reduktion von Risikofaktoren im Mittelpunkt. Dazu gehört neben einer Nikotin- und Alkoholkarenz auch das Vermeiden von Untergewicht und Immobilität (Kohn 2011; NIH 2001). Zudem sollten zugrunde liegende Grunderkrankungen (Diabetes mellitus, Schilddrüsenfunktionsstörungen, Morbus Cushing) effizient therapiert werden (Niethard 2009). 
Gegebenenfalls ist auch ein eventueller Mangel an Sexualhormonen zu substituieren (Schulte 1997).

\subsubsection{Allgemeinmaßnahmen}

Schmerzen sind ein Leitsymptom der Osteoporose. Eine suffiziente analgetische Therapie nach WHO-Stufenschema ist erforderlich, um eine Immobilisation sowie eine daraus resultierende Abnahme der Muskelmasse und einem zusätzlichen Knochenverlust vorzubeugen (Bartl 2011). In Folge einer Immobilisation können Patienten innerhalb von nur einer Woche so viel Knochenmasse verlieren wie in einem gesamten Jahr (Kanis et al. 2013). Weiterhin kommen physiotherapeutische Übungen, insbesondere auch Übungen zur Sturzprophylaxe und Hilfsmittel zur Entlastung der Wirbelsäule, wie Korsett oder Mieder, zur Anwendung (Niethard 2009).

\subsubsection{Pharmakologische Therapie}

Als Grundlage zum Erhalt eines guten Knochenstoffwechsels wird die Zufuhr von mindestens $1000 \mathrm{mg}$ Kalzium pro Tag und 400 bis 1000 I.E. (Internationale Einheit) Vitamin $\mathrm{D}_{3}$ empfohlen (Kanis et al. 2013; NIH 2001). Im Tierversuch konnte an ovarektomierten Ratten unter der Substitution von 1,25-Dihydroxy-Vitamin $\mathrm{D}_{3}$ ein stabilerer Kallus und ein erhöhtes Kallusvolumen während der Frakturheilung gesehen werden (Gruber 2010).

Im Rahmen einer postmenopausalen Osteoporose kann kausal eine Substitutionsbehandlung mit Östrogenen erfolgen. Östrogene wirken dabei direkt über die Interaktion mit den Knochenzellen osteoanabol. Zudem erhöhen sie die enterale Kalziumaufnahme (Schulte 1997). Vor Beginn einer Östrogensubstitution sollte eine Nutzen- und Risikoabwägung erfolgen. Bei einem bestätigten erhöhten Risiko für thrombembolische Ereignisse und einem erhöhten Risiko für die Entwicklung eines Mammakarzinoms, sollte die Indikation streng gestellt werden (Kluba 2010).

Eine vorteilhafte Weiterentwicklung der Östrogenbehandlung sind die selektiven Östrogen-Rezeptormodulatoren (selective estrogen receptor modulators, SERMs), welche sich ebenfalls, wie Östrogen, stabilisierend auf das Knochengewebe auswirken. Sie zeigen jedoch keine negativen, proliferierenden Effekte auf das Brust- und Endometriumgewebe (Kluba 2010; NIH 2001). Der bekannteste Vertreter der SERMs ist Raloxifen. Unter ihm konnte eine Risikoreduzierung von osteoporotischen Wirbelkörperfrakturen von 30 bis 50 Prozent gezeigt werden (Kanis et al. 2013). Für die Anwendung von Östradiol und 
Raloxifen hat sich im Tierversuch eine verbesserte Bildung von neuem Knochengewebe gezeigt (Stuermer et al. 2010b). Diese positiven Einflüsse konnten in Kombination mit einer vWBV noch verbessert werden (Stuermer et al. 2014), sodass in diesem Rahmen weitere positive Entwicklungen für die Osteoporosetherapie zu erwarten sind.

Als weitere knochenstabilisierende Substanzen kommen Bisphosphonate zum Einsatz. Sie hemmen die Osteoklastenaktivität und erhöhen deren Apoptoserate (Kanis et al. 2013). Dadurch verzögern sich jedoch auch die Umbauvorgänge im Rahmen der Knochenneubildung (Gruber 2010). Aufgrund einer geringen oralen Bioverfügbarkeit (kleiner ein Prozent) sind besondere Einnahmemodalitäten zu beachten. Ebenfalls stehen parenterale Applikationsformen zur Verfügung, welche bei mangelnder Therapieadhärenz bevorzugt werden sollten (Mikosch und Gosch 2013; Kanis et al. 2013). In verschiedenen Studien konnte gezeigt werden, dass unter einer Therapie mit Bisphosphonaten die Frakturrate reduziert werden konnte (Kanis et al. 2013). Während sich in Versuchen am Tiermodell ein biomechanischer stabilerer Kallus bestätigen ließ (Gruber 2010), konnte bisher kein direkter Einfluss einer Therapie mit Bisphosphonaten auf die Frakturheilung gezeigt werden (Goldhahn et al. 2012; Mikosch und Gosch 2013).

Strontiumranelat besitzt neben einem osteoanabolen Effekt auch die Eigenschaft, die Knochenresorption zu hemmen (Mikosch und Gosch 2013). Es zeigt sich vor allem in der Behandlung von osteoporotischen Wirbelkörper- und Hüftfrakturen eine Reduktion des Frakturrisikos (Grifka 2011). Strontium kann - als ebenfalls zweifach positiv geladenes Ion - die Kalziumionen in der Knochenmatrix ersetzen (Sobotta 2003). Im Rahmen von Tierexperimenten zeigte sich unter fortgesetzter oder begonnener Therapie ein positiver Einfluss auf die Frakturheilung (Komrakova et al. 2015), jedoch stehen Untersuchungen des Einflusses auf die Frakturheilung beim Patienten noch aus.

Parathormon bzw. rekombinantes humanes PTH (Teriparatid) kann durch diskontinuierliche Applikation über eine direkte Aktivierung der Osteoblasten die Knochenneubildung stimulieren (Dobnig und Turner 1997). Es verbessert zudem die Kalziumaufnahme im Darm und dessen Resorption über die Nierentubuli (Grifka 2011; Herold 2015). In Versuchen am Tiermodell wurde eine verbesserte Kallusbildung und beschleunigte Frakturheilung nachgewiesen. Diese Ergebnisse konnten auch in ersten klinischen Studien im Rahmen der Knochenheilung bei osteoporosebedingten Frakturen bestätigt werden (Babu et al. 2015; Huang et al. 2016).

Auch im Bereich der monoklonalen Antikörper wurden neue hochspezifische Anwendungsmöglichkeiten entwickelt. Denosumab ist ein humaner monoklonaler Anti- 
körper, welcher RANKL bindet. Durch die effektive Hemmung der Interaktion von RANKL zum RANK-Rezeptor wird die Knochenresorption über die Hemmung der Osteoklastenfunktion eingeschränkt (Mikosch und Gosch 2013; Herold 2015). Dadurch konnte im Mausmodell ein gesteigertes Volumen und ein verbesserter Mineralisationsgehalt des neugebildeten Kallus nachgewiesen werden (Gruber 2010). Andere Autoren fanden keinen direkten Einfluss auf die Frakturheilung (Goldhahn et al. 2012; Brandi 2012). Jedoch konnte in klinischen Studien unter einer Therapie mit Denosumab, im Rahmen einer bestehender Osteoporose, ein reduziertes Frakturrisiko gezeigt werden (Cummings et al. 2009; Baron et al. 2011; Kanis et al. 2013).

Für die Zukunft, zeigen sich in einer klinischen Phase-III-Studie vielversprechende Ergebnisse für Romosozumab, ein monoklonaler Antikörper gegen Sklerostin (McClung et al. 2014). Durch die Bindung von Sklerostin kann, durch die ausbleibende Hemmung der Osteoblasten, der Knochenaufbau und die Knochendichte verbessert werden (Goldhahn et al. 2012; McClung 2015). Ein weiterer aussichtsreicher Ansatz ist der Kathepsin-KInhibitor Odanacatib. Dieser befindet sich zum Zeitpunkt in einer klinischen Phase-IIStudie. Durch die Hemmung von Kathepsin K kann die Ausschüttung von Hydrolasen aus den Osteoklasten und damit ein Knochenabbau reduziert werden (McClung 2015).

\subsubsection{Interventionelle Verfahren}

Bei langanhaltenden, analgetisch therapierefraktären Schmerzen nach Wirbelkörpereinbrüchen steht interventionell die Vertebroplastie oder die Kyphoplastie zur Verfügung. Bei beiden Verfahren wird Zement in den Wirbelkörper eingespritzt. Im Rahmen der Kyphoplastie wird der Wirbelkörper im Vorfeld unter Verwendung eines aufblasbaren Ballons aufgerichtet. Aufgrund der veränderten Knochenhärte der behandelnden Wirbelkörper sind die Ergebnisse für langstreckige Stabilisationen nicht überzeugend, da sogenannte Anschluss-Wirbelkörperfrakturen resultieren können. Deshalb kommen die Kypho- und die Vertebroplastie nur im Rahmen von ausgeprägten Fehlstellungen zur Anwendung (Kanis et al. 2013; Kluba 2010).

\subsubsection{Ganzkörpervibration}

Wie bereits unter 1.1 dargestellt, ist das Knochengewebe in der Lage, sich gegenüber mechanischen Reizen anzupassen. Schon in frühen Versuchen konnte eine niedrigintensive vertikale Vibration von 50 Hertz über 30 Minuten an fünf Tagen der Woche, bei ovarektomierten Ratten einen Knochenverlust verhindern (Flieger et al. 1998). Ebenfalls resultierte bei bereits nachgewiesener reduzierter Knochenneuformation und reduzierter Belastbarkeit des Knochens nach Ovarektomie bei Ratten eine Vibrationsbehandlung mit 
45 Hertz in einer gesteigerten Umbaurate mit vermindertem Abbau von intrakortikalem Knochengewebe (Oxlund et al. 2003). Der knochenaufbauende Effekt der vWBV konnte auch in weiteren Versuchen an ovarektomierten Ratten bestätigt werden (Judex et al. 2007; Rubinacci et al. 2008). Weiterhin konnte auch eine Verbesserung des Knochenaufbaus, vor allem im Bereich des kortikalen Knochens, im sich noch entwickelnden Skelettsystem heranwachsender Mäuse bewiesen werden (Xie et al. 2006). Die positiven Einflüsse einer vertikalen Vibration wurden auch in Großtierversuchen an Schafen bestätigt. Hier konnte vor allem im Bereich des trabekulären Knochengewebes eine Verbesserung der Knochendichte und eine erhöhte Anzahl an Trabekeln dargestellt werden (Rubin et al. 2002a; Rubin et al. 2002b; Rubin et al. 2006).

Die Ergebnisse aus den Tierversuchen stellen eine gute Voraussetzung für eine erfolgversprechende Anwendung der WBV am humanen Skelettsystem dar. In einzelnen Studien bestätigte sich unter einer vertikalen Vibrationsbehandlung eine gesteigerte BMD der Hüftknochen menopausaler Frauen sowie am Skelett heranwachsender Personen (Slatkovska et al. 2010). Die erzielten Ergebnisse konnten jedoch nicht einheitlich reproduziert werden (Slatkovska et al. 2011), sodass sich Hinweise auf eine Abhängigkeit des Ergebnisses der WBV von der Intensität, der Dauer und der Ausrichtung der Vibrationsbehandlung ergaben. Dieser Verdacht bestätigte sich ebenfalls im Tierversuch. In den Untersuchungen von Marion Pasqualini konnte für eine vertikale Vibrationsbehandlung mit einer Frequenz von 90 Hertz an männlichen Ratten ein deutlich besserer Aufbau von trabekulären Knochen und kortikalen Knochen erzielt werden. Die Reduktion der Vibrationsstärke auf acht Hertz zeigte jedoch einen verringerten Knochenaufbau mit auch herabgesetzter BMD (Pasqualini et al. 2013).

Während der Frakturheilung am Femur heranwachsender Ratten konnte unter der Anwendung der vWBV eine verbesserte Kallusentwicklung (Leung et al. 2009) und ein beschleunigter Aufbau von neuer Knochensubstanz nachgewiesen werden (Shi et al. 2010). Jedoch zeigte sich auch hier ein abhängiges Verhalten von der angewendeten Frequenz. Bereits eine Erhöhung der Frequenz von 10 Hertz konnte eine Frakturheilung signifikant vermindern (Wehrle et al. 2014).

Auch in der eigenen Arbeitsgruppe erfolgten Untersuchungen zum Einfluss einer vWBV auf die Knochenstruktur und die Frakturheilung. Für eine Vibrationsbehandlung mit $90 \mathrm{~Hz}$ zweimal täglich für 15 Minuten über eine Dauer von 35 Tagen wurde an der Tibia ovarektomierter und sham-operierter Ratten eine verminderte Stabilität des Knochens gemessen. Dabei zeigten jedoch Trabekel, Kallus und Kortikalis verbesserte strukturelle Eigenschaften. Zudem konnte während der Frakturheilung eine beschleunigte 
Kallusbildung für den osteopenen, nicht aber den gesunden Knochen nachgewiesen werden (Utesch 2013; Stuermer et al. 2010a). Um den Einfluss der verwendeten Frequenz und Vibrationsdauer genauer zu betrachten, wurde das Vibrationsregime auf eine einmal tägliche vWBV bei unterschiedlichen Frequenzen (35, 50, 70 und $90 \mathrm{~Hz})$ modifiziert. Bei einer Vibrationsstärke von $35 \mathrm{~Hz}$ und $50 \mathrm{~Hz}$ konnte die Frakturheilung und die biomechanischen Eigenschaften der Tibiae verbessert werden. Zudem gelang unter dem Einfluss einer vWBV mit $70 \mathrm{~Hz}$ der Nachweis einer deutlich verbesserten Kallusstruktur. Unter der Anwendung einer vWBV mit $90 \mathrm{~Hz}$ konnte auch eine gute Bildung von neuem Knochengewebe dargestellt werden, jedoch mit herabgesetzter Stabilität (Trautmann 2014; Komrakova et al. 2013). Auch für die Rattenwirbelsäule wurde eine Abhängigkeit der Ergebnisse von der Frequenz bestätigt (Komrakova et al. 2014): Unter der alleinigen vWBV mit $90 \mathrm{~Hz}$ für 15 Minuten zweimal täglich über 35 Tagen wurden verbesserte biomechanische Eigenschaften des Knochens am osteopenen Lendenwirbelkörper nachgewiesen. Insbesondere der Yield Load (Streckgrenze) konnte im Kompressionsversuch auf das Niveau hormonintakter Ratten angehoben werden. Die positive Wirkung wurde auch im Bereich des trabekulären Knochens bestätigt (Sehmisch et al. 2009). Die Anwendung unterschiedlicher Frequenzen (35, 50, 70 und $90 \mathrm{~Hz}$ ) der vWBV am Lendenwirbelkörper einmal täglich für 15 Minuten über 30 Tage zeigte eine verbesserte Knochenstruktur bei 35, 50 und $70 \mathrm{~Hz}$. Für eine Stimulation mit $90 \mathrm{~Hz}$ wurden teilweise gegenteilige Ergebnisse gezeigt (Döll 2011), sodass sich der Therapieerfolg abhängig von unterschiedlichen Parametern wie der Vibrationsdauer und der verwendeten Frequenz darstellt.

Als passive Applikationsform der mechanischen Stimulation ist die WBV besonders für bewegungseingeschränkte Personen geeignet (Kasturi und Adler 2011) und damit empfehlenswert für ältere Personen mit einem erhöhten Sturzrisiko. In klinischen Studien konnte unter dem Einfluss einer vWBV und einer rotierenden WBV im Vergleich zu einer alleinigen regelmäßigen sportlichen Aktivität bei postmenopausalen Frauen eine signifikante Zunahme der BMD im Bereich der Lendenwirbelkörper bestätigt werden (Stengel et al. 2011). 


\section{Material und Methoden}

\subsection{Versuchsablauf}

Für den Versuch wurden neunzig drei Monate alte weibliche Ratten (Sprague Dawley; Firma Harlan Winkelmann, Borchen, Deutschland) in 6 Gruppen zu jeweils 15 Tieren eingeteilt. Eine Gruppe davon verblieb als Referenzgruppe und wurde, hinsichtlich der Ovarektomie, scheinoperiert (SHAM). Alle weiteren Gruppen wurden ovarektomiert. Nach Entfernung der Eierstöcke wird durch den fehlenden hormonellen Einfluss die Entwicklung einer Osteoporose begünstigt (Kalu 1991). Im weiteren Verlauf erfolgte acht Wochen nach der Ovarektomie für alle Tiere in einer weiteren Operation die Osteotomie mit stabilisierender Osteosynthese der metaphysären Tibiae. Am 5. postoperativen Tag wurde mit der horizontalen WBV begonnen. Dafür wurden die Versuchstiere bei einer gruppenspezifischen Frequenz einmal täglich 15 Minuten lang über einen Zeitraum von 30 Tagen einer WBV ausgesetzt (Tabelle 2). Die Gruppen 1 und 2 verblieben ohne Vibrationsbehandlung. Um gleiche Umgebungsfaktoren zu erreichen wurden diese Gruppen ebenfalls täglich, für die Zeitspanne einer Vibrationsbehandlung der anderen Versuchstiere, in denselben Raum verbracht. Zur Darstellung der dynamischen Veränderungen der Knochenstruktur während der Frakturheilung wurde das sich neubildende Knochengewebe im Zeitraum der horizontalen WBV mittels einer polychromen Sequenzmarkierung markiert (Rahn 1976). Dafür wurde den Versuchstieren am 13. Tag $90 \mathrm{mg} / \mathrm{kg} \mathrm{KG} \mathrm{Xylenol-Orange} \mathrm{(Merck,} \mathrm{Darmstadt,} \mathrm{Deutschland),} \mathrm{am}$ 18. Tag $10 \mathrm{mg} / \mathrm{kg}$ KG Calcein-Grün (Chroma/Waldeck, Münster, Deutschland), am 24. Tag und 26. Tag je $30 \mathrm{mg} / \mathrm{kg}$ KG Alizarin-Komplexon (Merck, Darmstadt, Deutschland) und am 35. Tag nach Osteotomie $25 \mathrm{mg} / \mathrm{kg} \mathrm{KG} \mathrm{Tetracyclin} \mathrm{(Roth,}$ Karlsruhe, Deutschland) injiziert (Tabelle 6) (Stuermer et al. 2010a). Nach Abschluss der Versuchsreihe, entsprechend einer Gesamtversuchsdauer von 13 Wochen, erfolgte die Tötung der Tiere durch Dekapitation in tiefer $\mathrm{CO}_{2}$ (Kohlenstoffdioxid)-Narkose. Während der operativen Eingriffe verstarben insgesamt 5 Tiere, sodass sich das Gesamtkollektiv auf 85 Versuchstiere reduzierte. 
Tabelle 2: Gruppeneinteilung und Behandlung der Versuchstiere

\begin{tabular}{|c|c|c|}
\hline Gruppe & Operation & Vibration [Hz] \\
\hline 1: „SHAM“ & SHAM + Osteotomie & Keine \\
\hline 2: „OVX“ & OVX + Osteotomie & Keine \\
\hline 3: „30 Hz“ & OVX + Osteotomie & 30 \\
\hline 4: „,50 Hz“ & OVX + Osteotomie & 50 \\
\hline 5: „,70 Hz““ & OVX + Osteotomie & 70 \\
\hline 6: „90 Hz“ & OVX + Osteotomie & 90 \\
\hline
\end{tabular}

\subsubsection{Versuchstiere und Versuchstierhaltung}

Die Versuchstiere wurden in den Räumlichkeiten der Zentralen Tierexperimentellen Einrichtung der Universität Göttingen untergebracht. Die Haltung erfolgte in Gruppen von vier bis fünf Tieren in Polycarbonkäfigen vom Typ Makrolon ${ }^{\circledR}$ IV (Tecniplast, Pontremoli, Italien), welche alle drei Tage durch desinfizierte Käfige ausgetauscht wurden. Futter (ssniff SM R/M, ssniff Spezialdiäten GmbH, Soest, Deutschland) und Wasser stand den Ratten ohne Begrenzung zur Verfügung. Zur Erhaltung des Tag-Nacht-Rhythmus regulierte ein Beleuchtungsautomatismus einen 12-Stunden-Wechsel zwischen Hell und Dunkel. Die Temperatur des Raumes betrug konstant $20^{\circ} \mathrm{C}$ bei einer relativen Luftfeuchtigkeit von 55 Prozent. Die Ratten wurden wöchentlich, zur Ovarektomie, Osteotomie und Obduktion gewogen. Die Messung des durchschnittlichen Futterverbrauches der Tiere eines Käfigs erfolgte ebenfalls einmal wöchentlich. Die durchgeführten Tierversuche wurden von der Bezirksregierung Braunschweig genehmigt (AZ 33.42502-04-011/07).

\subsubsection{Ovarektomie}

Zur Durchführung der Ovarektomie wurden die Ratten initial mit einer $\mathrm{CO}_{2}$-Narkose betäubt. Eine tiefe Narkose wurde durch die intraperitoneale Applikation von Ketamin (90 mg/kg KG, Hostaket ${ }^{\circledR}$, Hoechst, Bad Soden, Deutschland) und Xylazin (7,5 mg/kg KG, Rompun ${ }^{\circledR}$, Bayer, Leverkusen, Deutschland) im Verhältnis $5: 3$ mit einer Dosierung von $0,01 \mathrm{ml} / \mathrm{kg} \mathrm{KG}$ aufrechterhalten. Des Weiteren erfolgte zur postoperativen Analgesierung die subkutane Injektion von Rimadyl (4 mg/kg KG, Pfizer, Karlsruhe, Deutschland). Alle Tiere wurden zur Identifikation mit einem Transponder (Uno Micro-IdSystem, Iso-Transponder, UNO Roestvaststaal BV, Zevenaar, Niederlande) im nuchalen Fettgewebe markiert. Im Rahmen der OP-Vorbereitung erfolgte die Rasur der lateralen 
Hautbereiche zwischen den Rippenbögen und den Hinterläufen. Zudem wurde eine Hornhautreizung der Augen während der Narkosephase durch das Auftragen von Augengel (Corneregel, Bausch \& Lomb, Berlin, Deutschland) vermieden.

Im Anschluss erfolgte - nach Lagerung und Desinfektion (Softasept ${ }^{\circledR}$, B. Braun, Melsungen, Deutschland) des OP-Gebietes - die Ovarektomie. Dafür erfolgte eine beidseitige paravertebrale Schnittführung unter dem dorsalen Rippenbogen. Nach sorgfältiger Präparation bis zum Peritoneum, wurde das Ovar mit anhängendem Fettgewebe nach Ligatur der Tubae uterinae entfernt. Die Bauchhöhle wurde mit Vicryl Fäden (Ethicon, Johnson \& Johnson, Norderstedt, Deutschland) in Einzelknopfnaht verschlossen. Die äußeren Wundränder wurden mit Klammern (Michel wound brackets 12 x 3 mm, Gebrüder Martin GmbH \& Co.KG, Tuttlingen, Deutschland) adaptiert und mit PovidonIod (Braunol ${ }^{\circledR}$, B. Braun, Melsungen, Deutschland) desinfiziert. Im Anschluss wurden die Tiere auf einer Wärmematte (Medtide GmbH, Burgdorf, Deutschland) bis zum Erwachen beobachtet. Ein möglicher Flüssigkeitsverlust wurde durch die subkutane Applikation von $3 \mathrm{ml} \mathrm{NaCl}$ (Natriumchlorid) 0,9\% (B. Braun, Melsungen, Deutschland) ausgeglichen. Sobald sich eine zunehmende Vigilanz zeigte, wurden die Ratten wieder in ihren Käfig zurückgesetzt.

\subsubsection{Osteotomie und Plattenosteosynthese}

Acht Wochen nach der Ovarektomie erfolgte für alle Gruppen die Osteotomie mit anschließender Plattenosteosynthese. Die Narkotisierung der Versuchstiere wurde analog zu 2.1.2 durchgeführt. Im Anschluss an die Rasur und Desinfektion der hinteren Extremitäten erfolgte ein circa $3 \mathrm{~cm}$ langer Hautschnitt über der medio-ventralen Tibia. Nach vorsichtiger Präparation der Muskulatur wurde die ventrale Tibiakante dargestellt. Die Streckmuskulatur wurde vorsichtig vom Knochen gelöst.

Als Osteosynthesematerial wurde eine 5-Loch-Leibinger-Titanplatte (57-05140 XSTitanfixationsplatte T-Form 90 , Stryker Trauma, Selzach, Schweiz) verwendet. Diese wurde auf der freien Tibia platziert, sodass die beiden körpernahen Bohrlöcher auf Höhe der Epiphyse lagen (Abbildung 1a und b). Zunächst wurden jeweils ein proximales (Abbildung 1, a) und das am weitesten distal gelegene Bohrloch (Abbildung 1, e) vorgebohrt und mittels Schrauben besetzt. Im Anschluss wurden zur späteren Fixierung der Titanplatte der zweite proximale (Abbildung 1, b) und der zweite distale Schraubenkanal (Abbildung 1, d) vorgebohrt, jedoch noch ohne Besetzung durch Schrauben belassen. Das letzte freie Bohrloch der Platte wurde nicht verwendet, denn unmittelbar darunter sollte die Osteotomie erfolgen (Abbildung 1, c). Zur Durchführung der Osteotomie wurde das Osteosynthesematerial temporär entfernt. Um für alle Tibiae den gleichen Abstand der Osteotomie zum Gelenkspalt zu gewährleisten, wurde in Vorversuchen eine Schablone 
(Abbildung 2 und Abbildung 3) entwickelt, sodass die Osteotomie exakt $7 \mathrm{~mm}$ distal des Tibiaplateaus lokalisiert war. Unter Schonung des umliegenden Gewebes wurde nach Entfernung der Schablone durch gepulsten Ultraschall (OT 7 Piezosurgery ${ }^{\circledR}$, Mectron Medical Technology, Carasco, Italien) entsprechend der Dicke des OT 7 Piezosurgery ${ }^{\circledR}$ Sägeblatt ein standardisierter Osteotomiespalt von $0,5 \mathrm{~mm}$ gesetzt. Im Anschluss wurde die Titanplatte auf den Knochenfragmenten repositioniert und am proximalen Ende mit zwei $7 \mathrm{~mm} 1.1$ er Schrauben, am distalen Ende mit einer $5 \mathrm{~mm}$ und einer $4 \mathrm{~mm} 1.1$ er Schraube endgültig fixiert (Abbildung 4).

Nach Readaption der Streckmuskulatur mit Vicryl-Nähten und Subcutannaht wurde die Haut mit Wundklammern verschlossen. Die Operation erfolgte in gleicher Weise am kontralateralen Hinterlauf. Zur Stress- und Schmerzreduktion wurde den Tieren einmalig Decentan ( $5 \mathrm{mg} / \mathrm{kg} \mathrm{KG}$, Merck, Darmstadt, Deutschland) und an den beiden folgenden Tagen als analgetische Therapie jeweils zweimal täglich Rimadyl (4 mg/kg KG, Pfizer, Karlsruhe, Deutschland) subkutan verabreicht. Analog zur Ovarektomie wurden

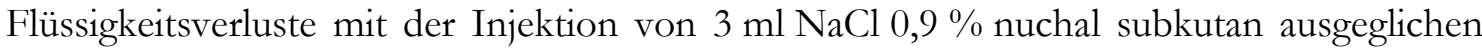
und die Tiere bis zum vollständigen Erwachen auf einer Wärmematte gelagert und beaufsichtigt.

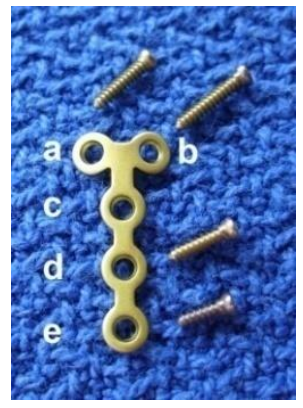

Abbildung 1: 5-Loch-Leibinger-Titanplatte mit Schrauben: $\mathrm{a}+\mathrm{b}$ : proximale Bohrlöcher mit $7 \mathrm{~mm}$ Schrauben, c: Osteotomieregion, d: zweites distales Bohrloch mit $5 \mathrm{~mm}$ Schraube, e: distales Bohrloch mit $4 \mathrm{~mm}$ Schraube 


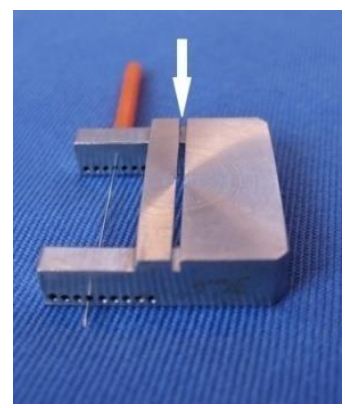

Abbildung 2: Schablone zur Definition der Osteotomiehöhe in $7 \mathrm{~mm}$ Abstand zum Tibiaplateau: Akupunkturnadel zur Fixation im Gelenkspalt, Pfeil: Spalt zur Markierung der Sägestelle (Osteotomielinie)

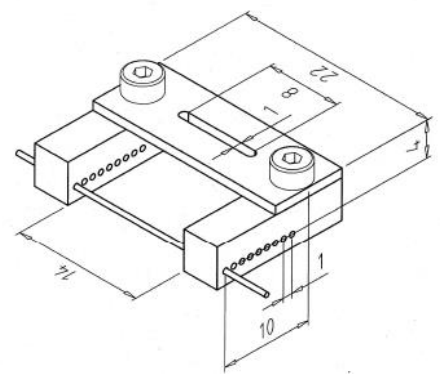

Abbildung 3: Schematische Darstellung der Sägeschablone: alle Angaben in Millimeter [mm]

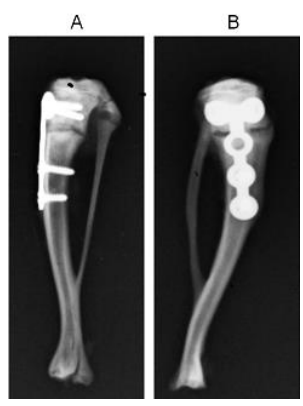

Abbildung 4: Röntgendarstellung einer Tibia inklusive Osteotomiematerial: A: a.p. (anteriorposterior), B: laterale Projektion (Komrakova et al. 2010, seite 482). Abgedruckt von Bone 47, Komrakova M, Stuermer EK, Werner C, Wicke M, Kolios L, Sehmisch S, Tezval M, Daub F, Martens T, Witzenhausen P, „Effect of human parathyroid hormone hPTH (1-34) applied at different regimes on fracture healing and muscle in ovariectomized and healthy rats", Seite 482., Copyright (2018), mit Genehmigung von Elsevier. 


\subsubsection{Horizontale Ganzkörpervibration}

Fünf Tage nach der Osteotomie und Osteosynthese wurde mit der horizontalen Ganzkörpervibration der Ratten begonnen. Dafür wurden die Tiere einmal täglich an dreißig aufeinanderfolgenden Tagen zur gleichen Zeit für fünfzehn Minuten auf einem Vibriertisch (Vibra Maschinenfabrik Schultheis, Offenbach, Deutschland) entsprechend ihrer gruppenspezifischen Vibrationsstärke (Tabelle 2) vibriert. Auf der Vibrationsplatte war ein Käfig ( $50 \mathrm{~cm}$ x $50 \mathrm{~cm} \times 25 \mathrm{~cm}$ ) befestigt, in welchem jeweils sieben bis acht Ratten gleichzeitig behandelt wurden. Um Wirkungsverluste zu vermeiden, sollten die Versuchstiere während der Vibration mit allen vier Extremitäten Bodenkontakt halten. Die horizontale Vibrationsamplitude betrug $0,5 \mathrm{~mm}$. Im Zeitraum der Vibrationsbehandlung wurde die sich neubildende Knochensubstanz durch die Applikation verschiedener Fluorochrome markiert (Rahn 1976) (Tabelle 6).

\subsubsection{Obduktion und Präparation}

Nach einer Gesamtversuchsdauer von 13 Wochen erfolgte die Dekapitation der Tiere in tiefer $\mathrm{CO}_{2}$-Narkose. Für die weiterführende Untersuchung der Tibiae wurde randomisiert eine Tibia im Knie- und im Sprunggelenk exartikuliert und unter Erhalt der Verbindung von Tibia und Fibula vom umgebenen Weichteilgewebe gelöst. Im Anschluss daran wurde das Osteosynthesematerial entfernt und die gewonnenen Proben bis zu den sich anschließenden Untersuchungen bei einer Temperatur von $-20^{\circ} \mathrm{C}$ aufbewahrt. Der Kallus der kontralateralen Tibia und der sechste Lendenwirbelkörper wurden für weiterführende genanalytische Analysen aufbewahrt, welche nicht Bestandteil dieser Arbeit sind. Ebenso erfolgte die Entnahme von Femur, der restlichen Lendenwirbelkörper und der Wadenmuskulatur (M. gastrognemius, M. soleus). Die Auswertung dieser Proben sind Grundlage der Promotionsarbeiten von Tim Genotte, Cordula Sauerhoff, sowie Daniel Terschüren und werden in diesen detailliert betrachtet.

\subsection{Biomechanischer Kompressionstest}

\subsubsection{Durchführung des biomechanischen Kompressionstests}

Die Stabilität des während der Frakturheilung neuentstandenen Kallus wurde im biomechanischen Kompressionstest untersucht. Zur Vorbereitung wurden die Tibiae inklusive verbundener Fibula eine Stunde bei Raumtemperatur langsam aufgetaut. Um Flüssigkeitsverluste zu vermeiden, verblieb die Probe während des Auftauens im Probenbehältnis. Im Anschluss daran konnte die Fibula abgetrennt werden. Die so vorbereitete Tibia wurde auf einer bereits in früheren Versuchen entwickelten 
Prüfvorrichtung (Stuermer et al. 2006) mit dem Tibiakopf in der dafür vorgesehenen Rinne positioniert. Seitliches Verrutschen wurde mit lateralen und medialen Begrenzungen, welche jedoch eine Vor- und Rückwärtsdehnung zuließen, verhindert (Abbildung 5). Ebenfalls wurde ein Austrocknen der Tibia durch regelmäßiges Befeuchten mit isotoner Kochsalzlösung vermieden. Im Anschluss wurde die Prüfvorrichtung in der Werkstoffprüfmaschine (Typ 145660 Z020/TND Zwick/Roell, Ulm, Deutschland) positioniert (Abbildung 6).

Der Test wurde mit dem Programm „test Xpert“ (Zwick/Roell, Ulm, Deutschland) und einer eigens für den Biegetest der Rattentibia erstellten Prüfvorschrift durchgeführt. Nach Starten des Programms bewegte sich der Druckkopf senkrecht auf die ventrale Tibiakante zu, bis eine Vorkraft von $1 \mathrm{~N}$ erreicht wurde. Während dieses Vorgangs war darauf zu achten, dass die Rinne des Druckstempels genau auf der Tibiakante zum Aufliegen kam. Gegebenenfalls war eine manuelle Anpassung der Position der Prüfvorrichtung notwendig. Nach Erreichen der Vorkraft von $1 \mathrm{~N}$ begann die eigentliche Messung. Der Druckstempel wurde mit einer Geschwindigkeit von $5 \mathrm{~mm} / \mathrm{min}$ weiter auf die Tibia abgesenkt. Die dabei aufgewendete Kraft wurde alle 0,1 mm gemessen und in einem Kraft-Weg-Diagramm dargestellt (Abbildung 7). Der Messbereich lag im Bereich von $2 \mathrm{~N}$ bis $200 \mathrm{~N}$ bei einer relativen Genauigkeit von 0,2 bis 0,4 Prozent. Durch den steigenden Druck wurde die Tibia elastisch verformt. Um eine Refraktur zu verhindern, wurde der Versuch über das Programm vor Erreichen der Maximalkraft beendet. Dafür wurde die in früheren Versuchen entwickelte Prüfvorschrift (Stuermer et al. 2006) dahingehend angepasst, dass die Krafteinwirkung bei einem Kraftabfall von $2 \mathrm{~N}$ abgebrochen wurde.

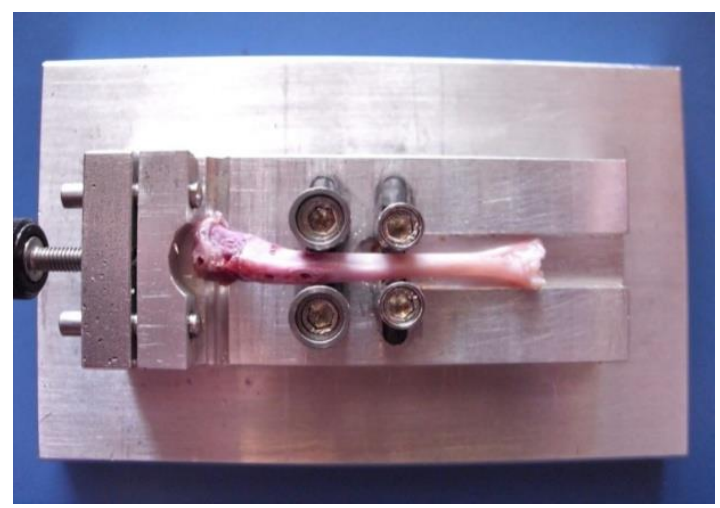

Abbildung 5: Prüfvorrichtung mit aufliegender Tibia 


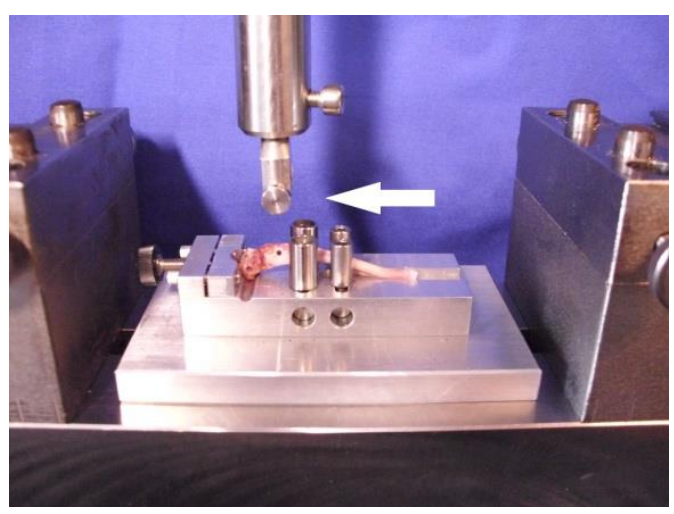

Abbildung 6: Werkstoffprüfmaschine mit Prüfvorrichtung: weißer Pfeil = Druckkopf

\subsubsection{Auswertung des biomechanischen Kompressionstests}

Der typische Kurvenverlauf des Kraft-Weg-Diagramms (Abbildung 7) wurde zuvor in (Stuermer et al. 2006) beschrieben und zeigt Bereiche mit elastischer (Steigung) und plastischer Verformung (ab Yield Load) bei zunehmender Krafteinwirkung. Unter der größten Krafteinwirkung $\left(\mathrm{F}_{\text {max }}\right)$ kommt es durch zahlreiche Mikrofrakturen zum Bruch des Knochens, was sich in einem Abfall der Kurve im Kurvenverlauf darstellte (Stuermer et al. 2006). Um die Tibiae für weitere Versuche zur Verfügung zu stellen, galt es einen Bruch zu vermeiden, sodass der Versuch vor Erreichen der Maximalkraft entsprechend der Prüfvorschrift beendet wurde.

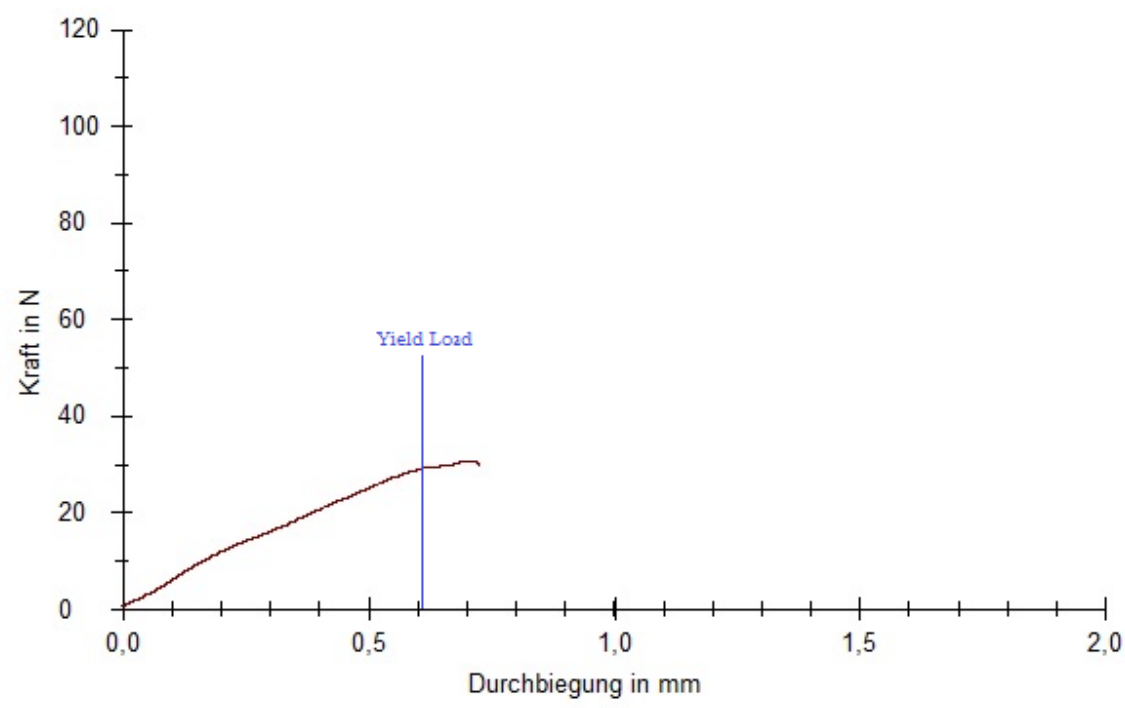

Abbildung 7: Kraft-Weg-Diagramm aus dem Programm „test Xpert“: Tibia 47, Gruppe 4, $\mathrm{OVX}+50 \mathrm{~Hz}$ 
Die lineare Steigung der Kraft-Weg-Kurve entspricht der Festigkeit des Knochens. Sie ist die elastische Verformungsphase. In dieser Phase kommt es zu keinen Mikro- oder Trabekelfrakturen (Stuermer et al. 2006).

Mit Yield Load (Streckgrenze) wird der Übergang von plastischer zu elastischer Verformung des Knochens während einer zunehmenden Krafteinwirkung bezeichnet. Er spiegelt demnach den Bereich wieder, in welchem durch die einwirkende Kraft erste irreversible strukturelle Veränderungen am Knochen, also Mikrofrakturen und Trabekeleinbrüche, entstanden sind. Dies zeigt sich in der Kurve des Kraft-Weg-Diagramms als Steigungsabfall. Der Yield Load ist definiert als der Punkt, an dem der Steigungsabfall der Kurve größer ist als das Doppelte der Standardabweichung der Regressionsgeraden und ist für jede Tibia separat zu bestimmen (Stuermer et al. 2006).

\subsection{Mikrocomputertomographie}

Die Mikrocomputertomographien der zu untersuchenden Tibiae wurden mit einem eXplore Locus SP $\mu$ CT (GE Healthcare, Ontario, Kanada) erstellt. Es wurden jeweils drei Tibiae gleichzeitig gescannt. Insgesamt erfolgte die Darstellung von 81 Tibiae, mindestens 11 Stück pro Versuchsgruppe. Dabei wurden folgende Scanparameter berücksichtigt (Tabelle 3):

Tabelle 3: Scanparameter für die Erstellung der Mikrocomputertomographien

\begin{tabular}{|l|l|}
\hline Parameter [Einheit] & Wert \\
\hline Röhrenspannung $[\mathrm{kVp}]$ & 72 \\
\hline Röhrenstrom $[\mu \mathrm{A}]$ & 90 \\
\hline Belichtungszeit $[\mathrm{ms}]$ & 1600 \\
\hline Modus & $360^{\circ}$ Rotation \\
\hline Pixelgröße $[\mathrm{mm}]$ & 0,029 \\
\hline Bildanzahl & 900 \\
\hline
\end{tabular}

\subsubsection{Scanvorgang}

Pro Scanvorgang wurden jeweils drei Tibiae ohne weitere Präparation in einem vorgefertigten dreikammerigen Zylinder untersucht. Um ein Verrutschen der Proben durch die Rotation der Messkammer zu vermeiden, wurden diese mit dem Tibiakopf nach unten 
zeigend in Schaumstoff gebettet. An dem Zylinder wurde für jeden Scanvorgang ein Dichtephantom für Wasser, Luft und Knochensubstanz (Hydroxylapatit) befestigt, bevor er in der Scankammer platziert wurde. Für den Scanvorgang wurde eine eigens für das Scannen der Tibiae erstellte Scananleitung (UMG_LARGETube_Fastbin2) verwendet. In deren Abfolge wurde initial ein Übersichtsbild erstellt, an welchem die Bildeinstellungen optimiert werden konnten. Anschließend erfolgte manuell die Anpassung des Bildrahmens, sodass die Tibia bis zum zweiten distalen Bohrloch einschließlich des Dichtephantoms abgebildet wurde. Darauf folgte der eigentliche Scanvorgang. Von dem erfassten Datensatz wurden mittels des Programms GEHC Mikro View (v2.1.2, GE Healthcare) dreidimensionale (3-D) Abbildungen erstellt. Durch einen speziellen Algorithmus (filtred back projection) wurden 3-D Rekonstruktionen angefertigt. Dazu musste in jeder Probenkammer der einzelnen Dichteäquivalente und der Tibiae ein Messbereich zur Bestimmung der entsprechenden Graustufen definiert werden. Im Anschluss daran erfolgte die Kalibrierung anhand der Grauwerte des Dichtephantoms und die Rekonstruktion der einzelnen Tibiae.

\subsubsection{Auswertung der Mikrocomputertomographien}

Die Datensätze wurden mit dem Programm „3D-OsteoAnalyze v1.00.3“ visualisiert und hinsichtlich der Knochendichte und des Knochenvolumens analysiert. Das Programm bietet eine Darstellung im 2-D (zweidimensional) und auch im 3-D Format an. Zur besseren Orientierung wurde der Cursor in der 2-D-Darstellung im Kallusbereich mittig zum Osteotomiespalt gelegt und die Tibia im 3-D-Fenster senkrecht ausgerichtet. Anschließend wurde ein Messrahmen gewählt, welcher den gesamten Kallus einrahmte. Dabei hatte sich zur Erfassung des gesamten Kallusbereichs eine standardisierte Messrahmengröße von $9 \mathrm{~mm}$ Breite und jeweils 2,5 mm Abstand zur Mittellinie etabliert (Trautmann 2014) (Abbildung 8). Sobald der Messrahmen platziert war, wurden alle Daten außerhalb dieses Bereiches durch das Programm herausgerechnet.

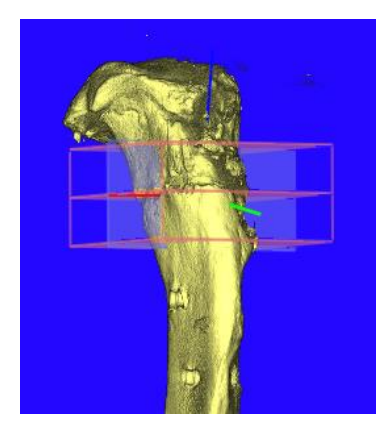

Abbildung 8: Messrahmen zur Erfassung des Kallusbereiches: Tibia 44, Gruppe 3, OVX $+30 \mathrm{~Hz}$ 
Zur weiteren Analyse wurde von dem nun eingegrenzten Kallusbereich ein Grauwerthistogramm erstellt. Dabei stellen sich auf der Abszisse die Helligkeitsstufen in aufsteigender Stärke und auf der Ordinate die Anzahl der zugehörigen Bildpunkte dar. Demnach waren im Verlauf der X-Achse zunehmend dichtere Strukturen abgebildet (Abbildung 9). Um von den unterschiedlichen Helligkeitsstufen, welche mit einer Abschwächung der Röntgenstrahlen korrelierten, auf den Mineralgehalt schließen zu können, mussten diese in Bezug zu einer definierten Dichte anhand unseres Dichtephantoms gesetzt werden (Weidemann 2014). Die Werte für Luft und den Probenzylinder wurden herausgerechnet, sodass sich anschließend ein dreigipfliges Histogramm für die Parameter Weichteilgewebe (W), nichtkortikaler Knochen (NK, entspricht dem Kallus) und kortikaler Knochen (entspricht der Kortikalis) abbildete (Abbildung 9).

Die einzelnen Strukturen konnten entsprechend dem Kurvenverlauf eingegrenzt werden und wurden in der 2-D-Darstellung grün eingefärbt dargestellt. Dadurch konnte eine visuelle Anpassung entsprechend der grün eingefärbten Bereiche erfolgen. Anhand des Kurvenverlaufs wurden - entsprechend jedem einzelnen Gipfel - die Grauwerte und das Volumen für die Kortikalis, den Kallus sowie den gesamten Knochen als Zusammenfassung der Parameter Kortikalis und Kallus bestimmt (Trautmann 2014). Die gewonnenen Graustufenwerte wurden in GV alues [GVal] und die Volumina in Kubikmillimeter [ $\mathrm{mm}^{3}$ ] angegeben.

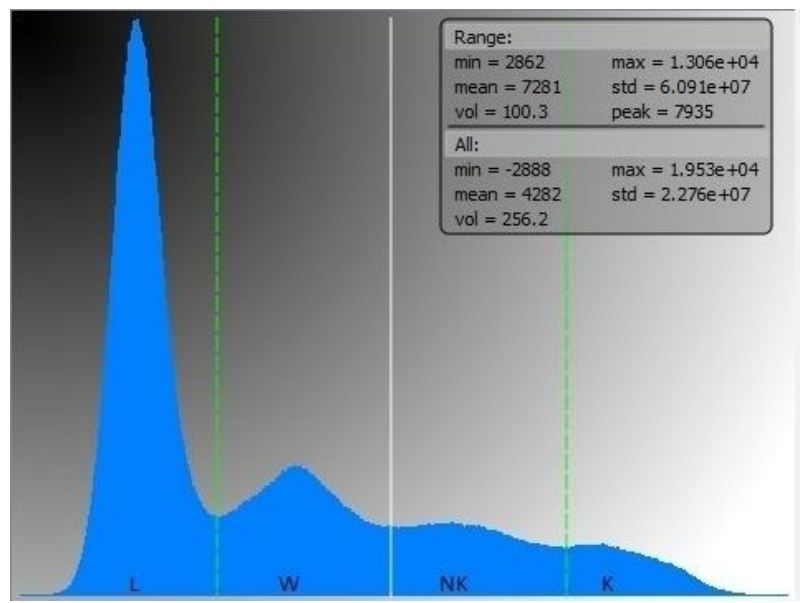

Abbildung 9: Grauwerthistogramm der metaphysären Rattentibia: modifiziert nach Trautmann (Trautmann 2014, Seite 31) L: Luft, W: Weichteilgewebe, NK: nichtkortikaler Knochen, K: kortikaler Knochen. Die Verwendung erfolgt mit freundlicher Genehmigung von Lukas Trautmann. 


\subsubsection{Umrechnung der Bone Mineral Density}

Durch die Korrelation der Messwerte mit einem Phantom mit verschiedenen bekannten Dichteäquivalenten ist eine Umrechnung der Werte in Dichtewerte BMD in Gramm pro Kubikzentimeter $\left[\mathrm{g} / \mathrm{cm}^{3}\right]$ möglich.

\subsubsection{Messparameter der Mikrocomputertomographie}

In der Tabelle 4 sind die einzelnen Parameter der Auswertung der Mikrocomputertomographie zusammengefasst.

Tabelle 4: Messparameter der Mikrocomputertomographie

\begin{tabular}{|l|l|}
\hline Messparameter [Einheit] & Berechnungsgrundlage \\
\hline Gesamtknochendichte $\left[\mathrm{g} / \mathrm{cm}^{3}\right]$ & Dichte des Kortikalis- und Kallusbereiches \\
\hline Kortikalisdichte $\left[\mathrm{g} / \mathrm{cm}^{3}\right]$ & Dichte des Kortikalisbereiches \\
\hline Kallusdichte $\left[\mathrm{g} / \mathrm{cm}^{3}\right]$ & Dichte des Kallusbereiches \\
\hline Gesamtknochenvolumen $(\mathrm{BV})\left[\mathrm{mm}^{3}\right]$ & Gesamtvolumen des Kortikalis- und Kallusbereiches \\
\hline Kortikalisvolumen $\left[\mathrm{mm}^{3}\right]$ & Volumen des Kortikalisbereiches \\
\hline Kallusvolumen $\left[\mathrm{mm}^{3}\right]$ & Volumen des Kallusbereiches \\
\hline Gesamtgewebevolumen $(\mathrm{TV})\left[\mathrm{mm}^{3}\right]$ & Gesamtvolumen aller Strukturen $(\mathrm{L}+\mathrm{W}+\mathrm{NK}+\mathrm{K})$ \\
\hline bone volume fraction $(\mathrm{BV} / \mathrm{TV})[\%]$ & Quotient aus Gesamtknochenvolumen und Gesamtgewebevolumen \\
\hline
\end{tabular}

\subsection{Mikroradiographie}

\subsubsection{Histologische Aufarbeitung und Erstellen der Mikroradiographien}

Im Anschluss an den biomechanischen Kompressionstest erfolgte die Entwässerung und Entfettung der Tibiae in einer aufsteigenden Alkoholreihe (40\%, $70 \%, 80 \%, 100 \%)$. Dabei wurde die Konzentration von Ethanol (Merck, Darmstadt, Deutschland) jeweils nach einer Woche erhöht. Daran schloss sich die Einbettung der einzelnen Tibiae in Rollrandflaschen (40 ml; $80 \times 30 \mathrm{~mm})$ in einer Mischung aus $1000 \mathrm{ml}$ Methylmethacrylsäure (MMA) (Merck, Darmstadt, Deutschland), $200 \mathrm{ml}$ Dibutylphthalat (Merck, Darmstadt, Deutschland) und 29 g Benzoylperoxid (Merck, Darmstadt, Deutschland) an. Nach drei Wochen wurden die ausgehärteten MMA-Blöcke mittels einer Innenlochsäge (Leica SP 1600 Sägemikrotom, Nussloch, Deutschland) in $150 \pm 20 \mu \mathrm{m}$ dicke Schnitte gesägt. Dabei diente die ehemalige Schraubenebene als sagittale Schnittebene. Für jede Tibia wurden dabei bis zu zehn Schnitte angefertigt, wovon drei zentrale 
aufeinanderfolgende für die weitere mikroradiographische Untersuchung ausgewählt wurden. Mittels einem Faxitron Röntgengerät (Model-Nr. 43855 A, Hewlett-Packard, San Diego, USA) erfolgte mit einer Belichtungszeit von drei Minuten, einer Röhrenspannung von $40 \mathrm{kV}$ und einer Stromstärke von $0,3 \mathrm{~mA}$ die Ablichtung der Knochenschnitte auf Kodak Professional Film (INDUSTREX SR45 Film ISO 9002, Rochester, New York, USA).

\subsubsection{Auswertung der Mikroradiographien}

Mit einem Leica Stereomakroskop (MZ 7-5, Bensheim, Deutschland) erfolgte die Evaluation der angefertigten Mikroradiographien. Als Lichtquelle wurde eine Kaltlichtlampe (Leica KL 1500 LCD, Bensheim, Deutschland) verwendet. Die Mikroradiographien wurden über eine Kamera (Leica DC 300F; Bensheim; Deutschland) digitalisiert (Intel Pentium 4, 2,6 GHz). Die weitere histomorphometrische Auswertung erfolgte über die Software „Leica Quantiment QWin 2003“ (Leica; Bensheim; Deutschland). Es haben sich in früheren Versuchen die Verwendung eines 1,0er Objektivs am Makroskop, welches eine vollständige Abbildung der Schnitte entsprechend der Monitorgröße gewährleistet, sowie eine mittlere Blendenöffnung (Schalterposition „B“) und eine Temperatur der Halogenlampe bei $3000 \mathrm{~K}$, als optimale Messsituation herausgestellt. Die Belichtungszeit lag in einem Bereich zwischen 345 bis 460 ms und musste aufgrund der Schwankungsbreite der Schnitte von $\pm 20 \mu \mathrm{m}$ für jedes Bild separat angepasst werden.

Die Auswertung der einzelnen Schnitte erfolgte randomisiert. In der Tabelle 5 sind die einzelnen Parameter der Auswertung der Mikroradiographien zusammengefasst. Folgende Arbeitsschritte wurden in gleicher Reihenfolge nacheinander an je drei Schnitten pro Präparat durchgeführt: 


\section{Digitalisierung der Mikroradiographien}

Mit dem unter 2.4.2 beschriebenen Makroskop und dem Intuos ${ }^{\circledR} 3$ Grafiktablett (Wacom, Saitama, Japan) wurden die Mikroradiographien digitalisiert. Die Abbildung erfolgte dabei standardisiert unter der Zuhilfenahme eines festgesetzten Messrahmens ( $2 \mathrm{~mm}$ vertikal, $5 \mathrm{~mm}$ horizontal) (Daub 2010) (Abbildung 10, I und III). Dabei diente eine horizontale Linie, welche an der Osteotomielinie (Abbildung 10, II) ausgerichtet wurde, als Orientierung. Um eine vergleichende Auswertung zu gewährleisten, wurde stets die gleiche Position für die Schnitte gewählt, sodass sich der kraniale Teil der Abbildung am oberen, der kaudale am unteren, der plattennahe am rechten und der plattenferne am linken Bildrand auf dem Monitor darstellte.

\section{Graudetektion}

Mit der Graudetektion erfasste das Programm alle Knochenstrukturen und färbte diese, um sie von den nichtknöchernen Strukturen zu unterscheiden, blau an. Dabei war eine manuelle Korrektur des Untersuchers möglich, um eventuell nicht aufgezeichnete Areale mit zu erfassen. Eine leichte Überdetektion wurde dabei toleriert.

\section{Flächenzuordnung}

Um die einzelnen Flächen der Abbildung zu definieren, wurden diese mit dem Intuos $^{\circledR} 3$ Grip Pen (Wacom, Saitama, Japan) auf dem Grafiktablett umfahren, wobei die Flächenbegrenzung zur Kontrolle als Linie (Linienstärke 2,1 Pixel $\triangleq 6,73 \mu \mathrm{m}$ ) abgebildet wurde. Diese konnte im Anschluss korrigiert werden. Ebenfalls war es möglich, mehrere markierte Areale als eine Fläche zusammenzufassen, wobei jedoch eine Mehrfachzuordnung durch das Programm verhindert wurde. Die einzelnen Flächen wurden wie folgt bestimmt (Abbildung 10): 


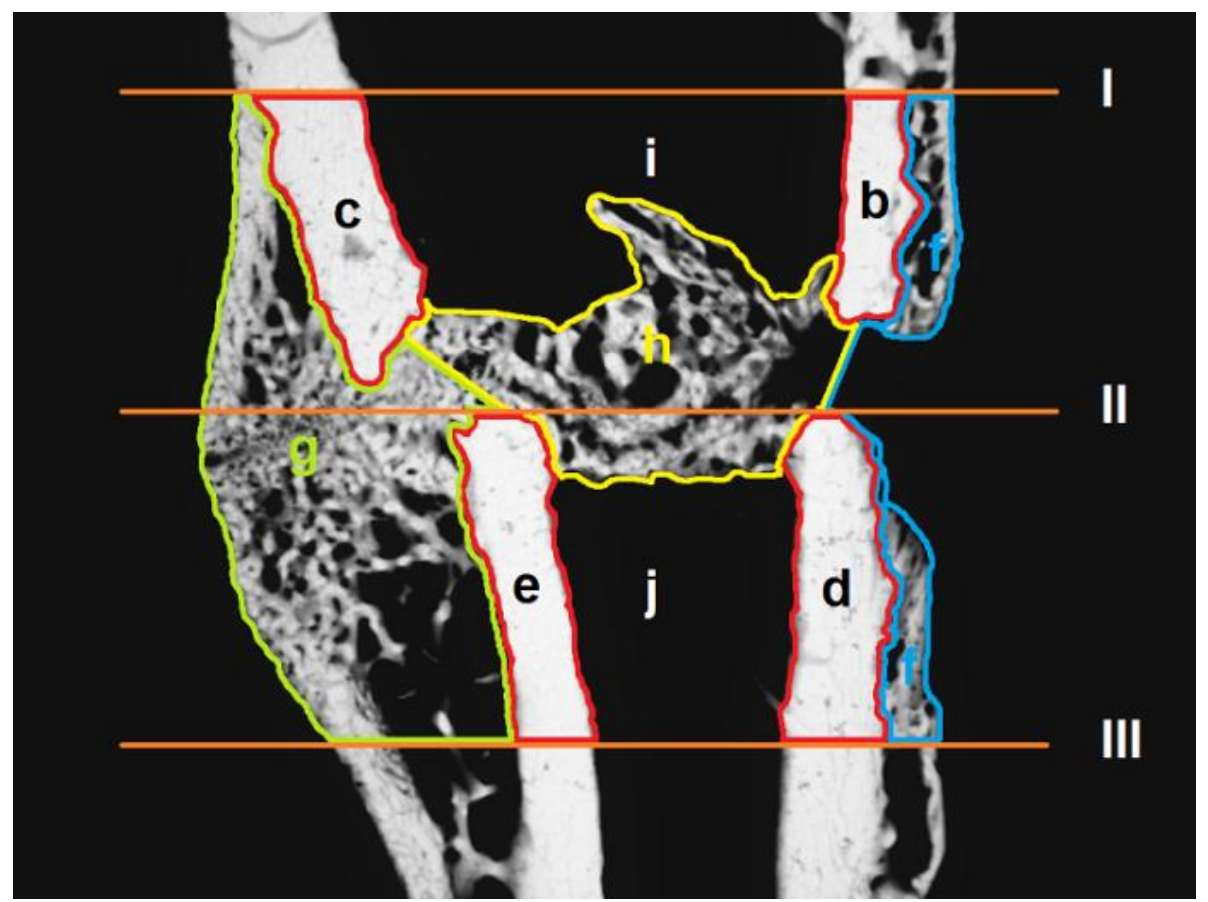

Abbildung 10: Schematische Darstellung der Flächenzuordnung am Beispiel eines mikroradiographischen Bildes: Tibia 58, Schnitt 7, Gruppe 4, I: obere Messgrenze, II: Osteotomielinie, III: untere Messgrenze, b: Kortikalisfläche proximal plattennah, c: Kortikalisfläche proximal plattenfern, d: Kortikalisfläche distal plattennah, e: Kortikalisfläche distal plattenfern, f: Kallusfläche plattennah, g: Kallusfläche plattenfern, h: Kallusfläche endostal, i: Trabekelfläche proximal, j: Trabekelfläche distal

Gesamter Knochen einschließlich Kallus

Der gesamte Knochen wurde möglichst weit über den Messrahmen hinaus umfahren, um alle Knochenanteile mit in die Berechnungen einzuschließen.

Kortikalisfläche proximal plattennah

Von der Gesamtknochenfläche wurde der plattennahe proximale Anteil der Kortikalis umfahren. Dieser wird auf dem Röntgenfilm aufgrund seiner hohen Knochendichte und der damit geringeren Strahlentransparenz deutlich heller abgebildet (Abbildung 10, b).

Kortikalisfläche proximal plattenfern

In gleicher Weise wurde die Kortikalisfläche (Abbildung 10, c) proximal plattenfern definiert. 
Kortikalisfläche distal plattennah

Es wurde der distale plattennahe Anteil der Kortikalis markiert (Abbildung 10, d).

Kortikalisfläche distal plattenfern

Analog der vorhergehenden Schritte erfolgte die Definition von den distal der Osteotomie gelegenen plattenfernen Kortikalisstrukturen (Abbildung 10, e).

Kallusfläche plattennah

Durch die Bestimmung der Kortikalisfläche in den vorhergegangenen Schritten erfolgte bereits die Abgrenzung vom Kallus. Um zwischen endostalem und plattennahem Kallus zu unterscheiden, wurde die zentrale Verbindungslinie zwischen proximaler und distaler Kortikalis genutzt (Abbildung 10, f).

Kallusfläche plattenfern

Analog zur Markierung der Kallusfläche plattennah erfolgte die Definition der Kallusfläche plattenfern (Abbildung 10, g).

Kallusfläche endostal

Da die Abgrenzung des endostalen Kallus von den weiteren Kallusflächen schon bei den vorausgegangenen Schritten erfolgte, war nun noch die Abgrenzung derer vom weniger dichten Trabekelwerk durchzuführen (Abbildung 10, h).

Trabekelfläche proximal

Die proximale Trabekelfläche wurde durch die bereits durchgeführten Schritte bestimmt und musste daher nicht gesondert umrandet werden. Es war aber darauf zu achten, dass eventuell ein in das Trabekelwerk reichender Schraubenkanal mit dazugehörigen Kallus aus der Fläche zu separieren war (Abbildung 10, i).

Trabekelfläche distal

Analog zur Bestimmung der Trabekelfläche proximal erfolgte die Zuordnung der Trabekelfläche distal (Abbildung 10, j). 
Kortikalisdicke distal plattennah und plattenfern

Zur Bestimmung der Kortikalisdicke distal plattennah wurden fünf Vektoren in möglichst gleichem Abstand rechtwinklig zur Längsachse durch die distale plattennahe Kortikalis gesetzt. Mit Hilfe der verwendeten Software konnte nun die Kortikalisdicke über die Vektoren aus der zuvor bestimmten Kortikalisfläche berechnet werden. Durch die Software wurde der Mittelwert der Kortikalisdicke in Millimeter berechnet. In gleicher Weise erfolgte dies für die Kortikalisdicke distal plattenfern.

Knochendurchmesser proximal und distal der Osteotomie

Zur Bestimmung des gesamten Knochendurchmessers wurden fünf Vektoren senkrecht zur Längsachse durch den gesamten Knochendurchmesser gelegt. Um zu verhindern, dass der Kallus mit in die Berechnungen einbezogen wird, wurden die Vektoren auf die Strecke zwischen plattennahen und plattenfernen Periost beschränkt. Durch die Software wurde dann der Mittelwert des Knochendurchmessers in Millimeter berechnet. Auch hier erfolgte die Bestimmung des Knochendurchmessers distal der Osteotomie entsprechend der des proximalen Knochendurchmessers.

Kallusdicke plattennah und plattenfern

Die Bestimmung der Kallusdicke plattennah erfolgte durch das Setzen von zehn Vektoren, jeweils fünf proximal und fünf distal der Osteotomielinie, welche über den Kallusrand hinausreichten. Durch die Software wurde dann das arithmetische Mittel der Kallusdicke in Millimeter berechnet. Für die Kallusdicke plattenfern wurde entsprechend verfahren.

Des Weiteren wurde durch das Programm die Knochenflächendichte Kortikalis distal plattennah, plattenfern und die Knochenflächendichte Trabekel plattennah, plattenfern, endostal und distal als prozentualer Anteil des Knochens an der jeweils definierten Fläche in Prozent berechnet. Dem folgte auch die Bestimmung der Anzahl von Trabekelkreuzungen als absolute Zahl an Trabekelkreuzungen in der distalen Trabekelfläche und die Bestimmung der Dichte an Trabekelkreuzungen als Anzahl von Trabekelkreuzungen pro Quadratmillimeter im Bereich der distalen Trabekelfläche. Anhand des Mittelwertes der Trabekeldurchmesser im Bereich der distalen Trabekelfläche konnte die Software die mittlere Trabekeldicke in Mikrometern bestimmen. 
Tabelle 5: Messparameter der mikroradiographischen Auswertung und deren Berechnungsgrundlage

\begin{tabular}{|c|c|}
\hline Messparameter [Einheit] & Berechnungsgrundlage \\
\hline Kortikalisdicke plattennah [mm] & $\begin{array}{l}\text { Mittelwert der } 5 \text { durch die distale plattennahe Kortikalis gelegten } \\
\text { Vektoren }\end{array}$ \\
\hline Kortikalisdicke plattenfern [mm] & $\begin{array}{l}\text { Mittelwert der } 5 \text { durch die distale plattenferne Kortikalis gelegten } \\
\text { Vektoren }\end{array}$ \\
\hline Kallusdicke plattennah $[\mathrm{mm}]$ & Mittelwert der 5 durch den plattennahen Kallus gelegten Vektoren \\
\hline Kallusdicke plattenfern [mm] & Mittelwert der 5 durch den plattenfernen Kallus gelegten Vektoren \\
\hline Kortikalisdichte plattennah [\%] & $\begin{array}{l}\text { prozentualer Knochenanteil der als "Kortikalis distal pattennah" } \\
\text { definierten Fläche }\end{array}$ \\
\hline Kortikalisdichte plattenfern [\%] & $\begin{array}{l}\text { prozentualer Knochenanteil der als "Kortikalis distal plattenfern" } \\
\text { definierten Fläche }\end{array}$ \\
\hline Kallusdichte plattennah [\%] & $\begin{array}{l}\text { prozentualer Knochenanteil der als "Kallus plattennah" definierten } \\
\text { Fläche }\end{array}$ \\
\hline Kallusdichte plattenfern [\%] & $\begin{array}{l}\text { prozentualer Knochenanteil der als "Kallus plattenfern" definierten } \\
\text { Fläche }\end{array}$ \\
\hline Kallusdichte endostal [\%] & $\begin{array}{l}\text { prozentualer Knochenanteil der als "Kallus endostal" definierten } \\
\text { Fläche }\end{array}$ \\
\hline Dichte der Trabekelfläche [\%] & $\begin{array}{l}\text { prozentualer Knochenanteil der als "Trabekelfläche distal" } \\
\text { definierten Fläche }\end{array}$ \\
\hline Anzahl Trabekelkreuzungen absolut & $\begin{array}{l}\text { absolute Anzahl der Trabekelkreuzungen im Bereich der distalen } \\
\text { Trabekelfläche }\end{array}$ \\
\hline Anzahl Trabekelkreuzungen $\left[1 / \mathrm{mm}^{2}\right]$ & $\begin{array}{l}\text { Anzahl der Trabekelkreuzungen pro } \mathrm{mm}^{2} \text { im Bereich der distalen } \\
\text { Trabekelfläche }\end{array}$ \\
\hline Mittlere Trabekeldicke $[\mu \mathrm{m}]$ & $\begin{array}{l}\text { Mittelwert des Trabekeldurchmessers im Bereich der distalen } \\
\text { Trabekelfläche }\end{array}$ \\
\hline
\end{tabular}

\subsection{Polychrome Sequenzmarkierung}

\subsubsection{Methode der polychromen Sequenzmarkierung}

Durch die polychrome Sequenzmarkierung lassen sich dynamische Umbauvorgänge während des Knochenumbaus darstellen (Rahn 1976). Dazu wurde den Ratten während der Knochenheilung zu bestimmten Zeiten eine definierte Menge an Fluorochromen als Markersubstanz appliziert (Tabelle 6). Diese wurden in das neugebildete Knochengewebe 
als Calcium-Chelat-Komplex eingelagert. Durch die Applikation an zuvor definierten Tagen lässt sich eine genaue Zuordnung des neugebildeten Kallus zum Bildungszeitpunkt und -ort herstellen und so die Kallusbildung nachvollziehen (Stuermer et al. 2010b). Die eingelagerten Farbstoffe lassen sich nach Präparation und Anfertigung von Schnittpräparaten analog zu 2.4.1 und Fixation auf Objektträgern durch eine fluoreszenzsmikroskopische Untersuchung nachweisen und analysieren.

\subsubsection{Fluorochrome}

Als Markersubstanz fanden die Fluorochrome Xylenol-Orange (XO), Calcein-Grün (CG), Alizarin-Komplexon (AK) und Tetracyclin (TC) Anwendung (Tabelle 6). Dazu wurden diese Farbstoffe in Kochsalzlösung (für TC) oder in destilliertem Wasser (für XO, CG und AK) gelöst und intravital subkutan den Ratten appliziert. Daraufhin wurden die Fluorochrome durch Komplexbildung in das neuentstandene Knochengewebe eingelagert.

Tabelle 6: Einteilung der Fluorochrome nach verwendetem Farbstoff, Dosierung, Applikationstag, Markierungszeitraum und Fluoreszenz

\begin{tabular}{|l|l|l|l|l|}
\hline Fluorochrom & $\begin{array}{l}\text { Dosierung } \\
\text { [mg/kg KG] }\end{array}$ & $\begin{array}{l}\text { Applikationstag } \\
\text { [nach Osteotomie] }\end{array}$ & $\begin{array}{l}\text { Markierungszeitraum } \\
\text { [nach Osteotomie] }\end{array}$ & Fluoreszenz \\
\hline XO & 90 & 13 & $0-13$ & orange \\
\hline CG & 10 & 18 & $14-18$ & grün \\
\hline AK & 30 & 24,26 & $19-26$ & rot \\
\hline TC & 25 & 35 & $27-35$ & gelb \\
\hline
\end{tabular}

\subsubsection{Auswertung der polychromen Sequenzanalyse}

Die bereits in Punkt 2.4.1 beschriebenen angefertigten Schnitte wurden für die polychrome Sequenzanalyse mittels Eukitt (Firma Kindler, Freiburg, Deutschland) auf Objektträgern fixiert. Die Auswertung erfolgte mit einem Auflicht-Fluoreszenz-Stereomakroskop (Leica Stereomakroskop MZ 7-5 mit FluoCombi III, Bensheim, Deutschland) in Blaufluoreszenz. Eine Quecksilberhöchstdrucklampe (50 W) wurde als Lichtquelle verwendet und die erforderliche Fluorochromanregung mit Blaulicht durch einen Anregungsfilter für den Wellenbereich 450 bis $490 \mathrm{~nm}$ erreicht. Wie auch in Punkt 2.4.2 erfolgte das Einlesen der Schnitte über eine Kamera (Leica DC 300F) und die Auswertung über die Software „Leica Quantiment QWin 2003“ (Leica; Bensheim; Deutschland). Analog zur Mikroradiographie hat sich für die polychrome Sequenzanalyse die Verwendung eines 1,6er Objektivs am 
Makroskop für eine vollständige Abbildung entsprechend des Kallus etabliert. Die Belichtungszeit für eine ausreichende Helligkeit bei Abbildung der Schnitte betrug für jedes Bild in Abhängigkeit von der Schnittdicke 9,7 bis 12,9 s.

Die histologische Auswertung erfolgte randomisiert. In der Tabelle 7 sind die einzelnen Parameter der polychromen Sequenzmarkierung, welche anhand der Software bestimmt wurden, mit ihrer Berechnungsgrundlage im Einzelnen dargestellt. Folgende Arbeitsschritte wurden in gleicher Reihenfolge nacheinander an je drei Schnitten pro Tibia durchgeführt:

\section{Digitalisieren der Präparate}

Mit der unter 2.5.3 beschriebenen Hard- und Software erfolgte die Digitalisierung. Um eine vergleichende Auswertung zu gewährleisten, wurde stets die identische Position für die Schnitte gewählt, sodass sich der kraniale Teil der Tibia am oberen, der kaudale am unteren, der plattennahe am linken und der plattenferne am rechten Bildrand des Monitors darstellte.

\section{Flächendefinition}

Analog zu Punkt 2.4.2 erfolgte das Umfahren der zu bestimmenden Strukturen auf dem Grafiktablett. Dabei wurde die Flächenbegrenzung zur Kontrolle als Linie (Linienstärke 2,1 Pixel $\triangleq 6,73 \mu \mathrm{m})$ abgebildet und konnte im Anschluss korrigiert werden. Ebenfalls war es möglich, verschiedene markierte Areale als eine Fläche zusammenzufassen, wobei jedoch eine Mehrfachzuordnung durch das Programm verhindert wurde.

\section{Flächen-Fluorochrom-Zuordnung}

Im Anschluss an die Flächendefinition wurden die Gebiete, welche fluoreszierten, von der Gesamtfläche abgegrenzt und je nach Fluoreszensverhalten der jeweiligen Substanz zugeordnet (Abbildung 11). Die Reihenfolge der Flächen-Fluorochrom-Zuordnung (XO, CG, AK, TC) war durch das Programm vorgegeben. Anwendung fanden dabei nur die plattennahen, plattenfernen und endostalen Kallusflächen. In die Auswertung gingen dabei nur die CG, AK und TC gefärbten Flächen ein. Die XO gefärbten Flächen wurde von CG überlagert, sodass dem standardisierten Messprogramm eine getrennte Identifizierung dieser Flächen nicht möglich war. 


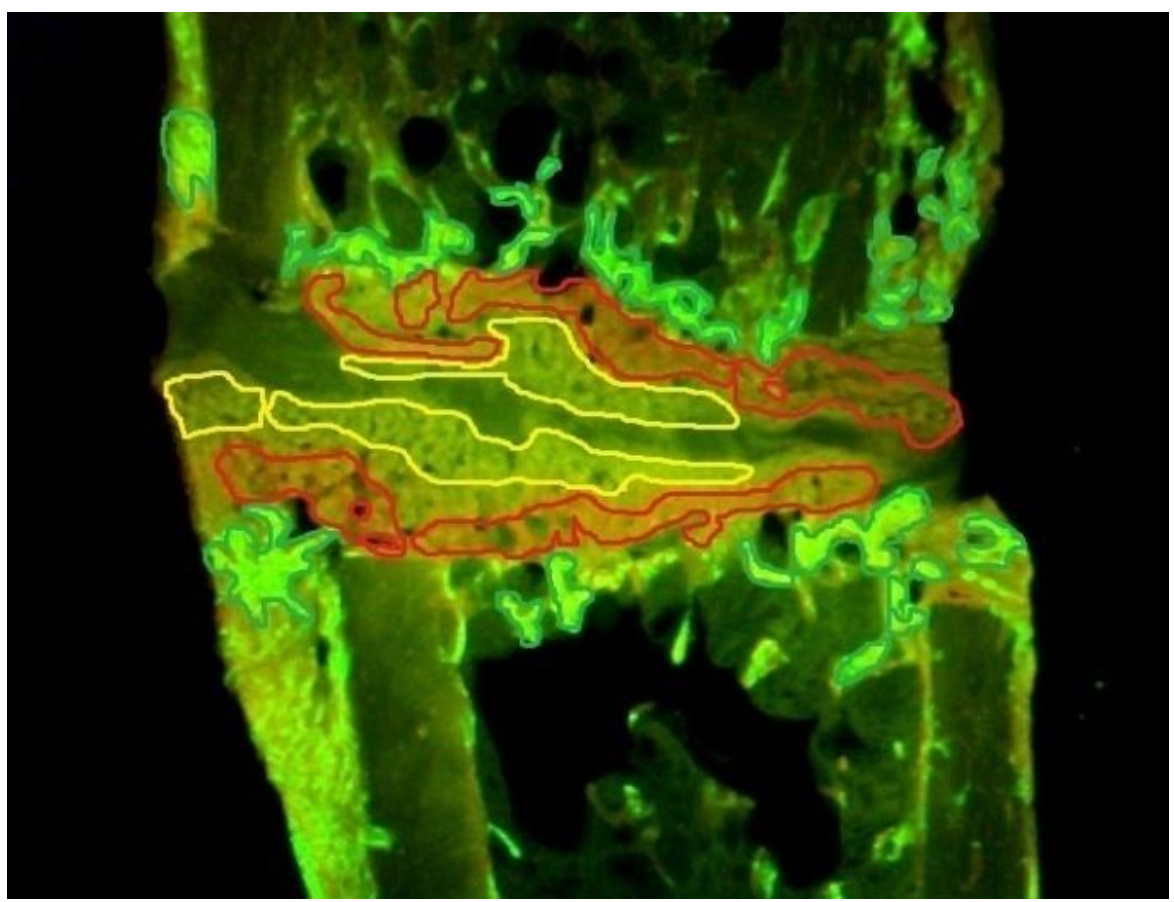

Abbildung 11: Polychrome Sequenzanalyse des Osteotomiekallus der Rattentibia (Tibia 10, Gruppe 1, Schnitt 5, grün-fluoreszierend $\triangleq$ CG markierte Fläche, rot-fluoreszierend $\hat{=}$ AK markierte Fläche, gelb-fluoreszierend $\triangleq \mathrm{TC}$ markierte Fläche)

Die Gesamtfläche des Kallus, der CG-Fläche, der AK-Fläche und der TC-Fläche des Kallus wurde durch das Programm als absolute Fläche von plattennahem, plattenfernem bzw. endostalem Kallus in Quadratmillimetern bestimmt. Der Additivkallus setzt sich als absolute Kallusfläche, errechnet aus der Summe von plattennaher, plattenferner und endostaler Kallusfläche zusammen und wird ebenfalls in Quadratmillimetern angeben. 
Tabelle 7: Messparameter der polychromen Sequenzmarkierung und deren Berechnungsgrundlage

\begin{tabular}{|c|c|}
\hline Messparameter [Einheit] & Berechnungsgrundlage \\
\hline Gesamtfläche Kallus plattennah $\left[\mathrm{mm}^{2}\right]$ & absolute Fläche des gesamten plattennahen Kallus \\
\hline CG-Fläche Kallus plattennah $\left[\mathrm{mm}^{2}\right]$ & absolute Fläche des CG-markierten plattennahen Kallus \\
\hline AK-Fläche Kallus plattennah $\left[\mathrm{mm}^{2}\right]$ & absolute Fläche des AK-markierten plattennahen Kallus \\
\hline TC-Fläche Kallus plattennah $\left[\mathrm{mm}^{2}\right]$ & absolute Fläche des TC-markierten plattennahen Kallus \\
\hline Gesamtfläche Kallus plattenfern $\left[\mathrm{mm}^{2}\right]$ & absolute Fläche des gesamten plattenfernen Kallus \\
\hline CG-Fläche Kallus plattenfern $\left[\mathrm{mm}^{2}\right]$ & absolute Fläche des CG-markierten plattenfernen Kallus \\
\hline AK-Fläche Kallus plattenfern $\left[\mathrm{mm}^{2}\right]$ & absolute Fläche des AK-markierten plattenfernen Kallus \\
\hline TC-Fläche Kallus plattenfern $\left[\mathrm{mm}^{2}\right]$ & absolute Fläche des TC-markierten plattenfernen Kallus \\
\hline Gesamtfläche Kallus endostal $\left[\mathrm{mm}^{2}\right]$ & absolute Fläche des gesamten endostalen Kallus \\
\hline CG-Fläche Kallus endostal $\left[\mathrm{mm}^{2}\right]$ & absolute Fläche des CG-markierten endostalen Kallus \\
\hline AK-Fläche Kallus endostal $\left[\mathrm{mm}^{2}\right]$ & absolute Fläche des AK-markierten endostalen Kallus \\
\hline TC-Fläche Kallus endostal $\left[\mathrm{mm}^{2}\right]$ & absolute Fläche des TC-markierten endostalen Kallus \\
\hline Additivkallus $\left[\mathrm{mm}^{2}\right]$ & $\begin{array}{l}\text { Summe der gesamten plattennahen, plattenfernen und endostalen } \\
\text { Kallusflächen }\end{array}$ \\
\hline
\end{tabular}

\subsection{Zuverlässigkeit der Messergebnisse}

\subsubsection{Benutzerabhängigkeit}

Die Auswertungsmethoden des biomechanischen Kompressionstests, der Mikroradiographie und der polychromen Sequenzanalyse sind entsprechend dem Arbeitsablauf benutzerabhängig. Deswegen musste vor Beginn dieser Versuche eine Validierung des Prüfenden erfolgen. Ebenso durften die jeweiligen Untersuchungen nur von einem 
einzigen Prüfer durchgeführt werden, um individuelle Schwankungen und damit unsystematische Fehler zu vermeiden.

\section{Validierung des biomechanischen Kompressionstests}

Zur Validierung des biomechanischen Kompressionstests wurde der Test an größenidentischen Tibiae von zehn Ratten der gleichen Rasse geprüft. Dazu erfolgte jeweils an der linken und der rechten Tibia die Bestimmung der Steigung und des Yield Loads. Die Ergebnisse wurden dann in einem Rechts-Links-Vergleich ausgewertet und durften eine Schwankungsbreite von zehn Prozent nicht überschreiten.

\section{Validierung für die Mikroradiographie- und die polychrome Sequenzanalyse}

Zur Validierung des Untersuchers für die Auswertung der Mikroradiographien wurde ein histologischer Schnitt einer willkürlich ausgewählten Tibia (Tibia 61, Schnitt 2) an drei aufeinanderfolgenden Tagen insgesamt zehn Mal analysiert. Dabei durften die Messergebnisse für die einzelnen Parameter nicht um mehr als fünf Prozent schwanken. Die Validierung für die polychrome Sequenzanalyse erfolgte analog zur Validierung für die Auswertung der Mikroradiographien.

\subsection{Statistik}

Die Auswertung der Versuchsergebnisse erfolgte mit der Software GraphPad Prism (Version 5,01 GraphPad Software Inc., San Diego, USA). Nach Prüfung der einzelnen Messparameter anhand der Gauß'schen Normalverteilung wurden, nach Testgruppen getrennt, die jeweiligen Mittelwerte und Standardabweichungen bestimmt. Mittels one-way ANOVA und dem Tukey-Kramer-post-hoc-Test wurden die Ergebnisse auf signifikante Unterschiede untersucht. Dabei wurde das Signifikanzniveau als $\mathrm{p}<0,05$ definiert. 


\section{Ergebnisse}

\subsection{Auswertung der Gewichte}

Die Bestimmung des Körpergewichts $(K G)$ und der Futtermengenaufnahme erfolgte jeweils zu Beginn einer Versuchswoche. Zusätzlich wurden die Tiere zum Zeitpunkt der Ovarektomie, Osteotomie und Obduktion gewogen. Aufgrund des gleichen Versuchstierkollektivs werden das Körper- und Uterusgewicht, sowie die Futtermengenaufnahme auch in den Promotionsarbeiten von Tim Genotte, Cordula Sauerhoff und Daniel Terschüren betrachtet.

\subsubsection{Körpergewicht der Versuchstiere}

In der Tabelle 8 ist das durchschnittliche Körpergewicht einer Ratte in Gramm [g] (Mittelwert (MW) \pm Standardabweichung (SD)) im Verlauf der 13 Versuchswochen, nach entsprechenden Gruppen gegliedert, dargestellt. Die initiale Verteilung der einzelnen Versuchstiere in die entsprechenden Gruppen erfolgte willkürlich. Dabei wurde nach Auswertung der Gewichte bereits zu Versuchsbeginn ein signifikanter Unterschied des durchschnittlichen KG unter den einzelnen Gruppen registriert. Dieser Gewichtsunterschied wurde in den Gruppen $30 \mathrm{~Hz}$ und $90 \mathrm{~Hz}$ bereits ab der zweiten Woche ausgeglichen, sodass nur die Signifikanzen für die Gruppen $50 \mathrm{~Hz}$ und $70 \mathrm{~Hz}$ für das Ausgangsgewicht dargestellt werden. Nach einer Versuchsdauer von acht Wochen erfolgte die Osteotomie und Osteosynthese, wodurch bezüglich der Körpergewichte der Versuchstiere eine sichtbare Gewichtsabnahme erkennbar war. Weitere signifikante Unterschiede kamen dabei nicht zur Darstellung. 
Tabelle 8: Durchschnittliches Körpergewicht $[g]$ einer Ratte (MW $\pm S D$ ) eingeteilt nach sham-operierten und ovarektomierten Versuchstieren ohne oder mit einer horizontalen Vibrationsbehandlung bei 30, 50, 70 oder 90 Hertz

\begin{tabular}{|c|c|c|c|c|c|c|}
\hline Woche & SHAM & OVX & $30 \mathrm{~Hz}$ & $50 \mathrm{~Hz}$ & $70 \mathrm{~Hz}$ & $90 \mathrm{~Hz}$ \\
\hline 0 & $239 \pm 12$ & $247 \pm 15$ & $242 \pm 13$ & $237^{* \circ} \pm 10$ & $231 * \pm 6$ & $247 \pm 10$ \\
\hline 1 & $247 \pm 12$ & $261^{\#} \pm 14$ & $258^{\# \wedge} \pm 19$ & $256^{\# \wedge} \pm 9$ & $246^{*} \pm 7$ & $258^{\# \wedge} \pm 9$ \\
\hline 2 & $253 ₫ \pm 13$ & $293 \pm 18$ & $289 \pm 13$ & $287 \pm 11$ & $277 \S \pm 10$ & $291 \pm 10$ \\
\hline 3 & $256 ₫ 13$ & $311 \pm 25$ & $308 \pm 17$ & $309^{\wedge} \pm 12$ & $299 * \pm 11$ & $314^{\wedge} \pm 12$ \\
\hline 4 & $258 ₫ \pm 11$ & $320 \pm 22$ & $314 \pm 18$ & $325^{\wedge} \pm 23$ & $308 \pm 11$ & $320 \pm 12$ \\
\hline 5 & $267 \S \pm 14$ & $332 \pm 20$ & $321 \pm 20$ & $324 \pm 12$ & $315^{*} \pm 13$ & $328^{\wedge} \pm 15$ \\
\hline 6 & $272 \S \pm 14$ & $337 \pm 15$ & $327 \pm 20$ & $331 \pm 13$ & $321 * \pm 13$ & $332 \pm 15$ \\
\hline 7 & $275 \S \pm 14$ & $342 \pm 14$ & $335 \pm 27$ & $336 \pm 15$ & $325^{*} \pm 13$ & $335 \pm 15$ \\
\hline 8 & $272 \sqrt{ } \pm 24$ & $341 \pm 15$ & $329 \pm 23$ & $335 \pm 15$ & $325^{*} \pm 14$ & $335 \pm 16$ \\
\hline 9 & $267 \S \pm 14$ & $327 \pm 15$ & $312 \pm 20$ & $318 \pm 14$ & $309 * \pm 12$ & $319 \pm 17$ \\
\hline 10 & $267 \S \pm 15$ & $322 \pm 16$ & $306 \pm 20$ & $311 \pm 13$ & $303^{*} \pm 12$ & $312 \pm 16$ \\
\hline 11 & $269 \$ \pm 14$ & $328 \pm 17$ & $310 \pm 21$ & $316 \pm 13$ & $309 * \pm 14$ & $313 \pm 16$ \\
\hline 12 & $273 ₫ \pm 15$ & $332 \pm 15$ & $314 \pm 22$ & $320 \pm 15$ & $310^{*} \pm 13$ & $315 \pm 16$ \\
\hline 13 & $275 \unlhd \pm 16$ & $333 \pm 15$ & $317 \pm 23$ & $323 \pm 15$ & $313^{*} \pm 14$ & $317 \pm 14$ \\
\hline
\end{tabular}

$\S \mathrm{p}<0,05$ vs. allen anderen Gruppen, $\# \mathrm{p}<0,05$ vs. SHAM, ${ }^{*} \mathrm{p}<0,05$ vs. OVX, ${ }^{\wedge} \mathrm{p}<0,05$ vs. $70 \mathrm{~Hz},{ }^{\circ} \mathrm{p}$ $<0,05$ vs. $90 \mathrm{~Hz}$

\subsubsection{Gewichtsverlauf der Versuchstiere im Einzelnen}

Die Tabelle 9 veranschaulicht die Veränderungen des Körpergewichtes der Versuchstiere über die Gesamtversuchsdauer von 13 Wochen. Unmittelbar nach der Ovarektomie erfolgte in allen Gruppen, die diesem Eingriff unterzogen wurden, eine signifikante Gewichtszunahme. Es konnte in den Wochen 1 bis 5 und den Wochen 9 bis 11 eine signifikant geringere Gewichtszunahme der sham-operierten Tiere gegenüber allen anderen Versuchsgruppen nachgewiesen werden. Nach erfolgter Osteotomie und Osteosynthese wurde in den Wochen 8 bis 10 eine allgemeine Gewichtsabnahme, jedoch ohne weitere signifikante Unterschiede unter den Versuchsgruppen, ermittelt. 
Tabelle 9: Durchschnittliche Gewichtszu- oder -abnahme pro Ratte $[g](\mathrm{MW} \pm \mathrm{SD}$ ) pro Woche eingeteilt nach sham-operierten und ovarektomierten Versuchstieren ohne oder mit einer horizontalen Vibrationsbehandlung bei 30, 50, 70 oder 90 Hertz

\begin{tabular}{|c|c|c|c|c|c|c|}
\hline Woche & SHAM & OVX & $30 \mathrm{~Hz}$ & $50 \mathrm{~Hz}$ & $70 \mathrm{~Hz}$ & $90 \mathrm{~Hz}$ \\
\hline 1 & $7,7 \S \pm 4,9$ & $13,8 \pm 8,4$ & $16,1 \pm 6,9$ & $19,1 \pm 6,5$ & $15,1 \pm 5,4$ & $11,2 \pm 7,1$ \\
\hline 2 & $6,3 \S \pm 3,7$ & $31,5 \pm 6,9$ & $30,7 \pm 5,5$ & $30,9 \pm 4,7$ & $31,4 \pm 5,0$ & $32,6 \pm 5,8$ \\
\hline 3 & $3,1 \S \pm 4,4$ & $18,3 \pm 11,9$ & $18,8 \pm 4,6$ & $22,1 \pm 4,1$ & $21,6 \pm 5,1$ & $22,8 \pm 4,8$ \\
\hline 4 & $2,1 \S \pm 4,2$ & $8,7 \pm 5,4$ & $6,5 \pm 4,3$ & $15,9 \pm 23,8$ & $9,5 \pm 4,2$ & $6,7 \pm 4,0$ \\
\hline 5 & $8,4 \S \pm 4,5$ & $12,9 \pm 4,9$ & $7,3 \pm 3,2$ & $-1,1 \pm 25,2$ & $6,5 \pm 3,6$ & $7,8 \pm 3,9$ \\
\hline 6 & $5,1 \pm 4,7$ & $4,7 \pm 5,9$ & $5,9 \pm 2,7$ & $7,4 \pm 3,9$ & $6,0 \pm 3,5$ & $4,1 \pm 3,3$ \\
\hline 7 & $3,5 \pm 9,0$ & $4,6 \pm 4,7$ & $7,1 \pm 13,4$ & $5,1 \pm 4,0$ & $4,2 \pm 2,9$ & $2,8 \pm 3,1$ \\
\hline 8 & $0,0 \pm 7,6$ & $-0,7 \pm 3,3$ & $-1,6 \pm 3,5$ & $-1,7 \pm 3,0$ & $-0,2 \pm 2,9$ & $-1,8 \pm 8,9$ \\
\hline 9 & $-8,3 \S \pm 8,9$ & $-14,9 \pm 5,8$ & $-16,6 \pm 7,2$ & $-16,3 \pm 6,3$ & $-15,6 \pm 4,8$ & $-16,4 \pm 5,6$ \\
\hline 10 & $-0,5 \S \pm 9,0$ & $-5,4 \pm 4,4$ & $-6,4 \pm 4,2$ & $-6,9 \pm 6,2$ & $-6,2 \pm 4,6$ & $-6,9 \pm 5,1$ \\
\hline 11 & $2,3 \S \pm 4,7$ & $6,8 \pm 3,2$ & $4,1 \pm 5,8$ & $4,3 \pm 4,2$ & $5,9 \pm 4,1$ & $1,4 \pm 4,9$ \\
\hline 12 & $3,4 \pm 4,1$ & $3,6 \pm 2,9$ & $3,5 \pm 2,4$ & $4,1 \pm 4,4$ & $1,0 \pm 3,0$ & $2,2 \pm 3,1$ \\
\hline 13 & $1,9 \pm 3,8$ & $0,9 \pm 4,1$ & $3,5 \pm 4,8$ & $2,9 \pm 3,5$ & $3,1 \pm 3,7$ & $1,7 \pm 4,0$ \\
\hline
\end{tabular}

$\int \mathrm{p}<0,05$ vs. allen anderen Gruppen

\subsubsection{Futteraufnahme}

In der Tabelle 10 ist die durchschnittliche Futteraufnahme in $[g]$ pro Ratte und Tag $(\mathrm{MW} \pm \mathrm{SD})$ im Verlauf der 13 Versuchswochen, nach Gruppen gegliedert, abgebildet. Es kam, unabhängig von der Art der Behandlung, zu einer vermehrten Futteraufnahme bei den ovarektomierten Tieren. Diese war in den Wochen 2 bis 4 signifikant höher als bei den sham-operierten Tieren. Nach der Osteotomie mit Osteosynthese (Tabelle 10, ab Woche 8) kam es in allen Gruppen zu einem geringeren Futterverbrauch, jedoch ohne signifikante Gruppenunterschiede. 
Tabelle 10: Durchschnittliche Futteraufnahme $[\mathrm{g}] / \mathrm{Ratte} / \mathrm{Tag}(\mathrm{MW} \pm \mathrm{SD}$ ) eingeteilt nach sham-operierten und ovarektomierten Versuchstieren ohne oder mit einer horizontalen Vibrationsbehandlung bei 30, 50, 70 oder 90 Hertz

\begin{tabular}{|l|l|l|l|l|l|l|}
\hline Woche & SHAM & $\mathbf{O V X}$ & $\mathbf{3 0 ~ H z}$ & $\mathbf{5 0 ~ H z}$ & $\mathbf{7 0 ~} \mathbf{~ z}$ & $\mathbf{9 0 ~} \mathbf{~ z}$ \\
\hline $\mathbf{1}$ & $17 \pm 1,0$ & $17 \pm 0,9$ & $18 \pm 1,7$ & $17 \pm 0,8$ & $15 \pm 1,1$ & $14 \pm 0,3$ \\
\hline $\mathbf{2}$ & $19 \pm \pm 1,1$ & $23 \pm 2,5$ & $24 \pm 0,8$ & $24 \pm 1,2$ & $23 \pm 1,2$ & $24 \pm 0,3$ \\
\hline $\mathbf{3}$ & $195 \pm 3,0$ & $23 \pm 1,6$ & $24 \pm 2,3$ & $24 \pm 0,5$ & $23 \pm 1,0$ & $24 \pm 0,6$ \\
\hline $\mathbf{4}$ & $18 \pm 1,1$ & $23 \pm 1,3$ & $22 \pm 1,5$ & $23 \pm 0,1$ & $23 \pm 0,6$ & $23 \pm 0,3$ \\
\hline $\mathbf{5}$ & $19 \pm 0,8$ & $23 \pm 0,5$ & $23 \pm 1,3$ & $22 \pm 1,3$ & $23 \pm 3,3$ & $23 \pm 0,4$ \\
\hline $\mathbf{6}$ & $19 \pm 2,7$ & $22 \pm 0,5$ & $22 \pm 1,7$ & $22 \pm 0,5$ & $21 \pm 0,8$ & $22 \pm 0,4$ \\
\hline $\mathbf{7}$ & $21 \pm 1,6$ & $24 \pm 1,0$ & $23 \pm 0,6$ & $24 \pm 1,3$ & $23 \pm 0,7$ & $24 \pm 0,7$ \\
\hline $\mathbf{8}$ & $15 \pm 1,9$ & $17 \pm 0,3$ & $17 \pm 0,2$ & $17 \pm 0,7$ & $17 \pm 0,7$ & $17 \pm 0,2$ \\
\hline $\mathbf{9}$ & $16 \pm 2,4$ & $17 \pm 2,1$ & $18 \pm 6,3$ & $18 \pm 8,0$ & $18 \pm 6,7$ & $19 \pm 6,5$ \\
\hline $\mathbf{1 0}$ & $17 \pm 2,0$ & $16 \pm 0,6$ & $15 \pm 0,4$ & $16 \pm 0,8$ & $16 \pm 1,2$ & $17 \pm 0,4$ \\
\hline $\mathbf{1 1}$ & $16 \pm 0,7$ & $17 \pm 0,9$ & $23 \pm 6,4$ & $21 \pm 5,7$ & $24 \pm 6,6$ & $17 \pm 0,8$ \\
\hline $\mathbf{1 2}$ & $17 \pm 1,8$ & $17 \pm 0,4$ & $17 \pm 0,5$ & $18 \pm 0,7$ & $17 \pm 1,5$ & $17 \pm 0,6$ \\
\hline $\mathbf{1 3}$ & $16 \pm 1,7$ & $19 \pm 0,4$ & $18 \pm 0,3$ & $18 \pm 0,3$ & $18 \pm 1,3$ & $18 \pm 0,5$ \\
\hline
\end{tabular}

$\mathbb{~} \mathrm{p}<0,05$ vs. allen anderen Gruppen

\subsubsection{Uterusgewicht}

Das Uterusgewicht wurde bei der Obduktion der Tiere bestimmt (Tabelle 11). Das mittlere Uterusgewicht der sham-operierten Versuchstiere war zum Tötungszeitpunkt erwartungsgemäß signifikant höher als das aller ovarektomierten Ratten.

Tabelle 11: Uterusgewicht $[\mathrm{mg}](\mathrm{MW} \pm \mathrm{SD})$ eingeteilt nach sham-operierten und ovarektomierten Versuchstieren ohne oder mit einer horizontalen Vibrationsbehandlung bei 30, 50, 70 oder 90 Hertz

\begin{tabular}{|l|l|l|l|l|l|l|}
\hline & SHAM & OVX & $\mathbf{3 0} \mathbf{H z}$ & $\mathbf{5 0 ~} \mathbf{H z}$ & $\mathbf{7 0} \mathbf{~ H z}$ & $\mathbf{9 0} \mathbf{~ H z}$ \\
\hline Uterusgewicht [mg] & $550 \varsigma \pm 131$ & $119 \pm 17$ & $116 \pm 19$ & $116 \pm 18$ & $116 \pm 18$ & $126 \pm 13$ \\
\hline
\end{tabular}

$\S \mathrm{p}<0,05$ vs. allen anderen Gruppen 


\subsection{Auswertung des biomechanischen Kompressionstests}

Im Folgenden sind die Ergebnisse der einzelnen Messwerte des biomechanischen Kompressionstests aufgezeigt. Zuerst folgt die Darstellung anhand von Säulendiagrammen und im Anschluss als tabellarische Zusammenfassung (Tabelle 12).

\subsubsection{Elastizität des Kallus}

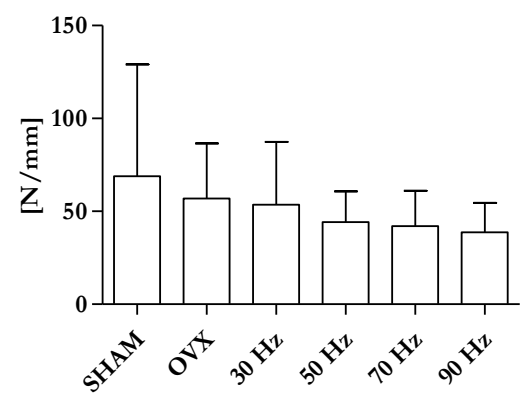

Abbildung 12: Abbildung der Messwerte für die Elastizität des Kallus $[\mathrm{N} / \mathrm{mm}]$ der Gruppen ermittelt aus den Kraft-Weg-Diagrammen

Für die Elastizität des Kallus (Abbildung 12) konnten keine signifikanten Unterschiede zwischen den Gruppen registriert werden. Eine tendenziell höhere Festigkeit wurde in der Gruppe SHAM gezeigt. 


\subsubsection{Yield Load}

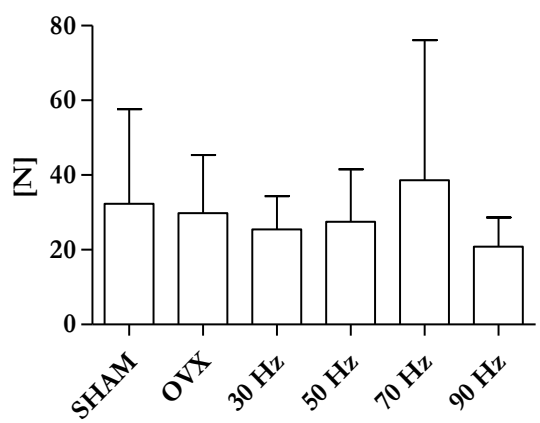

Abbildung 13: Abbildung der Messwerte für den Yield Load [N] ermittelt aus den KraftWeg-Diagrammen

Ebenso konnten für den Yield Load (Abbildung 13) keine signifikanten Gruppenunterschiede nachgewiesen werden. In der Gruppe der ovarektomierten Ratten mit einer Vibrationsbehandlung bei $70 \mathrm{~Hz}$ wurde einerseits eine hohe Resistenz gegenüber Mikrofrakturen gefunden, andererseits war aber auch eine hohe Standardabweichung auffällig.

Tabelle 12: Tabellarische Zusammenfassung der Parameter des biomechanischen Kompressionstests (MW $\pm \mathrm{SD}$ ) eingeteilt nach sham-operierten und ovarektomierten Versuchstieren ohne oder mit einer horizontalen Vibrationsbehandlung bei 30, 50, 70 oder 90 Hertz

\begin{tabular}{|l|l|l|l|l|l|l|}
\hline & SHAM & OVX & $\mathbf{3 0 ~} \mathbf{~ z z}$ & $\mathbf{5 0 ~ H z}$ & $\mathbf{7 0 ~} \mathbf{~ H z}$ & $\mathbf{9 0 ~} \mathbf{~ z z}$ \\
\hline Elastizität [N/mm] & $69 \pm 60$ & $57 \pm 30$ & $54 \pm 34$ & $44 \pm 16$ & $42 \pm 19$ & $39 \pm 16$ \\
\hline Yield Load [N] & $32 \pm 25$ & $29 \pm 16$ & $26 \pm 9$ & $28 \pm 14$ & $39 \pm 37$ & $21 \pm 8$ \\
\hline
\end{tabular}

\subsection{Auswertung der Mikrocomputertomographie}

Analog zur Ergebnisdarstellung des biomechanischen Kompressionstests werden die Ergebnisse der Mikrocomputertomographie zunächst in Form von Säulendiagrammen dargestellt (Abbildung 14 bis Abbildung 18), bevor sie tabellarisch zusammengefasst werden (Tabelle 13). 


\subsubsection{BMD des Kallus}

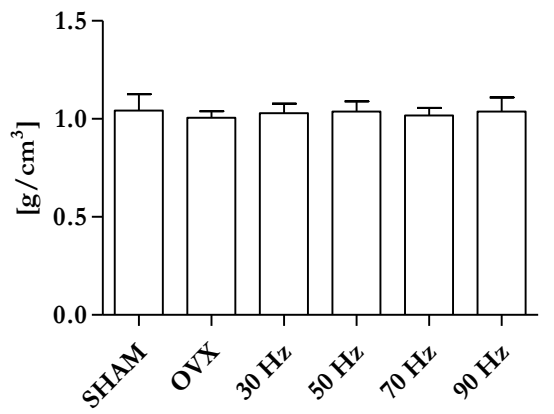

Abbildung 14: Abbildung der im $\mu \mathrm{CT}$ ermittelten BMD $\left[\mathrm{g} / \mathrm{cm}^{3}\right]$ des Kallus der Versuchstiergruppen

Die BMD des gesamten Kallus (Abbildung 14) zeigte ein homogenes Verhalten zwischen den Gruppen. Es konnten keine signifikanten Unterschiede gemessen werden.

\subsubsection{BMD des Knochens}

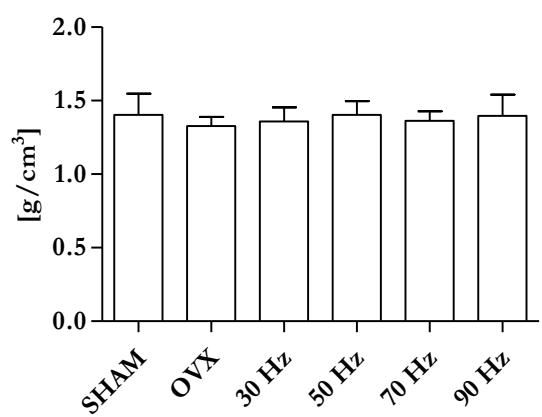

Abbildung 15: Abbildung der im $\mu$ CT ermittelten BMD $\left[\mathrm{g} / \mathrm{cm}^{3}\right]$ des Knochens außerhalb des Kallus der Versuchstiergruppen

Ebenso waren für die BMD des Knochens (Abbildung 15) keine signifikanten Unterschiede zwischen den Gruppen bei einem relativ konstanten Verhalten des Parameters nachweisbar. 


\subsubsection{BMD der Kortikalis}

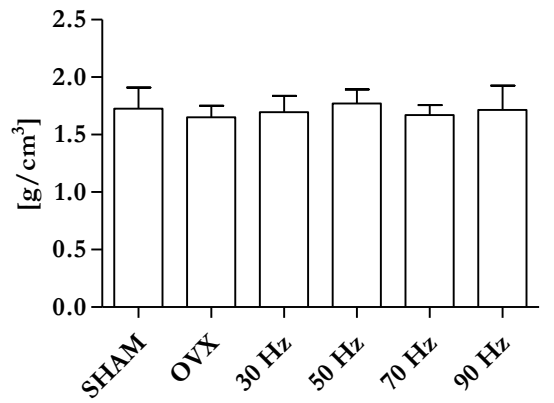

Abbildung 16: Abbildung der im $\mu \mathrm{CT}$ ermittelten BMD $\left[\mathrm{g} / \mathrm{cm}^{3}\right]$ der Kortikalis der Versuchstiergruppen

Für die BMD der Kortikalis (Abbildung 16) wurde unter den Gruppen kein signifikanter Unterschied festgestellt. Vergleichend war die BMD der Kortikalis und die BMD des Knochens (Abbildung 15), entsprechend dem strukturellen Knochenaufbau, gegenüber der BMD des Kallus (Abbildung 14) erhöht.

\subsubsection{Gesamt-BMD}

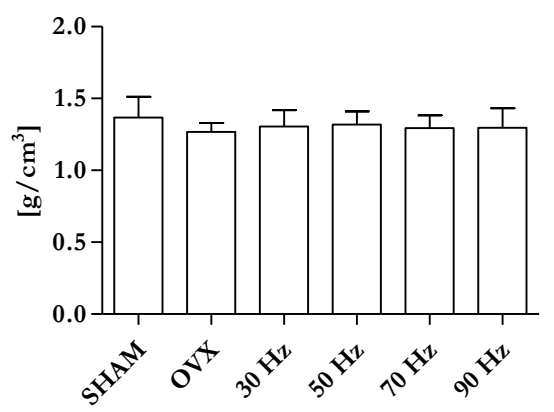

Abbildung 17: Abbildung der im $\mu$ CT ermittelten Gesamt-BMD $\left[\mathrm{g} / \mathrm{cm}^{3}\right]$

Es konnten keine signifikanten Unterschiede zwischen den Gruppen für die Gesamt-BMD (Abbildung 17) gezeigt werden. Die Gesamt-BMD von SHAM ist vergleichend minimal erhöht und die der OVX (ovarektomiert)-Gruppe minimal erniedrigt. 


\subsubsection{Anteil des Knochenvolumens am Gesamtvolumen}

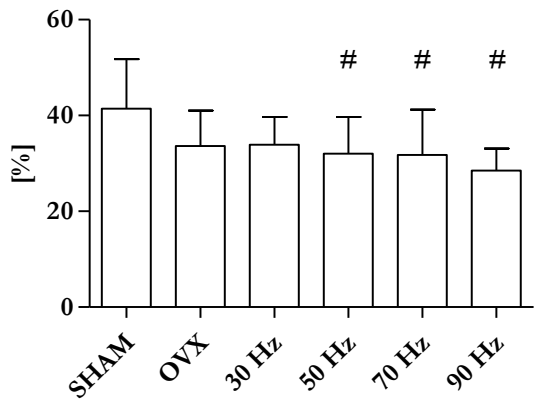

Abbildung 18: Abbildung des im $\mu \mathrm{CT}$ ermittelten Anteils des Knochenvolumens am Gesamtvolumen; \# $\mathrm{p}<0,05$ vs. SHAM

Der Anteil des Knochenvolumens (BV) am Gesamtvolumen (TV) der metaphysären Rattentibia (Abbildung 18) war in den Gruppen $50 \mathrm{~Hz}, 70 \mathrm{~Hz}$ und $90 \mathrm{~Hz}$ signifikant geringer gegenüber der Gruppe SHAM. In der Gruppe SHAM konnte das höchste Knochenvolumen erreicht werden.

Tabelle 13: Tabellarische Zusammenfassung der Messwerte für die BMD der verschiedenen Knochenstrukturen in Gramm pro Kubikzentimeter ( $M W \pm S D$ ) eingeteilt nach sham-operierten und ovarektomierten Versuchstieren ohne oder mit einer horizontalen Vibrationsbehandlung bei 30, 50, 70 oder 90 Hertz

\begin{tabular}{|c|c|c|c|c|c|c|}
\hline $\begin{array}{l}\text { Messparameter } \\
\text { [Einheit] }\end{array}$ & SHAM & OVX & $30 \mathrm{~Hz}$ & $50 \mathrm{~Hz}$ & $70 \mathrm{~Hz}$ & $90 \mathrm{~Hz}$ \\
\hline $\begin{array}{l}\text { Kallus BMD } \\
{\left[\mathrm{g} / \mathrm{cm}^{3}\right]}\end{array}$ & $1,04 \pm 0,08$ & $1,01 \pm 0,03$ & $1,03 \pm 0,05$ & $1,04 \pm 0,05$ & $1,02 \pm 0,04$ & $1,04 \pm 0,07$ \\
\hline $\begin{array}{l}\text { Knochen BMD } \\
{\left[\mathrm{g} / \mathrm{cm}^{3}\right]}\end{array}$ & $1,40 \pm 0,14$ & $1,33 \pm 0,06$ & $1,36 \pm 0,09$ & $1,40 \pm 0,09$ & $1,36 \pm 0,06$ & $1,40 \pm 0,14$ \\
\hline $\begin{array}{l}\text { Kortikalis } \\
\text { BMD }\left[\mathrm{g} / \mathrm{cm}^{3}\right]\end{array}$ & $1,73 \pm 0,18$ & $1,65 \pm 0,10$ & $1,70 \pm 0,14$ & $1,77 \pm 0,12$ & $1,67 \pm 0,09$ & $1,71 \pm 0,21$ \\
\hline $\begin{array}{l}\text { Gesamt-BMD } \\
{\left[\mathrm{g} / \mathrm{cm}^{3}\right]}\end{array}$ & $1,37 \pm 0,15$ & $1,27 \pm 0,06$ & $1,30 \pm 0,11$ & $1,32 \pm 0,09$ & $1,29 \pm 0,09$ & $1,30 \pm 0,14$ \\
\hline BV/TV [\%] & $41,5 \pm 10,3$ & $33,6 \pm 7,39$ & $33,9 \pm 5,79$ & $\begin{array}{l}32,1^{\#} \quad \pm \\
7,60\end{array}$ & $\begin{array}{l}31,8^{\#} \quad \pm \\
9,48\end{array}$ & $28,5^{\#} \pm 4,58$ \\
\hline
\end{tabular}

$\#$ p $<0,05$ vs. SHAM 


\subsection{Auswertung der Mikroradiographie}

Wie auch in den vorhergehenden Kapiteln erfolgt die Darstellung der Ergebnisse der einzelnen Parameter der mikroradiographischen Untersuchung zunächst in Form von Säulendiagrammen (Abbildung 19 bis Abbildung 33) und im Anschluss als tabellarische Zusammenfassung (Tabelle 14).

\subsubsection{Kortikalisdicke distal plattennah}

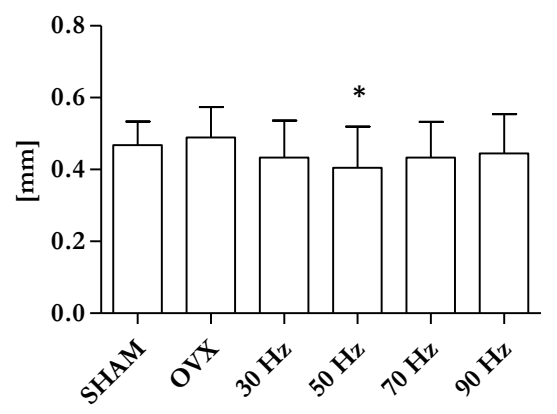

Abbildung 19: Abbildung der Messwerte der Mikroradiographie für den Parameter „Kortikalisdicke distal plattennah“; * $\mathrm{p}<0,05$ vs. OVX

Eine horizontale WBV von $50 \mathrm{~Hz}$ erniedrigt die Kortikalisdicke distal plattenfern (Abbildung 19) signifikant gegenüber der Gruppe OVX. Zwischen den anderen Gruppen konnten keine weiteren signifikanten Unterschiede gefunden werden. Interessanterweise hat die Gruppe der ovarektomierten Tiere die größte Kortikalisdicke. 


\subsubsection{Kortikalisdicke distal plattenfern}

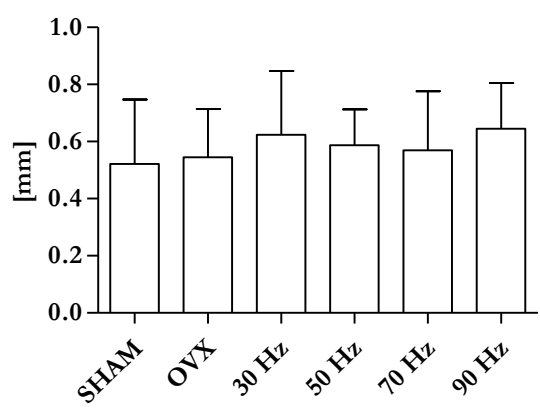

Abbildung 20: Abbildung der Messwerte der Mikroradiographie für den Parameter „Kortikalisdicke distal plattenfern“

Für die Dicke der Kortikalis distal plattenfern (Abbildung 20) konnten keine signifikanten Unterschiede zwischen den Gruppen erfasst werden. Es wurde eine stärkere Kortikalis bei den mit $30 \mathrm{~Hz}$ und mit $90 \mathrm{~Hz}$ behandelten Tieren nachgewiesen.

\subsubsection{Knochendurchmesser proximal}

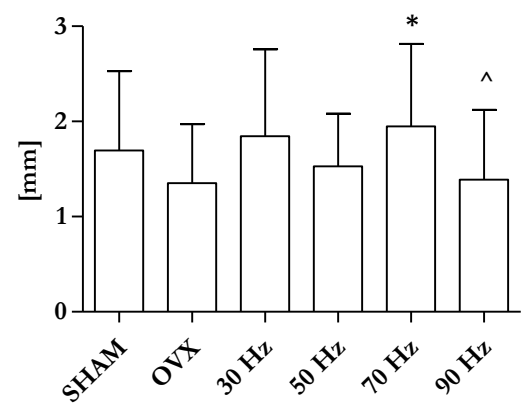

Abbildung 21: Abbildung der Messwerte der Mikroradiographie für den Parameter „Knochendurchmesser proximal““; * p $<0,05$ vs. OVX, ^ p $<0,05$ vs. $70 \mathrm{~Hz}$

Der proximale Knochendurchmesser (Abbildung 21) war in den Gruppen der mit $30 \mathrm{~Hz}$ und mit $70 \mathrm{~Hz}$ behandelten Tiere am größten, wobei die mit $70 \mathrm{~Hz}$ vibrierte Gruppe einen signifikant größeren Durchmesser gegenüber der Gruppe mit nur ovarektomierten Tieren zeigte. Der Knochendurchmesser der mit $90 \mathrm{~Hz}$ behandelten Ratten war signifikant kleiner gegenüber den Tieren, welche mit einer Frequenz von $70 \mathrm{~Hz}$ vibriert wurden. 


\subsubsection{Knochendurchmesser distal}

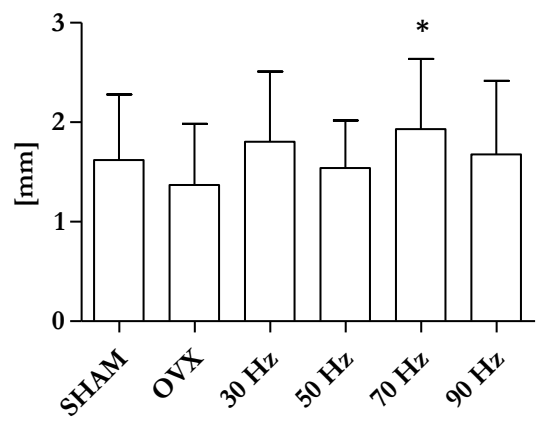

Abbildung 22: Abbildung der Messwerte der Mikroradiographie für den Parameter „Knochendurchmesser distal“; $* \mathrm{p}<0,05$ vs. OVX

Der Knochendurchmesser distal der Osteotomie (Abbildung 22) war signifikant größer in der Gruppe der mit $70 \mathrm{~Hz}$ vibrierten Tiere als bei den alleinig ovarektomierten Tieren. Der niedrigste Wert war in der Gruppe OVX darstellbar.

\subsubsection{Kallusdicke plattennah}

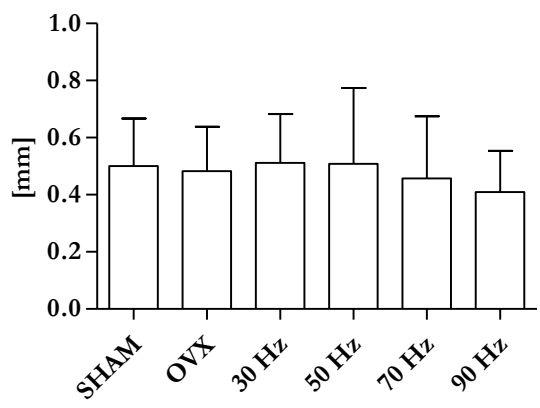

Abbildung 23: Abbildung der Messwerte der Mikroradiographie für den Parameter „Kallusdicke plattennah“

Die Kallusdicke (Abbildung 23) auf der ventro-medialen, also plattennahen Seite, zeigte keine signifikanten Unterschiede unter den Versuchsgruppen. Für die mit $90 \mathrm{~Hz}$ behandelten Tiere konnte die geringste Kallusdicke gemessen werden. 


\subsubsection{Kallusdicke plattenfern}

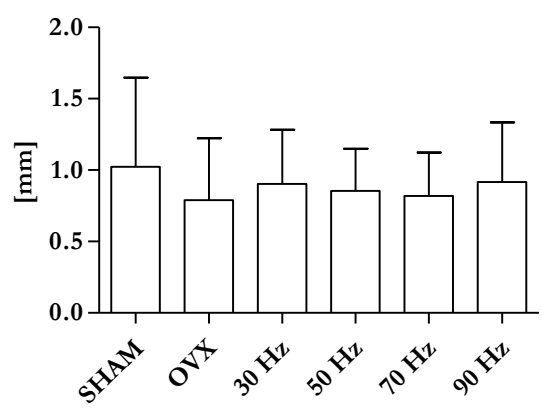

Abbildung 24: Abbildung der Messwerte der Mikroradiographie für den Parameter „Kallusdicke plattenfern“

Für den Parameter der plattenfernen, Kallusdicke (Abbildung 24) konnte ein relativ konstanter Wert bei allen Gruppen gezeigt werden. In der Gruppe SHAM wurde dabei eine größere Dicke, in der OVX-Gruppe die geringste nachgewiesen.

\subsubsection{Knochendichte Kortikalis distal plattennah}

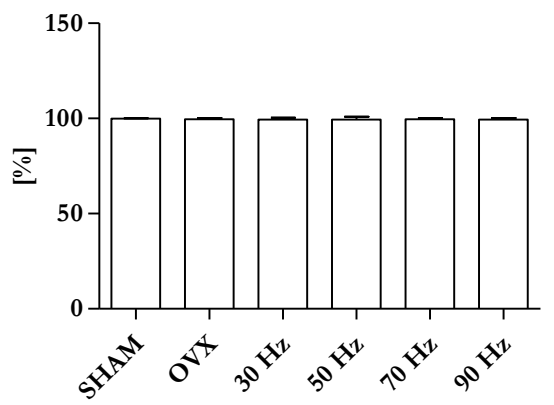

Abbildung 25: Abbildung der Messwerte der Mikroradiographie für den Parameter „Knochendichte Kortikalis distal plattennah“

Für die Knochendichte der Kortikalis distal plattennah (Abbildung 25) konnten keine Unterschiede gemessen werden. Der Wert verhielt sich bei allen Gruppen nahezu konstant. 


\subsubsection{Knochendichte Kortikalis distal plattenfern}

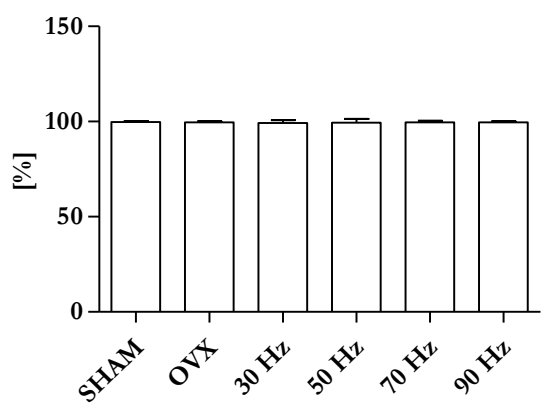

Abbildung 26: Abbildung der Messwerte der Mikroradiographie für den Parameter „Knochendichte Kortikalis distal plattenfern“"

Ebenfalls konnte für die Knochendichte der Kortikalis distal plattenfern (Abbildung 26) kein signifikanter Unterscheide zwischen den Gruppen, bei einem annähernd gleichen Verhalten des Parameters, nachwiesen werden.

\subsubsection{Knochendichte Kallus plattennah}

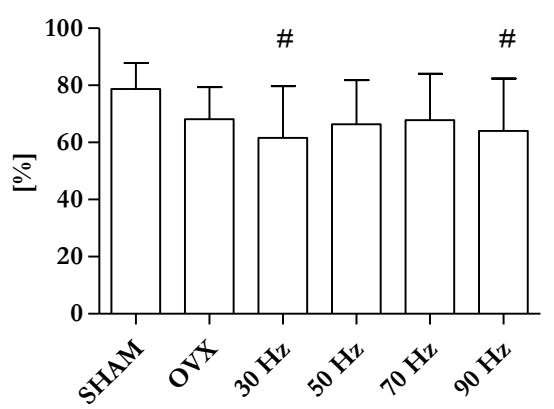

Abbildung 27: Abbildung der Messwerte der Mikroradiographie für den Parameter „Knochendichte Kallus plattennah“; \# p $<0,05$ vs. SHAM

Die Knochendichte des Kallus plattennah (Abbildung 27) ergab für die Gruppe der SHAM-Tiere den höchsten Wert. Demgegenüber war die Dichte der Gruppen $30 \mathrm{~Hz}$ und $90 \mathrm{~Hz}$ signifikant erniedrigt. 


\subsubsection{Knochendichte Kallus plattenfern}

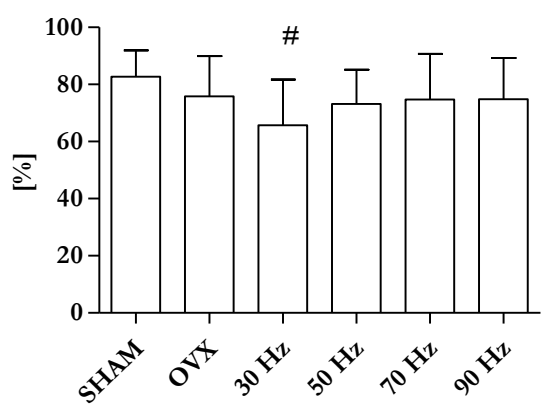

Abbildung 28: Abbildung der Messwerte der Mikroradiographie für den Parameter „Knochendichte Kallus plattenfern“; \# p <0,05 vs. SHAM

Für die Knochendichte Kallus plattenfern (Abbildung 28) wurde in der Gruppe SHAM der höchsten Wert, mit einer signifikanten Erhöhung gegenüber der Gruppe $30 \mathrm{~Hz}$, detektiert. Weitere signifikante Unterschiede zwischen den Gruppen bestanden nicht.

\subsubsection{Knochendichte Kallus endostal}

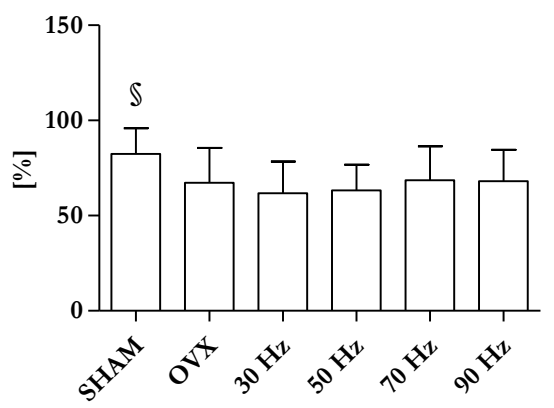

Abbildung 29: Abbildung der Messwerte der Mikroradiographie für den Parameter „Knochendichte Kallus endostal“; $\mathbb{~ p ~}<0,05$ vs. allen anderen Gruppen

Die Knochendichte des endostalen Kallus (Abbildung 29) war in der Gruppe SHAM gegenüber allen anderen Gruppen signifikant erhöht. Weitere signifikante Gruppenunterschiede konnten nicht nachgewiesen werden. In der 30-Hz-Gruppe wurden auch hier der geringste Werte gemessen. 


\subsubsection{Dichte der Trabekelfläche}

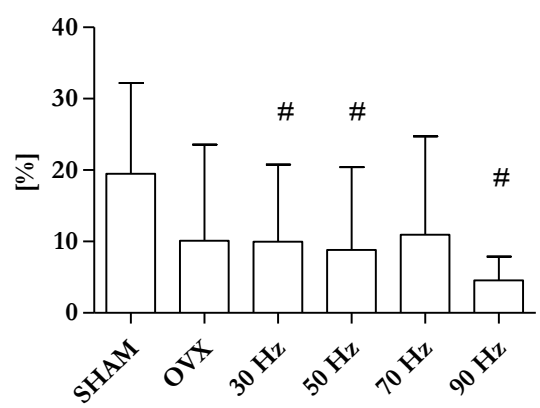

Abbildung 30: Abbildung der Messwerte der Mikroradiographie für den Parameter „Dichte der Trabekelfläche“; \# p $<0,05$ vs. SHAM

Die Dichte der Trabekelfläche (Abbildung 30) der SHAM-Gruppe war gegenüber allen anderen Gruppen mit einem signifikanten Unterschied zu den Gruppen $30 \mathrm{~Hz}, 50 \mathrm{~Hz}$ und $90 \mathrm{~Hz}$ erhöht. Nur die Gruppe $70 \mathrm{~Hz}$ lag auf dem gleichen Signifikanzniveau. Die geringste Dichte wurde in der mit $90 \mathrm{~Hz}$ behandelten Gruppe gemessen.

\subsubsection{Anzahl Trabekelkreuzungen absolut}

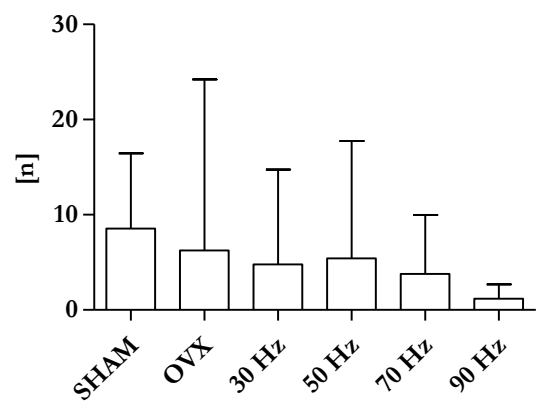

Abbildung 31: Abbildung der Messwerte der Mikroradiographie für den Parameter „Anzahl Trabekelkreuzungen absolut"

Aufgrund einer bemerkenswert hohen Standardabweichung konnten keine signifikanten Gruppenunterschiede für die Anzahl der Trabekelkreuzungen (Abbildung 31) nachgewiesen werden. Die höchste Anzahl an Trabekelkreuzungen wurde erwartungsgemäß in der Gruppe SHAM und die geringste Anzahl in der Gruppe $90 \mathrm{~Hz}$ festgestellt. 


\subsubsection{Dichte Trabekelkreuzungen}

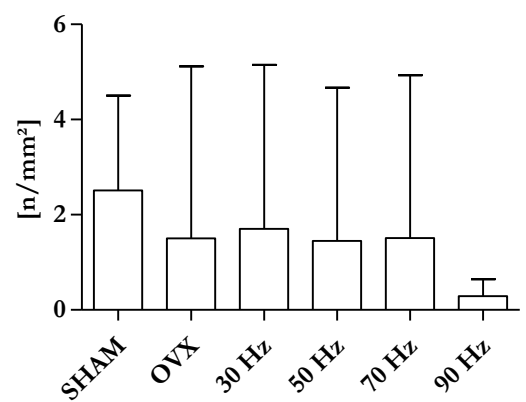

Abbildung 32: Abbildung der Messwerte der Mikroradiographie für den Parameter „Dichte Trabekelkreuzungen"

Auch für die Dichte der Trabekelkreuzungen (Abbildung 32) wurde eine sehr hohe Standardabweichung auffällig. Im Rahmen dessen konnten keine signifikanten Unterschiede zwischen den Gruppen gezeigt werden. Die Dichte der Trabekelkreuzungen war in der Gruppe der SHAM-Tiere am höchsten und in der Gruppe der mit $90 \mathrm{~Hz}$ vibrierten Tiere auffallend gering.

\subsubsection{Mittlere Trabekeldicke}

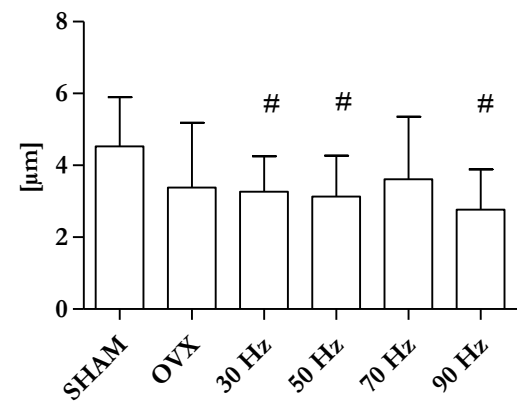

Abbildung 33: Abbildung der Messwerte der Mikroradiographie für den Parameter „mittlere Trabekeldicke“; \# $\mathrm{p}<0,05$ vs. SHAM

Die mittlere Trabekeldicke (Abbildung 33) zeigte eine signifikante Abnahme in den Gruppen $30 \mathrm{~Hz}, 50 \mathrm{~Hz}$ und $90 \mathrm{~Hz}$ gegenüber der SHAM-Gruppe. Nur die Gruppe $70 \mathrm{~Hz}$ lag auf dem gleichen Signifikanzniveau. 
Tabelle 14: Tabellarische Zusammenfassung der Messparameter der Mikroradiographie $(\mathrm{MW} \pm \mathrm{SD}$ ) eingeteilt nach sham-operierten und ovarektomierten Versuchstieren ohne oder mit einer horizontalen Vibrationsbehandlung bei 30, 50, 70 oder 90 Hertz

\begin{tabular}{|c|c|c|c|c|c|c|}
\hline Messparameter [Einheit] & SHAM & OVX & $30 \mathrm{~Hz}$ & $50 \mathrm{~Hz}$ & $70 \mathrm{~Hz}$ & $90 \mathrm{~Hz}$ \\
\hline $\begin{array}{l}\text { Kortikalisdicke distal plattennah } \\
\text { [mm] }\end{array}$ & $\begin{array}{l}0,47 \pm \\
0,07\end{array}$ & $\begin{array}{l}0,49 \pm \\
0,08\end{array}$ & $\begin{array}{l}0,43 \pm \\
0,10\end{array}$ & $\begin{array}{l}0,40^{*} \pm \\
0,12\end{array}$ & $\begin{array}{l}0,43 \pm \\
0,10\end{array}$ & $\begin{array}{l}0,45 \pm \\
0,11\end{array}$ \\
\hline $\begin{array}{l}\text { Kortikalisdicke distal plattenfern } \\
{[\mathrm{mm}]}\end{array}$ & $\begin{array}{l}0,52 \pm \\
0,23\end{array}$ & $\begin{array}{l}0,55 \pm \\
0,17\end{array}$ & $\begin{array}{l}0,62 \pm \\
0,22\end{array}$ & $\begin{array}{l}0,59 \pm \\
0,13\end{array}$ & $\begin{array}{l}0,57 \pm \\
0,21\end{array}$ & $\begin{array}{l}0,64 \pm \\
0,16\end{array}$ \\
\hline $\begin{array}{l}\text { Knochendurchmesser proximal } \\
\text { [mm] }\end{array}$ & $\begin{array}{l}1,70 \pm \\
0,83\end{array}$ & $\begin{array}{l}1,35 \pm \\
0,62\end{array}$ & $\begin{array}{l}1,85 \pm \\
0,91\end{array}$ & $\begin{array}{l}1,53 \pm \\
0,55\end{array}$ & $\begin{array}{l}1,95^{*} \pm \\
0,86\end{array}$ & $\begin{array}{l}1,38^{\wedge} \pm \\
0,73\end{array}$ \\
\hline Knochendurchmesser distal [mm] & $\begin{array}{l}1,62 \pm \\
0,66\end{array}$ & $\begin{array}{l}1,37 \pm \\
0,61\end{array}$ & $\begin{array}{l}1,80 \pm \\
0,71\end{array}$ & $\begin{array}{l}1,54 \pm \\
0,48\end{array}$ & $\begin{array}{l}1,93^{*} \pm \\
0,71\end{array}$ & $\begin{array}{l}1,68 \pm \\
0,74\end{array}$ \\
\hline Kallusdicke plattennah [mm] & $\begin{array}{l}0,50 \pm \\
0,17\end{array}$ & $\begin{array}{l}0,48 \pm \\
0,16\end{array}$ & $\begin{array}{l}0,51 \pm \\
0,17\end{array}$ & $\begin{array}{l}0,51 \pm \\
0,27\end{array}$ & $\begin{array}{l}0,46 \pm \\
0,22\end{array}$ & $\begin{array}{l}0,41 \pm \\
0,14\end{array}$ \\
\hline Kallusdicke plattenfern [mm] & $\begin{array}{l}1,02 \pm \\
0,63\end{array}$ & $\begin{array}{l}0,79 \pm \\
0,43\end{array}$ & $\begin{array}{l}0,90 \pm \\
0,38\end{array}$ & $\begin{array}{l}0,86 \pm \\
0,29\end{array}$ & $\begin{array}{l}0,82 \pm \\
0,30\end{array}$ & $\begin{array}{l}0,92 \pm \\
0,42\end{array}$ \\
\hline $\begin{array}{l}\text { Knochendichte Kortikalis distal } \\
\text { plattennah [\%] }\end{array}$ & $\begin{array}{l}99,9 \pm \\
0,17\end{array}$ & $\begin{array}{l}99,6 \pm \\
0,74\end{array}$ & $\begin{array}{l}99,4 \pm \\
1,00\end{array}$ & $\begin{array}{l}99,4 \pm \\
1,50\end{array}$ & $\begin{array}{l}99,6 \pm \\
0,66\end{array}$ & $\begin{array}{l}99,5 \pm \\
0,71\end{array}$ \\
\hline $\begin{array}{l}\text { Knochendichte Kortikalis distal } \\
\text { plattenfern [\%] }\end{array}$ & $\begin{array}{l}99,8 \pm \\
0,39\end{array}$ & $\begin{array}{l}99,6 \pm \\
0,54\end{array}$ & $\begin{array}{l}99,3 \pm \\
1,40\end{array}$ & $\begin{array}{l}99,4 \pm \\
2,10\end{array}$ & $\begin{array}{l}99,6 \pm \\
0,83\end{array}$ & $\begin{array}{l}99,6 \pm \\
0,47\end{array}$ \\
\hline $\begin{array}{l}\text { Knochendichte Kallus plattennah } \\
{[\%]}\end{array}$ & $\begin{array}{l}78,7 \pm \\
9,05\end{array}$ & $\begin{array}{l}68,2 \pm \\
11,2\end{array}$ & $\begin{array}{l}61,6^{\#} \pm \\
18,1\end{array}$ & $\begin{array}{l}66,4 \pm \\
15,4\end{array}$ & $\begin{array}{l}67,8 \pm \\
16,2\end{array}$ & $\begin{array}{l}64,1^{\#} \pm \\
18,3\end{array}$ \\
\hline $\begin{array}{l}\text { Knochendichte Kallus plattenfern } \\
{[\%]}\end{array}$ & $\begin{array}{l}72,8 \pm \\
9,14\end{array}$ & $\begin{array}{l}75,8 \pm \\
14,2\end{array}$ & $\begin{array}{l}65,7^{\#} \pm \\
16,0\end{array}$ & $\begin{array}{l}73,2 \pm \\
12,0\end{array}$ & $\begin{array}{l}74,7 \pm \\
16,0\end{array}$ & $\begin{array}{l}74,8 \pm \\
14,5\end{array}$ \\
\hline $\begin{array}{l}\text { Knochendichte Kallus endostal } \\
{[\%]}\end{array}$ & 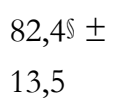 & $\begin{array}{l}67,3 \pm \\
18,4\end{array}$ & $\begin{array}{l}61,8 \pm \\
16,6\end{array}$ & $\begin{array}{l}63,2 \pm \\
13,6\end{array}$ & $\begin{array}{l}68,6 \pm \\
17,9\end{array}$ & $\begin{array}{l}68,1 \pm \\
16,5\end{array}$ \\
\hline Dichte der Trabekelfläche [\%] & $\begin{array}{l}19,5 \pm \\
12,7\end{array}$ & $\begin{array}{l}10,1 \pm \\
13,5\end{array}$ & $\begin{array}{l}9,98^{\#} \pm \\
10,8\end{array}$ & $\begin{array}{l}8,83^{\#} \pm \\
11,6\end{array}$ & $\begin{array}{l}11,0 \pm \\
13,8\end{array}$ & $\begin{array}{l}4,57^{\#} \pm \\
3,34\end{array}$ \\
\hline $\begin{array}{l}\text { Anzahl Trabekelkreuzungen } \\
\text { absolut [n] }\end{array}$ & $\begin{array}{l}8,55 \pm \\
7,90\end{array}$ & $\begin{array}{l}6,24 \pm \\
18,0\end{array}$ & $\begin{array}{l}4,79 \pm \\
9,96\end{array}$ & $\begin{array}{l}5,43 \pm \\
12,3\end{array}$ & $\begin{array}{l}3,79 \pm \\
6,18\end{array}$ & $\begin{array}{l}1,18 \pm \\
1,49\end{array}$ \\
\hline $\begin{array}{l}\text { Dichte Trabekelkreuzungen } \\
{\left[\mathrm{n} / \mathrm{mm}^{2}\right]}\end{array}$ & $\begin{array}{l}2,51 \pm \\
2,00\end{array}$ & $\begin{array}{l}1,51 \pm \\
3,61\end{array}$ & $\begin{array}{l}1,70 \pm \\
3,45\end{array}$ & $\begin{array}{l}1,45 \pm \\
3,22\end{array}$ & $\begin{array}{l}1,50 \pm \\
3,43\end{array}$ & $\begin{array}{l}0,29 \pm \\
0,35\end{array}$ \\
\hline Mittlere Trabekeldicke $[\mu \mathrm{m}]$ & $\begin{array}{l}4,53 \pm \\
1,37\end{array}$ & $\begin{array}{l}3,38 \pm \\
1,80\end{array}$ & $\begin{array}{l}3,27^{\#} \pm \\
0,99\end{array}$ & $\begin{array}{l}3,13^{\#} \pm \\
1,14\end{array}$ & $\begin{array}{l}3,61 \pm \\
1,74\end{array}$ & $\begin{array}{l}2,77^{\#} \pm \\
1,12\end{array}$ \\
\hline
\end{tabular}

${ }^{*} \mathrm{p}<0,05$ vs. OVX; ^ $\mathrm{p}<0,05$ vs. $70 \mathrm{~Hz}$ \# $\mathrm{p}<0,05$ vs. SHAM; $\mathrm{p}<0,05$ vs. allen anderen Gruppen 


\subsection{Auswertung der polychromen Sequenzmarkierung}

Entsprechend der vorhergehenden Kapitel erfolgt die Darstellung der Ergebnisse der einzelnen Parameter der polychromen Sequenzmarkierung zunächst in Form von Säulendiagrammen (Abbildung 34 bis Abbildung 46) bevor sie tabellarisch zusammengefasst werden (Tabelle 15).

\subsubsection{Gesamtfläche des plattennahen Kallus}

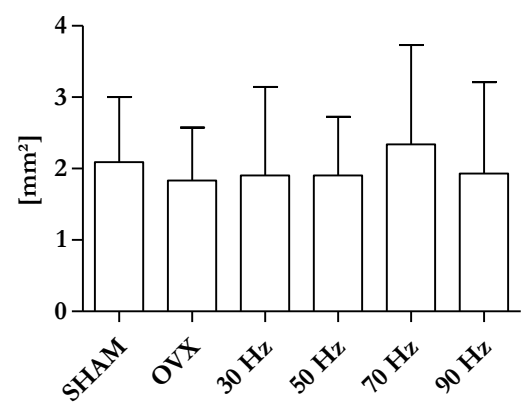

Abbildung 34: Abbildung der Messwerte der Gesamtfläche des plattennahen Kallus der polychromen Sequenzmarkierung nach horizontaler WBV

Für die Gesamt-Kallusfläche plattennah (Abbildung 34) konnte ein relativ konstantes Verhalten unter den Gruppen gezeigt werden. Es wurden keine signifikanten Unterschiede dargestellt. Die 70-Hz-Gruppe erreichte den höchsten Wert. 


\subsubsection{CG-Fläche Kallus plattennah}

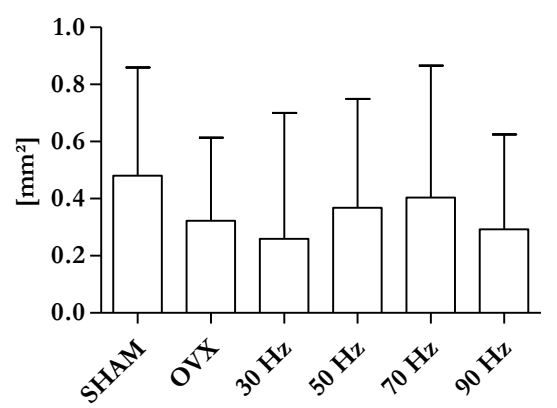

Abbildung 35: Abbildung der Messwerte der CG-Fläche Kallus plattennah der polychromen Sequenzmarkierung nach horizontaler WBV

Aufgrund der hohen Standardabweichungen konnten keine signifikanten Unterschiede zwischen den Gruppen für die frühe plattennahe Kallusbildung - markiert durch CG gefunden werden (Abbildung 35). Die größte Fläche wurde in der Gruppe SHAM nachgewiesen. Am kleinsten waren die Flächen in der 30-Hz- und 90-Hz-Gruppe.

\subsubsection{AK-Fläche Kallus plattennah}

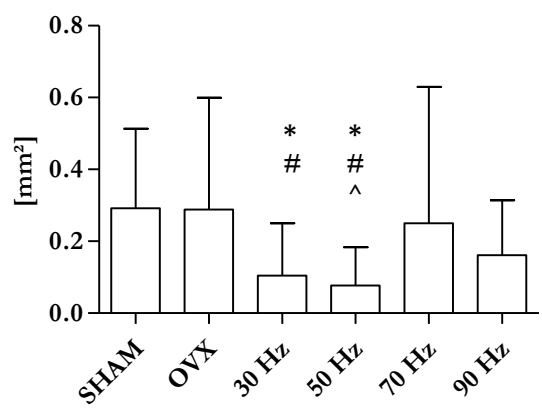

Abbildung 36: Abbildung der Messwerte der AK-Fläche Kallus plattennah der polychromen Sequenzmarkierung nach horizontaler WBV; ${ }^{*} \mathrm{p}<0,05$ vs. OVX, \# $\mathrm{p}<0,05$ vs. SHAM, ${ }^{\wedge}$ p $<0,05$ vs. $70 \mathrm{~Hz}$

Der Parameter AK-Fläche des plattennahen Kallus (Abbildung 36) zeigte bei einer Behandlung mit $30 \mathrm{~Hz}$ und $50 \mathrm{~Hz}$ eine sehr kleine Fläche. Diese war in der Gruppe der mit $30 \mathrm{~Hz}$ vibrierten Tiere signifikant kleiner gegenüber den Gruppen SHAM und OXV sowie in der Gruppe der mit $50 \mathrm{~Hz}$ vibrierten Ratten signifikant kleiner gegenüber SHAM, OVX und $70 \mathrm{~Hz}$. 


\subsubsection{TC-Fläche Kallus plattennah}

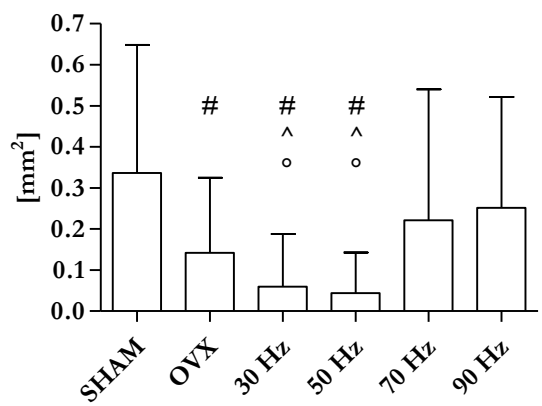

Abbildung 37: Abbildung der Messwerte der TC-Fläche Kallus plattennah der polychromen Sequenzmarkierung nach horizontaler WBV; \# $\mathrm{p}<0,05$ vs. SHAM, ^ $\mathrm{p}<0,05$ vs. $70 \mathrm{~Hz},{ }^{\circ} \mathrm{p}<0,05$ vs. $90 \mathrm{~Hz}$

Die TC-Fläche des plattennahen Kallus (Abbildung 37) war in den Gruppen SHAM, $70 \mathrm{~Hz}$ und $90 \mathrm{~Hz}$ größer als in den anderen Gruppen. Es konnten signifikante Unterschiede der SHAM-Tiere gegenüber den Gruppen OVX, $30 \mathrm{~Hz}$ und $50 \mathrm{~Hz}$ gezeigt werden. Des Weiteren wurden für die Gruppen $30 \mathrm{~Hz}$ und $50 \mathrm{~Hz}$ signifikant kleinere TC-Flächen plattennah als in den Gruppen $70 \mathrm{~Hz}$ und $90 \mathrm{~Hz}$ gesehen.

\subsubsection{Gesamtfläche des plattenfernen Kallus}

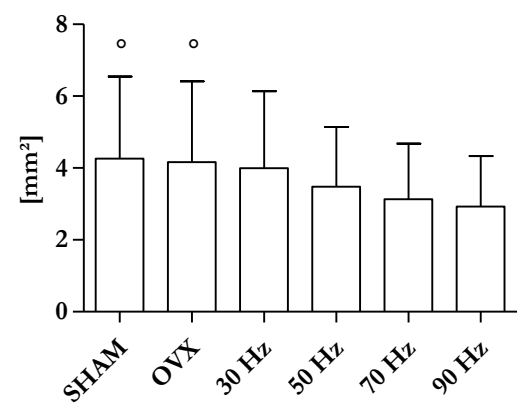

Abbildung 38: Abbildung der Messwerte der Gesamtfläche des plattenfernen Kallus der polychromen Sequenzmarkierung nach horizontaler WBV; ${ }^{\circ} \mathrm{p}<0,05 \mathrm{vs.} 90 \mathrm{~Hz}$

Die Gesamt-Kallusfläche plattenfern (Abbildung 38) war in den Gruppen SHAM und OVX signifikant größer als in der Gruppe der mit $90 \mathrm{~Hz}$ vibrierten Tiere. 


\subsubsection{CG-Fläche Kallus plattenfern}

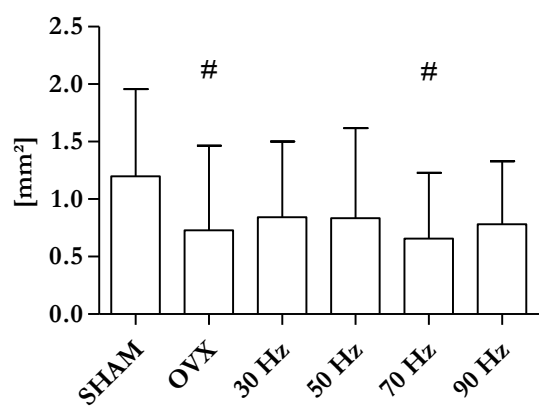

Abbildung 39: Abbildung der Messwerte der CG-Fläche Kallus plattenfern der polychromen Sequenzmarkierung nach horizontaler WBV; \# $\mathrm{p}<0,05$ vs. SHAM

Die größte CG-Fläche des plattenfernen Kallus (Abbildung 39) konnte bei den SHAMTieren gezeigt werden. Diese war signifikant größer gegenüber der OVX und der 70-HzGruppe.

\subsubsection{AK-Fläche Kallus plattenfern}

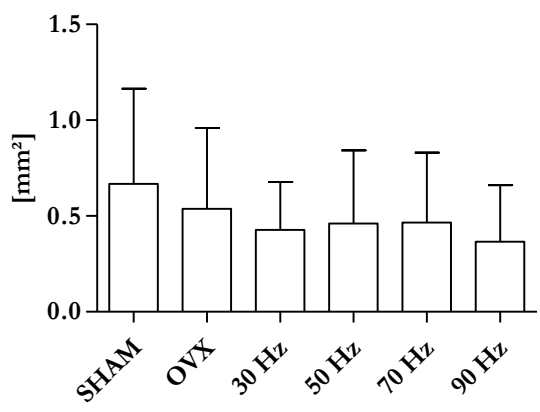

Abbildung 40: Abbildung der Messwerte der AK-Fläche Kallus plattenfern der polychromen Sequenzmarkierung nach horizontaler WBV

Für die AK-Fläche des plattenfernen Kallus (Abbildung 40) wurden keine signifikanten Unterschiede zwischen den Gruppen ermittelt. 


\subsubsection{TC-Fläche Kallus plattenfern}

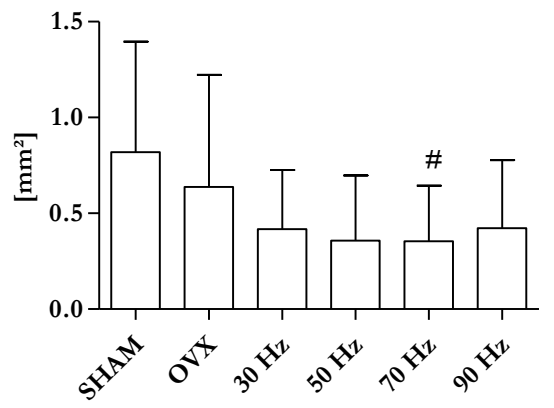

Abbildung 41: Abbildung der Messwerte der TC-Fläche Kallus plattenfern der polychromen Sequenzmarkierung nach horizontaler WBV; \# $\mathrm{p}<0,05$ vs. SHAM

Die größte TC-Fläche des plattenfernen Kallus (Abbildung 41) wurde in der Gruppe der SHAM-Tiere ermittelt. Diese war signifikant größer als in der 70-Hz-Gruppe.

\subsubsection{Gesamt-Kallusfläche endostal}

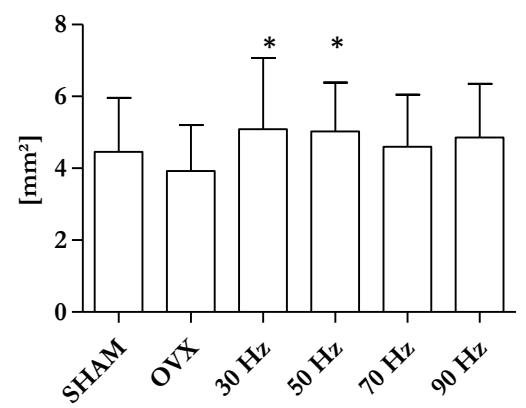

Abbildung 42: Abbildung der Messwerte der Gesamt-Kallusfläche endostal der polychromen Sequenzmarkierung nach horizontaler WBV; * $\mathrm{p}<0,05$ vs. OVX

Für die gesamte endostale Kallusfläche (Abbildung 42) konnte bei den ausschließlich ovarektomierten Tieren die kleinste Fläche bestimmt werden. Diese war signifikant kleiner gegenüber den mit $30 \mathrm{~Hz}$ und $50 \mathrm{~Hz}$ behandelten Tieren. 


\subsubsection{CG-Fläche Kallus endostal}

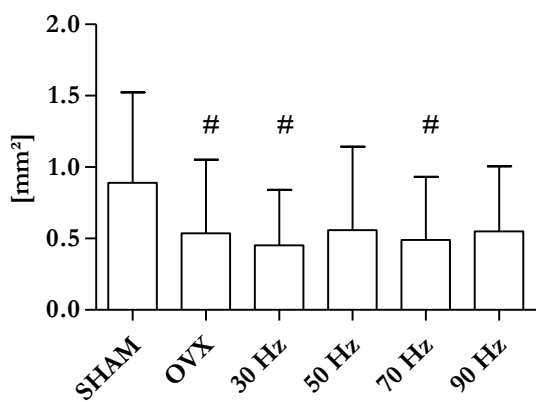

Abbildung 43: Abbildung der Messwerte der CG-Fläche Kallus endostal der polychromen Sequenzmarkierung nach horizontaler WBV; \# $\mathrm{p}<0,05$ vs. SHAM

Die CG-Fläche des endostalen Kallus (Abbildung 43) war für die Gruppe SHAM am größten, wobei ein signifikanter Unterschied dieser gegenüber OVX, $30 \mathrm{~Hz}$ und $70 \mathrm{~Hz}$ bestätigt wurde.

\subsubsection{AK-Fläche Kallus endostal}

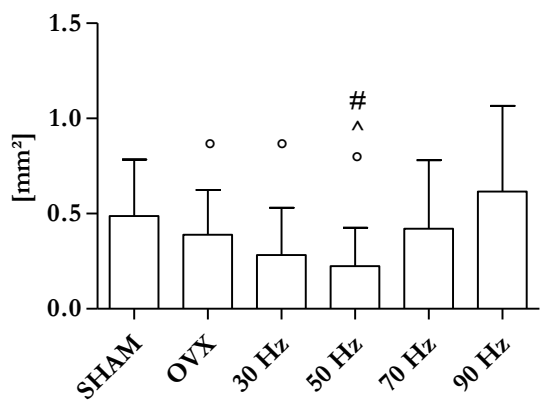

Abbildung 44: Abbildung der Messwerte der AK-Fläche Kallus endostal der polychromen Sequenzmarkierung nach horizontaler WBV; \# p $<0,05$ vs. SHAM, ${ }^{\wedge} \mathrm{p}<0,05$ vs. $70 \mathrm{~Hz},{ }^{\circ} \mathrm{p}<0,05$ vs. $90 \mathrm{~Hz}$

Die AK-Fläche des endostalen Kallus (Abbildung 44) war in der Gruppe $50 \mathrm{~Hz}$ signifikant kleiner gegenüber SHAM, $70 \mathrm{~Hz}$ und $90 \mathrm{~Hz}$. Ebenfalls konnte in der Gruppe OVX und $30 \mathrm{~Hz}$ eine signifikant kleinere Fläche gegenüber den mit $90 \mathrm{~Hz}$ behandelten Tieren dargestellt werden. In der 90-Hz-Gruppe wurde die größte Fläche festgestellt. 


\subsubsection{TC-Fläche Kallus endostal}

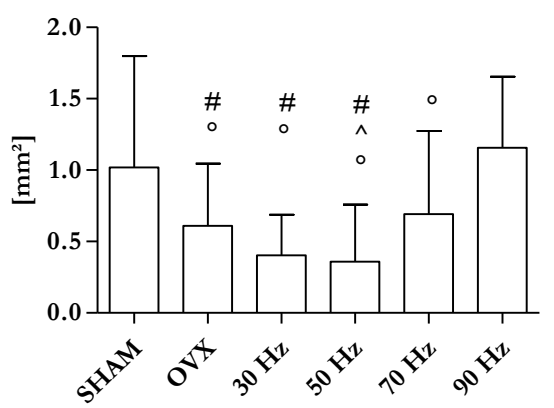

Abbildung 45: Abbildung der Messwerte der TC-Fläche Kallus endostal der polychromen Sequenzmarkierung nach horizontaler WBV; \# $\mathrm{p}<0,05$ vs. SHAM, ${ }^{\wedge} \mathrm{p}<0,05 \mathrm{vs.} 70 \mathrm{~Hz},{ }^{\circ} \mathrm{p}<0,05$ vs. $90 \mathrm{~Hz}$

Das Verhalten des Parameters TC-Fläche des endostalen Kallus (Abbildung 45) war sehr inhomogen zwischen den Gruppen. Die Gruppen SHAM und $90 \mathrm{~Hz}$ wiesen die größten Flächen auf. Es bestanden signifikante Unterschiede von SHAM gegenüber OVX, $30 \mathrm{~Hz}$ und $50 \mathrm{~Hz}$ sowie von $90 \mathrm{~Hz}$ gegenüber OVX, $30 \mathrm{~Hz}, 50 \mathrm{~Hz}$ und $70 \mathrm{~Hz}$. Ebenso konnte ein signifikanter Unterschied zwischen den Gruppen $50 \mathrm{~Hz}$ zu $70 \mathrm{~Hz}$ gezeigt werden.

\subsubsection{Gesamtfläche Kallus}

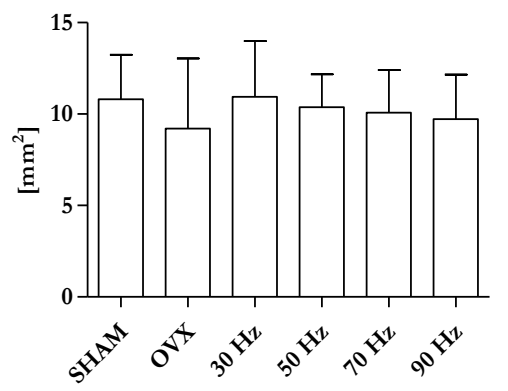

Abbildung 46: Abbildung der Messwerte der Gesamtfläche Kallus der polychromen Sequenzmarkierung nach horizontaler WBV

Für die Gesamtfläche des Kallus (Abbildung 46) wurden zwischen den Gruppen keine signifikanten Unterschiede nachgewiesen. Die Gruppen $30 \mathrm{~Hz}$ und SHAM zeigten jedoch den tendenziell größten Kallus. 
Tabelle 15: Tabellarische Zusammenfassung der Messparameter der polychromen Sequenzmarkierung (MW $\pm \mathrm{SD}$ ) eingeteilt nach sham-operierten und ovarektomierten Versuchstieren ohne oder mit einer horizontalen Vibrationsbehandlung bei 30, 50, 70 oder 90 Hertz

\begin{tabular}{|c|c|c|c|c|c|c|}
\hline Messparameter [Einheit] & SHAM & OVX & $30 \mathrm{~Hz}$ & $50 \mathrm{~Hz}$ & $70 \mathrm{~Hz}$ & $90 \mathrm{~Hz}$ \\
\hline $\begin{array}{l}\text { Gesamt-Kallusfläche } \\
\text { plattennah }\left[\mathrm{mm}^{2}\right]\end{array}$ & $\begin{array}{l}2,09 \pm \\
0,91\end{array}$ & $\begin{array}{l}1,83 \pm \\
0,75\end{array}$ & $\begin{array}{l}1,90 \pm \\
1,24\end{array}$ & $\begin{array}{l}1,90 \pm \\
0,82\end{array}$ & $\begin{array}{l}2,34 \pm \\
1,39\end{array}$ & $\begin{array}{l}1,93 \pm \\
1,28\end{array}$ \\
\hline $\begin{array}{l}\text { CG-Fläche Kallus plattennah } \\
{\left[\mathrm{mm}^{2}\right]}\end{array}$ & $\begin{array}{l}0,48 \pm \\
0,38\end{array}$ & $\begin{array}{l}0,32 \pm \\
0,29\end{array}$ & $\begin{array}{l}0,26^{* \#} \pm \\
0,44\end{array}$ & $\begin{array}{l}0,37^{* \# \wedge} \pm \\
0,38\end{array}$ & $\begin{array}{l}0,40 \pm \\
0.46\end{array}$ & $\begin{array}{l}0,29 \pm \\
0,33\end{array}$ \\
\hline $\begin{array}{l}\text { AK-Fläche Kallus plattennah } \\
{\left[\mathrm{mm}^{2}\right]}\end{array}$ & $\begin{array}{l}0,29 \pm \\
0,22\end{array}$ & $\begin{array}{l}0,29 \pm \\
0,31\end{array}$ & $\begin{array}{l}0,10 \pm \\
0,15\end{array}$ & $\begin{array}{l}0,08 \pm \\
0,11\end{array}$ & $\begin{array}{l}0,25 \pm \\
0,38\end{array}$ & $\begin{array}{l}0,16 \pm \\
0,15\end{array}$ \\
\hline $\begin{array}{l}\text { TC-Fläche Kallus plattennah } \\
{\left[\mathrm{mm}^{2}\right]}\end{array}$ & $\begin{array}{l}0,34 \pm \\
0,31\end{array}$ & $\begin{array}{l}0,14^{\#} \pm \\
0,18\end{array}$ & $\begin{array}{l}0,06^{\wedge \circ \#} \pm \\
0,13\end{array}$ & $\begin{array}{l}0,04^{\wedge \circ \#} \pm \\
0,10\end{array}$ & $\begin{array}{l}0,22 \pm \\
0,32\end{array}$ & $\begin{array}{l}0,25 \pm \\
0,27\end{array}$ \\
\hline $\begin{array}{l}\text { Gesamt-Kallusfläche } \\
\text { plattenfern }\left[\mathrm{mm}^{2}\right]\end{array}$ & $\begin{array}{l}4,26^{\circ} \pm \\
2,29\end{array}$ & $\begin{array}{l}4,17^{\circ} \pm \\
2,25\end{array}$ & $\begin{array}{l}4,00 \pm \\
2,14\end{array}$ & $\begin{array}{l}3,48 \pm \\
1,66\end{array}$ & $\begin{array}{l}3,13 \pm \\
1,55\end{array}$ & $\begin{array}{l}2,93 \pm \\
1,40\end{array}$ \\
\hline $\begin{array}{l}\text { CG-Fläche Kallus plattenfern } \\
{\left[\mathrm{mm}^{2}\right]}\end{array}$ & $\begin{array}{l}1,20 \pm \\
0,76\end{array}$ & $\begin{array}{l}0,73^{\#} \pm \\
0,74\end{array}$ & $\begin{array}{l}0,84 \pm \\
0,66\end{array}$ & $\begin{array}{l}0,83 \pm \\
0,78\end{array}$ & $\begin{array}{l}0,66^{\#} \pm \\
0,57\end{array}$ & $\begin{array}{l}0,78 \pm \\
0,55\end{array}$ \\
\hline $\begin{array}{l}\text { AK-Fläche Kallus plattenfern } \\
{\left[\mathrm{mm}^{2}\right]}\end{array}$ & $\begin{array}{l}0,67 \pm \\
0,50\end{array}$ & $\begin{array}{l}0,54 \pm \\
0,42\end{array}$ & $\begin{array}{l}0,43 \pm \\
0,25\end{array}$ & $\begin{array}{l}0,46 \pm \\
0,38\end{array}$ & $\begin{array}{l}0,47 \pm \\
0,37\end{array}$ & $\begin{array}{l}0,37 \pm \\
0,30\end{array}$ \\
\hline $\begin{array}{l}\text { TC-Fläche Kallus plattenfern } \\
{\left[\mathrm{mm}^{2}\right]}\end{array}$ & $\begin{array}{l}0,82 \pm \\
0,58\end{array}$ & $\begin{array}{l}0,64 \pm \\
0,58\end{array}$ & $\begin{array}{l}0,42 \pm \\
0,31\end{array}$ & $\begin{array}{l}0,36 \pm \\
0,34\end{array}$ & $\begin{array}{l}0,35^{\#} \pm \\
0,29\end{array}$ & $\begin{array}{l}0,42 \pm \\
0,36\end{array}$ \\
\hline $\begin{array}{l}\text { Gesamt-Kallusfläche endostal } \\
{\left[\mathrm{mm}^{2}\right]}\end{array}$ & $\begin{array}{l}4,46 \pm \\
1,50\end{array}$ & $\begin{array}{l}3,93 \pm \\
1,28\end{array}$ & $\begin{array}{l}5,10^{*} \pm \\
1,98\end{array}$ & $\begin{array}{l}5,03^{*} \pm \\
1,36\end{array}$ & $\begin{array}{l}4,60 \pm \\
1,45\end{array}$ & $\begin{array}{l}4,86 \pm \\
1,50\end{array}$ \\
\hline $\begin{array}{l}\text { CG-Fläche Kallus endostal } \\
{\left[\mathrm{mm}^{2}\right]}\end{array}$ & $\begin{array}{l}0,89 \pm \\
0,63\end{array}$ & $\begin{array}{l}0,54^{\#} \pm \\
0,52\end{array}$ & $\begin{array}{l}0,45^{\#} \pm \\
0,39\end{array}$ & $\begin{array}{l}0,56 \pm \\
0,59\end{array}$ & $\begin{array}{l}0,49^{\#} \pm \\
0,44\end{array}$ & $\begin{array}{l}0,55 \pm \\
0,45\end{array}$ \\
\hline $\begin{array}{l}\text { AK-Fläche Kallus endostal } \\
{\left[\mathrm{mm}^{2}\right]}\end{array}$ & $\begin{array}{l}0,49 \pm \\
0,30\end{array}$ & $\begin{array}{l}0,39^{\circ} \pm \\
0,24\end{array}$ & $\begin{array}{l}0,28^{\circ} \pm \\
0,25\end{array}$ & $\begin{array}{l}0,22 \pm \\
0,20\end{array}$ & $\begin{array}{l}0,42^{\wedge \circ \#} \pm \\
0,36\end{array}$ & $\begin{array}{l}0,62 \pm \\
0,45\end{array}$ \\
\hline $\begin{array}{l}\text { TC-Fläche Kallus endostal } \\
{\left[\mathrm{mm}^{2}\right]}\end{array}$ & $\begin{array}{l}1,08 \pm \\
0,76\end{array}$ & $\begin{array}{l}0,64 \pm \\
0,42\end{array}$ & $\begin{array}{l}0,43 \pm \\
0,27\end{array}$ & $\begin{array}{l}0,41 \pm \\
0,40\end{array}$ & $\begin{array}{l}0,69 \pm \\
0,58\end{array}$ & $\begin{array}{l}1,16 \pm \\
0,50\end{array}$ \\
\hline Gesamtfläche Kallus [ $\left.\mathrm{mm}^{2}\right]$ & $\begin{array}{l}10,8 \pm \\
2,44\end{array}$ & $\begin{array}{l}9,22^{\circ \#} \pm \\
3,83\end{array}$ & $\begin{array}{l}11,0^{\circ \#} \pm \\
3,05\end{array}$ & $\begin{array}{l}10,38^{\circ \# \wedge} \pm \\
1,79\end{array}$ & $\begin{array}{l}10,1^{\circ} \pm \\
2,33\end{array}$ & $\begin{array}{l}9,72 \pm \\
2,43\end{array}$ \\
\hline
\end{tabular}

${ }^{*} \mathrm{p}<0,05$ vs. OVX; ${ }^{\wedge} \mathrm{p}<0,05$ vs. $70 \mathrm{~Hz} ; \# \mathrm{p}<0,05$ vs. SHAM; ${ }^{\circ} \mathrm{p}<0,05$ vs. $90 \mathrm{~Hz}$ 


\section{Diskussion}

Das Knochengewebe ist in der Lage, sich äußeren Einflüssen anzupassen. Unter der Wirkung von mechanischen Kräften (Wolff 1892) kann die Knochenneuformation stimuliert werden. Dabei verläuft die Knochenresorption gerichtet (Butezloff et al. 2015). Im Rahmen dieser Anpassungsfähigkeit konnten unter einer alleinigen vertikalen Vibrationsbehandlung verbesserte Eigenschaften der trabekulären Knochensubstanz gezeigt werden (Rubin et al. 2002a; Rubin et al. 2002b; Flieger et al. 1998; Judex et al. 2007; Rubin et al. 2006; Xie et al. 2006). Dieser osteoanabole Effekt einer vertikalen Ganzkörpervibration konnte auch am osteopenen Skelett der Ratte gesichert werden (Oxlund et al. 2003; Rubinacci et al. 2008; Sehmisch et al. 2009). Durch einen Östrogenmangel wird die Knochenstabilität aufgrund eines beschleunigten Abbaus von trabekulärer Knochensubstanz negativ beeinflusst (Wronski et al. 1985; Wronski et al. 1988b; Hao et al. 2007). Der positive Einfluss einer äußeren Stimulation durch vertikale Ganzkörpervibration resultiert in einer verbesserten Frakturheilung und stabileren Kallusbildung (Leung et al. 2009; Butezloff et al. 2015). Jedoch sind die Ergebnisse abhängig vom Alter und vom Geschlecht der Versuchstiere sowie vom gewählten Vibrationsregime (Pasqualini et al. 2013; Shi et al. 2010; Stuermer et al. 2010a). Bereits kleine Änderungen im Bereich der Amplitude (Wehrle et al. 2014) oder der Auslenkungsrichtung der Vibration resultierten in unterschiedlichen oder sogar gegensätzlichen Effekten auf das Knochengewebe (Komrakova et al. 2013). Auch in ersten klinischen Studien wurden inhomogene Ergebnisse, abhängig von den gewählten Vibrationsparametern, gezeigt (Slatkovska et al. 2010; Slatkovska et al. 2011; Stengel et al. 2011). Um den genauen Einfluss der einzelnen Parameter zu prüfen, sind weitere Untersuchungen notwendig.

Auf diese Fragestellung zielt auch die vorliegende Arbeit mit der Untersuchung des Einflusses horizontal wirkender Kräfte bei unterschiedlichen Vibrationsfrequenzen auf die Frakturheilung des osteopenen Knochens am Versuchstiermodell der Ratte. Trotz Variation der Regime und täglicher Applikation konnte unter einer horizontalen Ganzkörpervibration keine Verbesserung der Knochenheilung gezeigt werden. Sie konnten die mechanischen und morphologischen Eigenschaften des Kallus, welche negativ durch das Östrogendefizit beeinflusst werden, nicht verbessern. 


\subsection{Die ovarektomierte Ratte als Tiermodell für postmenopausale Knochenveränderung}

Aufgrund der steigenden Inzidenz der Osteoporoseerkrankung existiert ein großes Patientenkollektiv. Dennoch ist eine einheitliche Analyse des Einflusses eines Östrogendefizits schwer realisierbar. Neben ethischen Motiven limitieren individuelle Lebensstilfaktoren und der lange Lebenszyklus die Grundlagenforschung am humanen Skelett. Tiermodelle geben die Möglichkeit, pathophysiologische Vorgänge einheitlich zu untersuchen (Turner 2001; Wessler 1989). Das gewählte Tiermodell sollte dabei einfach, standardisierbar, reproduzierbar und flexibel sein (Wessler 1989). Durch die kleine Versuchstiergröße und die Gruppentierhaltung besteht die Möglichkeit zur Untersuchung eines großen Kollektivs.

Das postmenopausale Östrogendefizit kann am Tiermodell durch eine Ovarektomie simuliert werden (Komori 2015). Am Modell der ovarektomierten Ratte wurden vergleichbare Strukturveränderungen im Knochengewebe wie bei postmenopausalen Frauen bestätigt (Frost und Jee 1992; Noor et al. 2014). Deshalb wurde die Ratte als Versuchstiermodell im vorliegenden Versuch für die Untersuchungen gewählt. Initial wird der Knochenabbau durch eine erhöhte Aktivität der Osteoklasten gefördert. Darauf folgt eine über Osteoblasten vermittelte reaktive Knochenneuformation (Noor et al. 2014). Dies resultiert in einem größeren Verlust an spongiöser als an kortikaler Knochensubstanz (Kalu 1991; Wronski et al. 1985; Hartke 1998).

Im Gegensatz zum menschlichen Skelett kommen am Skelett der osteopenen Ratten keine spontanen Frakturen zur Ausprägung. Diese können mit Hilfe von Testverfahren (Jee und Yao 2001) und standardisierten Frakturmodellen erzeugt werden (Stuermer et al. 2010b). Der Röhrenknochen der Ratte hat zudem keine Havers-Kanäle. Jedoch können nach entsprechender Aktivierung äquivalente Knochenumbauvorgänge beobachtet werden (Kalu 1991; Turner 2001). Auch das prolongierte Längenwachstum ist ab einem Alter von drei Monaten deutlich herabgesetzt (Kalu 1991). Der Verlust von Knochensubstanz ist bei drei Monate alten Tieren gleichwertig zu dem von älteren Tieren. Dadurch und aufgrund der erleichterten Anschaffung und besseren Verfügbarkeit besteht ein Vorteil für ein Lebensalter der Versuchstiere von drei Monaten (Kalu 1991). 


\subsection{Diskussion des metaphysären Frakturmodells}

Am osteoporotischen Skelett kommen neben pathognomonischen Wirbelkörperfrakturen häufig proximale Femur-, distale Radius-, subkapitale Humerus- und proximale Tibiafrakturen bei Bagatelltraumen zur Darstellung (Bartl 2011). Diese Kontinuitätsunterbrechungen liegen alle im Bereich der Metaphysen langer Röhrenknochen. Hier wirkt sich auch der Östrogenmangel innerhalb des Skeletts am stärksten aus (Namkung-Matthai et al. 2001). Auch die Frakturheilung im Bereich der Metaphysen zeigt deutliche Unterschiede zu derjenigen im Bereich der Diaphysen langer Röhrenknochen (Stuermer et al. 2006; Stuermer et al. 2010b). Im Bereich der Diaphyse entsteht neue Knochensubstanz indirekt über eine periostale Kallusbildung (Jee und Yao 2001). Nur unter einer komplett stabilen Osteosynthese kann in diesem Bereich, wie auch im Bereich der Metaphyse, direkt über eine Neuformation von Trabekeln, Knochengewebe gebildet werden (Claes et al. 2011). Die Verbindung der Knochenfragmente wird über die endostale Bildung von Mikrokallus realisiert (Stuermer et al. 2010b).

Am osteopenen Skelett der Ratte kommen keine spontanen Frakturen zur Ausprägung (Jee und Yao 2001), sodass diese iatrogen erzeugt werden müssen. In Vorversuchen unserer Arbeitsgruppe wurde eine stabile Plattenosteosynthese mit einem definierten Frakturspalt von 0,5 $\mathrm{mm}$ an der proximalen Tibia entwickelt. Durch diese kann die Frakturheilung im Bereich der Metaphyse untersucht werden (Stuermer et al. 2010b).

\subsection{Diskussion der Gewichte und der Futteraufnahme der Versuchstiere}

Im Rahmen des allgemeinen Wachstums konnte in den ersten acht Wochen in allen Versuchsgruppen eine Gewichtszunahme gezeigt werden (Berg und Harmison 1957). Dabei wurde in den Gruppen der ovarektomierten Tiere eine Gewichtszunahme von 39 Prozent zum durchschnittlichen Ausgangsgewicht von $241 \pm 11 \mathrm{~g}$ pro Versuchstier zu Beginn der Versuchsreihe detektiert. Im Vergleich dazu wurde in der Gruppe SHAM eine nur 15\%-prozentige Gewichtszunahme zum Ausgangsgewicht erreicht. Diese war in den Wochen eins bis fünf sowie neun bis elf signifikant geringer, als die der ovarektomierten Ratten.

Die gesteigerte Gewichtszunahme der ovarektomierten Tiere steht im Zusammenhang mit einer vermehrten Futteraufnahme und kommt vor allem in den ersten Wochen nach Ovarektomie zur Ausprägung (McElroy und Wade 1987). Dementsprechend war die Futteraufnahme der ovarektomierten Tiere, insbesondere in den ersten sieben Wochen, 
gegenüber der Futteraufnahme der scheinoperierten Tiere deutlich gesteigert. In dieser Gruppe konnte in der zweiten bis vierten Versuchswoche sogar eine signifikant geringere Futteraufnahme gesehen werden. Im Rahmen dessen scheint ein hemmender Einfluss von Östrogen auf die aufgenommene Futtermenge möglich (Butera 2010; Komrakova et al. 2009). Durch die erhöhte Körpermasse wird der Gewichtszunahme nach Ovarektomie eine Schutzfunktion gegenüber einem Knochenverlust zugeschrieben (Wronski et al. 1988b; Kalu 1991; Komrakova et al. 2011). Dabei konnte unabhängig von einer gesteigerten Nahrungsmenge auch eine Zunahme der fettfreien Körpermaße nachgewiesen werden (Toth et al. 2001). Dies kann neben dem Einfluss des Hormondefizits auch als Resultat einer reduzierten körperlichen Aktivität betrachtet werden (Komrakova et al. 2009).

Nach der Osteotomie konnte in allen Gruppen eine reduzierte Futteraufnahme beobachtet werden, welche durch eine Gewichtsabnahme der Tiere in der achten bis elften Versuchswoche bestätigt wurde. Es wird zwar eine schnelle Adaption der Versuchstiere beschrieben, jedoch ist ein Appetitsverlust in der postoperativen Phase unter dem Einfluss der applizierten Neuroleptika und der erfolgten Anästhesie denkbar (Komrakova et al. 2009). In der zwölften und dreizehnten Versuchswoche kam es zu einer Stabilisierung des Körpergewichts der Tiere. Dabei zeigten alle ovarektomierten Tiere ein diskretes Gewichtsdefizit zum Gewicht vor Osteotomie. Die Gruppen mit zusätzlicher Vibrationsbehandlung stagnierten durchschnittlich 4,7 Prozent unter dem Gewicht der Tiere mit alleiniger Ovarektomie. Dieser Wert entspricht annähernd der Standardabweichung. Allerdings wäre ein geringes Gewichtsdefizit aufgrund der Vibrationsbehandlung und der daraus resultierenden gesteigerten Aktivität der Muskulatur vorstellbar (van der Jagt, Olav $P$ et al. 2012). In unserem Versuch und in Vorversuchen unserer Arbeitsgruppe konnte insgesamt kein Einfluss einer vertikalen oder horizontalen Vibration auf die Futteraufnahme abgebildet werden (Komrakova et al. 2013; Stuermer et al. 2010a). Insgesamt bestätigt dies aber auch, dass alle untersuchten Vibrationsregimes von den Versuchstieren gut toleriert wurden.

Eine erfolgreiche Ovarektomie, die als Voraussetzung für die Entwicklung einer Osteoporose zu sehen ist, wird durch eine Atrophie des Uterus bestätigt (NamkungMatthai et al. 2001; Komrakova et al. 2013; Komrakova et al. 2009; Komrakova et al. 2010). Im vorliegenden Versuch betrug das durchschnittliche Gewicht der Uteri der ovarektomierten Tiere zum Zeitpunkt der Obduktion $119 \pm 17 \mathrm{mg}$ und war damit signifikant um 78 Prozent gegenüber dem Gewicht der Uteri der sham-operierten Tiere erniedrigt. 


\subsection{Diskussion der Ergebnisse des biomechanischen Kompressionstests}

Ein Östrogendefizit resultiert durch Knochenabbau über kompromittierte mechanische Eigenschaften des Knochengewebes in einer erhöhten Frakturanfälligkeit und verzögerten Frakturheilung (Wronski et al. 1988a). Mithilfe von mechanischen Testverfahren kann die Stabilität und somit die Knochenqualität ex vivo überprüft werden (Jee und Yao 2001). Dabei ist vor allem im Bereich des Frakturkallus eine herabgesetzte Elastizität und ein zeitigeres Auftreten von Mikrofrakturen im Bereich der trabekulären Knochensubstanz zu erwarten (Stuermer et al. 2006). So wurde auch am (intakten) Femurschaft osteopener Ratten eine eingeschränkte mechanische Stabilität des Frakturkallus durch eine reduzierte Anzahl an Trabekelverbindungen bestätigt (Hao et al. 2007). Bereits unter einer fünfmal geringeren Krafteinwirkung oder einer um 40 Prozent reduzierten Rotation konnte ein Bruch am Frakturkallus provoziert werden (Namkung-Matthai et al. 2001; Miwa et al. 1999).

Mittels einer vertikalen Ganzkörpervibration kann durch die übertragene mechanische Stimulation die Knochenneuformation trabekulärer Knochensubstanz induziert und die Knochenresorption reduziert werden. Dadurch wird die Knochenqualität und die mechanische Stabilität positiv beeinflusst (Rubin et al. 2006; Flieger et al. 1998; Oxlund et al. 2003). So konnte unter dem Einfluss einer vertikalen Ganzkörpervibration am osteopenen Femur der Ratte, neben einer verbesserten Knochenneubildung von trabekulärer Knochensubstanz, auch eine deutlich verbesserte mechanische Stabilität nachgewiesen werden (Tezval et al. 2011). Diese Ergebnisse wurden auch am Lendenwirbelkörper bestätigt (Sehmisch et al. 2009). Im Bereich der Tibia resultierte eine vertikale Vibration in einer verbesserten Belastbarkeit des Frakturkallus bei einer Frequenz von $70 \mathrm{~Hz}$ (Trautmann 2014). Zudem kann ein positiver Effekt einer zusätzlichen Hormonsubstitution vermutet werden. Es konnte eine bessere mechanische Stabilität der Knochenstrukturen bei einer gleichzeitigen Anwendung der vertikalen Ganzkörpervibration mit zusätzlicher Applikation von Östrogen oder Raloxifen (Stuermer et al. 2014) und unter einer kombinierten Therapie mit PTH gesehen werden (Komrakova et al. 2016).

Im hier vorliegenden Projekt konnten keine Vorteile für die Festigkeit des Frakturkallus unter einer horizontalen Vibration gesehen werden. Es wurden verbesserte biomechanische Eigenschaften unter dem Einfluss von Östrogen in der Gruppe der sham-operierten Tiere bestätigt. Auch für den Yield Load konnten aufgrund der hohen Standardabweichung keine signifikanten Gruppenunterschiede ermittelt werden. Insgesamt zeigten biomechanische Testverfahren eine große Variabilität, sodass morphologische Untersuchungen, wie die Mikrocomputertomographie oder histomorphologische Betrachtungen, spezifischere 
Aussagen zum Aufbau der Knochenstruktur und der daraus resultierenden Stabilität des Knochens geben können (Komrakova et al. 2015). Es konnte auch bei der horizontalen Vibration keine Beziehung der biomechanischen Ergebnisse mit den histomorphologischen Bildern gesehen werden. Dies könnte auf eine Abhängigkeit der Kallusqualität von umgebenden, nicht kalzifizierten Strukturen, welche hier nicht betrachtet wurden, hinweisen (Komrakova et al. 2013).

\subsection{Diskussion der Ergebnisse der Mikrocomputertomographie}

Durch die Mikrocomputertomographie steht ein nicht-invasives Verfahren zur Verfügung, welches es ermöglicht, den Strukturaufbau des Knochens im dreidimensionalen Bild bei einem hohen Auflösungsvermögen detailliert zu betrachten (Hao et al. 2007). Besonderes Interesse gilt dabei der trabekulären Knochensubstanz, welche die Knochenstabilität maßgeblich beeinflusst (Hao et al. 2007; Butezloff et al. 2015). Im Rahmen eines Östrogenmangels kommt es zu einem Abbau von Trabekeln und der Abnahme der Trabekeldicke (Noor et al. 2014). Diese Veränderungen konnten visuell mittels Bildrekonstruktion am $\mu C T$ bestätigt werden (Butezloff et al. 2015). Durch einen hohen Knochenvolumenanteil am Gesamtvolumenanteil (BV/TV) in der achten bis zwölften Woche nach Fraktur konnte am osteopenen Knochen eine herabgesetzte Frakturheilung gezeigt werden (Hao et al. 2007).

Bereits am gesunden Knochengewebe wurde unter dem Einfluss einer vertikalen Vibration, über eine erhöhte Anzahl an Trabekeln, eine verbesserte Knochenqualität erreicht (Rubin et al. 2002b). Im Rahmen der Frakturheilung konnte nach Fixation der Knochenfragmente per Kirschnerdrähten, durch eine zeitigere Kallusbildung und Mineralisierung, im Vergleich zu Tieren ohne Vibrationsbehandlung, ein positiver Einfluss der vertikalen Ganzkörpervibration auf die Frakturheilung gesehen werden (Leung et al. 2009). Im Gegensatz dazu konnten am Skelett heranwachsender Mäuse unter der Anwendung einer vertikalen Vibrationsbehandlung keine Veränderungen der anorganischen Substanz des trabekulären oder kortikalen Knochens aufgezeigt werden. Es bestätigte sich jedoch eine verbesserte Verbindung der Trabekel untereinander (Xie et al. 2006). Für den osteopenen Knochen konnten im Bereich der Epiphyse des distalen Rattenfemur bei einer Vibrationsfrequenz kleiner $90 \mathrm{~Hz}$ signifikant mehr Trabekel dargestellt werden, im Vergleich zu keiner oder einer vertikalen Vibration mit $45 \mathrm{~Hz}$. Diese Ergebnisse konnten jedoch nicht an der Metaphyse reproduziert werden (Judex et al. 2007). Zur horizontalen Vibration liegen auch hier keine Erkenntnisse vor. 
In dem vorliegenden Projekt konnten bei unterschiedlichen Frequenzen (30, 50, 70 und 90 $\mathrm{Hz}$ ) für die BMD des Kallus, des Knochens und der Kortikalis keine signifikanten Unterschiede zwischen den Gruppen nachgewiesen werden. Entsprechend dem strukturellen Aufbau war die Knochendichte des Kallus geringer als die des Knochens und der Kortikalis. Auch für die Gesamtknochendichte wurden keine signifikanten Unterschiede zwischen den Gruppen gezeigt. Diese war in der Gruppe der gesunden Tiere geringfügig höher als bei allen ovarektomierten Tieren, unabhängig von der Gruppenzugehörigkeit, was den knochenstabilisierenden Effekt von Östrogen bestätigt. Die horizontale Vibration zeigte anders als die vertikale Vibration (Trautmann 2014) keinen positiven Einfluss auf die Knochendichte. Für den Knochenanteil am Kallus konnte bei den gesunden Tieren der höchste Knochenanteil festgestellt werden. Demgegenüber war der Knochenanteil am Gesamtvolumen in allen vibrierten Gruppen erniedrigt, dabei signifikant kleiner bei einer Behandlung mit 50, 70 sowie $90 \mathrm{~Hz}$. Dieser Effekt könnte in größeren und weniger festen Kallusstrukturen unter der horizontalen Vibrationsbehandlung begründet sein (Komrakova et al. 2013).

Bei der Beurteilung der Mikrocomputertomographie erfolgte in der vorliegenden Arbeit eine peakorientierende Auswertung der einzelnen Messbereiche. Es wurde demzufolge manuell - anhand des Histogramms - der zu betrachtende Messbereich der einzelnen Knochenstrukturen definiert. Dabei stellte sich vor allem die Abgrenzung von Kallusgewebe zu Knochengewebe als schwer differenzierbar dar. Dadurch war keine elektronische, standardisierte Auswertung realisierbar. Im Rahmen der weiteren Entwicklung der Auswertungsmethode OsteoAnalyze ${ }^{\circledR}$ hat sich eine bessere Reliabilität für eine Betrachtung der Ergebnisse nach definierten Schwellenwerten gezeigt (Weidemann 2014). Aufgrund der peakorientierten Auswertung kann in der vorliegenden Arbeit eine detaillierte Analyse der Frakturregion nur anhand der histomorphometrischen Auswertung erreicht werden.

\subsection{Diskussion der Ergebnisse der Mikroradiographie}

Die Frakturheilung wird durch verschiedene Faktoren bestimmt. Maßgeblich für die erfolgreiche Überbrückung ist eine (relativ) stabile Verbindung der Frakturfragmente über einen neugebildeten Frakturkallus. Unter dem fehlenden protektiven Einfluss von Östrogen kommt es zu einer verzögerten Frakturheilung. Ursächlich dafür kann eine verzögerte Ossifikation und geringere Stabilität der Knochenstrukturen untereinander sein (Hao et al. 2007). Vor allem während der frühen Phase der Frakturheilung wurde am osteopenen Knochen, im Vergleich zu gesundem Knochengewebe, eine reduzierte Knochenneuformation gesehen. Dies kann im Rahmen einer verlängerten Knochen- 
umbauzeit und einem Funktionsverlust der Osteoblasten nach Ovarektomie begründet sein (Namkung-Matthai et al. 2001).

Unter dem Einfluss von mechanischen Reizen in Form einer vertikalen Vibrationsbehandlung konnte eine Verbesserung der Knochenstruktur im Bereich des trabekulären Knochens (Rubin et al. 2002b; Rubin et al. 2002a; Judex et al. 2007) und auch des kortikalen Knochens (Rubin et al. 2006) erreicht werden. Dabei resultierte unter einem Östrogendefizit ein verbessertes Ansprechen der Knochenstrukturen auf eine Vibrationsbehandlung als bei hormonintaktem Knochengewebe (Rubinacci et al. 2008; Pasqualini et al. 2013). Auch während der Frakturheilung konnte ein positiver Einfluss der vertikalen Vibration auf die Knochenneuformation gezeigt werden (Oxlund et al. 2003; Sehmisch et al. 2009). Trotz horizontaler Vibration erfolgte in allen ovarektomierten Gruppen durch den fehlenden Östrogeneinfluss nach Ovarektomie ein Abbau des trabekulären Knochens, welcher sich kaum von dem des osteoporotischen Knochens unterschied. In allen ovarektomierten Gruppen bestand eine verminderte Knochendichte, eine verringerte Anzahl an Trabekelkreuzungen, eine reduzierte Dichte der Trabekelkreuzungen und der mittleren Trabekeldicke, wie bereits ohne Vibration vorbeschrieben (Noor et al. 2014; Stuermer et al. 2006; Wronski et al. 1985). Die Dichte der Trabekelfläche und die mittlere Dicke der Trabekel waren unter einer horizontalen Ganzkörpervibration mit 30, 50 und $90 \mathrm{~Hz}$ signifikant geringer als bei den sham-operierten Tieren, sodass weder ein erhaltender, noch ein anaboler Einfluss der horizontalen Ganzkörpervibration auf die Trabekelstrukturen gezeigt werden konnte. Bei einer Vibration mit $90 \mathrm{~Hz}$ scheint der Knochenaufbau sogar gehemmt. Die horizontale Vibration konnte unter den angewendeten Parametern den geforderten osteoanabolen Effekt der vertikalen Vibration (Rubin et al. 2002a; Rubin et al. 2002b; Rubin et al. 2006) auf den trabekulären Knochen nicht bestätigen.

Kortikaler Knochen zeigt unter einem Östrogendefizit einen geringeren Abbau an Knochensubstanz (Kalu 1991). Dementsprechend konnte kein signifikanter Unterschied der Kortikalisdicke distal plattennah sowie distal plattenfern und für die Knochendichte der Kortikalis distal plattennah und plattenfern vor und - nach Ovarektomie - abgeleitet werden. Die Kortikalis distal plattennah war unter einer horizontalen Vibrationsbehandlung mit $50 \mathrm{~Hz}$ im Vergleich zur Kortikalis der nur ovarektomierten Tiere signifikant erniedrigt. Im Bereich der Kortikalis distal plattenfern wurde eine stärkere Kortikalis unter einer Vibration mit $30 \mathrm{~Hz}$ und $90 \mathrm{~Hz}$ gemessen. Hier könnte ein möglicher Einfluss auf die kortikalen Knochenstrukturen gesehen werden. Für die Knochendichte der distalen Kortikalis wurde bei einem sehr homogenen Verhalten des Parameters kein Einfluss der Ovarektomie oder einer Vibration gesehen. Aufgrund der hohen Dichte der Kortikalis konnte diese in der Auswertung gut definiert werden, sodass sich eine nur 
geringe Standardabweichung zeigte. Insgesamt bestätigt dies die Resultate von Rubin, welcher auch keinen Einfluss einer vertikalen Vibration auf den kortikalen Knochen nachweisen konnte. Dies ist wahrscheinlich in der geringeren Knochenumbaurate von kortikalem Knochen im Vergleich zu trabekulären Knochen begründet (Rubin et al. 2002a). Der Knochendurchmesser zeigte unter der horizontalen Ganzkörpervibration proximal wie auch distal ein inhomogenes Verhalten. Die Lokalisation zur Osteotomie zeigte keinen Einfluss auf den Knochendurchmesser. Den kleinsten Durchmesser hatten die ovarektomierten, nicht vibrierten Tiere.

Bei der Untersuchung der Frakturheilung konnte unter einer horizontalen Vibration eine geringere Kallusdicke für eine Vibration bei Frequenzen von $70 \mathrm{~Hz}$ und $90 \mathrm{~Hz}$ identifiziert werden. Plattenfern wurde die größte Kallusdicke bei den sham-operierten Tieren gesehen. Den kleinsten Kallus hatten die ovarektomierten, osteopenen Tiere, was auf eine eingeschränkte Kallusbildung im Rahmen des Östrogendefizits hinweist. Die horizontale Vibration zeigte entgegen den Erwartungen keinen signifikanten Einfluss auf die plattenferne Kallusdicke. Die Dichte des Kallus war bei den sham-operierten, gesunden Tieren erwartungsgemäß am höchsten, dabei im plattennahen Anteil signifikant höher als bei einer Vibration mit $30 \mathrm{~Hz}$ und $90 \mathrm{~Hz}$. Auch plattenfern konnte bei diesen Tieren der dichteste Knochen gesehen werden. Dieser war signifikant dichter gegenüber den mit $30 \mathrm{~Hz}$ behandelten Tieren. Die höchste endostale Kallusdichte stellt sich ebenfalls in der Gruppe der sham-operierten, gesunden Tiere dar. Damit bestätigt sich der positive Einfluss von Östrogen auf die Frakturheilung (Namkung-Matthai et al. 2001).

In Zusammenfassung der Ergebnisse der Mikroradiographie wird unter einer horizontalen Vibration an der osteopenen Rattentibia eine verminderte Bildung von Kallusgewebe bei einer Vibrationsfrequenz von $70 \mathrm{~Hz}$ und $90 \mathrm{~Hz}$ sowie eine herabgesetzte Dichte des Kallus bei $30 \mathrm{~Hz}$ und $90 \mathrm{~Hz}$ gesehen. Die Stabilität wird dabei durch verbesserte Eigenschaften des endostalen Kallus aufrechterhalten. In der vorliegenden Arbeit konnte eine horizontale Ganzkörpervibration die nachteiligen Wirkungen eines Östrogenmangels auf die Frakturheilung nicht abschwächen. Die Wirkung von horizontal einwirkenden Kräften erscheint, im Vergleich zu axialen Kräften (Komrakova et al. 2013) unvorteilhaft für die Frakturheilung.

\subsection{Diskussion der Ergebnisse der polychromen Sequenzmarkierung}

Die Betrachtung des zeitlichen Ablaufes des Knochenauf- und abbaus kann mittels einer polychromen Sequenzmarkierung realisiert werden (Rahn 1976). Mit dieser Technik konnte durch eine Markierung mit Tetracyclin eine vierfach höhere Resorption von Knochen- 
gewebe nach erfolgter Ovarektomie an der osteopenen Rattentibia gezeigt werden. Dies deutet auf einen erhöhten Knochenstoffwechsel im Rahmen des Östrogendefizits hin (Wronski et al. 1985; Wronski et al. 1988b; Namkung-Matthai et al. 2001).

An der Tibia ovarektomierter Tiere konnte unter einer vertikalen Vibrationsbehandlung eine frühere knöcherne Frakturüberbrückung erreicht werden. Insbesondere wurde eine Zunahme der Knochenbildung ab Tag 18 bis 35 nach Osteotomie gezeigt (Stuermer et al. 2010a). Auch am osteopenen Wirbelkörper konnte unter einer vertikalen WBV ein höherer Knochenumsatz erreicht werden (Sehmisch et al. 2009). Im vorliegenden Versuch konnte unter einer horizontalen Vibration für alle Versuchstiere eine knöcherne Überbrückung des Frakturspaltes im Bereich der metaphysären Tibiae erreicht werden. Dabei traten erste knöcherne Verbindungen am Tag 18 nach Osteotomie bei den sham-operierten, gesunden Tieren auf, gefolgt von den Tieren mit einer Vibrationsbehandlung bei $30 \mathrm{~Hz}$ an Tag 20, bei $70 \mathrm{~Hz}$ an Tag 21 und bei $90 \mathrm{~Hz}$ an Tag 22. In der Gruppe der ovarektomierten Tiere und der Gruppe mit einer Vibrationsbehandlung bei $50 \mathrm{~Hz}$ zeigten sich unter einer horizontalen Vibration an Tag 23 erste Zusammenschlüsse der Frakturelemente (Komrakova et al. 2013).

Bei der Betrachtung der plattennahen Gesamt-Kallusfläche wurde in der Gruppe der shamoperierten und der mit $70 \mathrm{~Hz}$ horizontal vibrierten Tiere der höchste Anteil an Kallusfläche gesehen. Hier konnte bei einer Mehranreicherung von Calcein-Grün (14 bis 18 Tage nach der Osteotomie) eine stärkere Knochenneuformation bestätigt werden. Diese zeigte sich auch im weiteren zeitlichen Verlauf bei deutlich reduzierten Werten für die Anreicherung von Alizarin-Komplexon in der Gruppe der mit $30 \mathrm{~Hz}$ und $50 \mathrm{~Hz}$ behandelten Tieren gegenüber den ovarektomierten, den sham-operierten und den mit $70 \mathrm{~Hz}$ vibrierten Tieren. Auch für den Markierungszeitraum von Tetracyclin (27 bis 35 Tage nach Osteotomie) war die Kallusformation in der Gruppe $30 \mathrm{~Hz}$ und $50 \mathrm{~Hz}$ deutlich reduziert gegenüber den ovarektomierten, den sham-operierten, den bei $70 \mathrm{~Hz}$ und den bei $90 \mathrm{~Hz}$ behandelten Tieren. An der plattenfernen Tibia konnte eine signifikant größere Kallusgesamtfläche bei den ovarektomierten und den sham-operierten Tieren gegenüber denen mit einer Vibration bei $70 \mathrm{~Hz}$ und $90 \mathrm{~Hz}$ gesehen werden.

Im Bereich der endostalen Frakturüberbrückung war die Kallusfläche der sham-operierten Tiere größer als die aller ovarektomierten Tiere. Hier bewirkte eine horizontale Vibration mit $30 \mathrm{~Hz}$ oder $50 \mathrm{~Hz}$ eine signifikante Größenzunahme gegenüber den ovarektomierten Tieren. Endostal konnte ebenfalls während des Markierungszeitraumes mit Calcein-Grün eine deutliche Knochenneuformation in der Gruppe der gesunden, sham-operierten Tiere gesehen werden. In den späteren Markierungszeiträumen wurde vor allem eine geringe 
Anreicherung bei $30 \mathrm{~Hz}$ und $50 \mathrm{~Hz}$ gezeigt. Dies lässt vermuten, dass in diesem Zeitraum die Neuformation nach erhöhter Aktivität bei der frühen Phase der Calcein-GrünMarkierung schon rückläufig war. Auffällig war eine spätere Kallusformation unter einer Behandlung mit $90 \mathrm{~Hz}$. Hier wird eine frühe knöcherne Frakturüberbrückung durch einen übermäßigen mechanischen Stimulus gestört.

In der Betrachtung der Gesamtkallusfläche wurde unter einem Östrogeneinfluss eine größere Fläche für die sham-operierten Tiere gesehen. Insgesamt war die Kallusformation in der dritten Woche, also in der frühen Phase der Frakturheilung, am stärksten ausgeprägt.

\subsection{Schlussfolgerung}

In der vorliegenden Arbeit konnte unter einer horizontalen Ganzkörpervibration keine Verbesserung der Knochenheilung an der osteopenen Rattentibia gezeigt werden. Die mechanischen Eigenschaften des Knochens werden insbesondere durch den strukturellen Knochenaufbau bestimmt, auf den sich das Östrogendefizit nach Ovarektomie negativ auswirkt. Diese Wirkung konnte durch die horizontale Ganzkörpervibration nicht abgeschwächt werden. Durch die insgesamt verminderte Bildung von Kallus bei Vibrationsfrequenzen von $70 \mathrm{~Hz}$ und $90 \mathrm{~Hz}$ ist sogar eine mechanische Beeinträchtigung der Frakturheilung zu vermuten.

Im Rahmen einer vertikalen Vibration mit ähnlichen Versuchsaufbau und Vibrationsparametern konnte ein positiverer Einfluss auf die Frakturheilung gezeigt werden (Komrakova et al. 2013; Trautmann 2014). Möglicherweise eignen sich horizontale Bewegungen nicht als Stimulus. Die horizontale Vibration imitiert keine natürliche Bewegung. Im Rahmen von alltäglichen Bewegungen wie Gehen und Stehen, wirken vor allem axiale Kräfte auf das Skelettsystem. Scherbewegungen, wie bei der horizontalen Vibration, kommen dabei kaum vor.

Insgesamt werden der passiven Ganzkörpervibrationsbehandlung gute Voraussetzungen für einen nicht-pharmakologischen Ansatz zur Unterstützung der Frakturheilung zugeschrieben (Wysocki et al. 2011). Dies ist gerade im Rahmen des zunehmenden Alters der Patienten und einer möglichen Polypharmazie als bedeutender Vorteil zu werten. Ebenso wird durch die passive Applikationsform das Risiko von Verletzungen minimiert und die Balance und Muskelstärke gefördert (Moreira et al. 2014; Iwamoto et al. 2012; Weber-Rajek et al. 2015). Jedoch zeigen sich die Ergebnisse erster klinischer Studien (Slatkovska et al. 2010; Slatkovska et al. 2011), wie auch die der präklinischen Forschung, 
sehr inhomogen und stark vom Versuchsablauf und den angewandten Vibrationsparametern abhängig.

Demnach muss in weiteren Untersuchungen der Einfluss der einzelnen Parameter erforscht werden, um eine optimale Therapieempfehlung für die Anwendung während der Frakturheilung am osteoporotischen Knochen geben zu können. 


\section{$5 \quad$ Zusammenfassung}

Osteoporose ist durch einen Verlust an Knochenmineraldichte charakterisiert. Hierdurch bedingt steigt das Risiko von atraumatischen Frakturen. Besonders sturzgefährdete und betagte Patienten haben ein erhöhtes Risiko von osteoporotisch bedingten Knochenbrüchen. Dadurch gewinnt die Osteoporose aufgrund einer zunehmend alternden Gesellschaft an Bedeutung. Unter dem Einfluss einer vertikalen Ganzkörpervibration konnte eine verbesserte Knochenstruktur am gesunden wie auch am osteoporotischen Knochengewebe nachgewiesen werden. Daraus kann ein positiver Effekt auf die Frakturheilung abgeleitet werden. Die Ganzkörpervibration bietet dabei als passive Applikationsform und nichtpharmakologischer Therapieansatz den Vorteil, Verletzungen und Medikamenteninteraktionen insbesondere bei älteren Patienten zu reduzieren. Aus den Ergebnissen bisheriger Studien konnte allerdings noch kein eindeutiges Vibrationsregime abgeleitet werden, welches die Frakturheilung optimal fördert.

In der vorliegenden Arbeit wurde deshalb der Einfluss einer horizontalen Ganzkörpervibration auf die Frakturheilung zunächst an der osteopenen Rattentibia untersucht. Dafür wurden neunzig drei Monate alte weibliche Sprague-Dawley-Ratten in sechs Gruppen eingeteilt. Davon wurden fünf Gruppen ovarektomiert, wodurch nach einer Zeitspanne von acht Wochen bei diesen Tieren eine Osteopenie erzeugt werden konnte. Eine Gruppe wurde scheinoperiert, sodass die Ovarialfunktion erhalten blieb. Im Anschluss erfolgte für alle Versuchstiere eine Osteotomie mit stabilisierender Plattenosteosynthese durch eine 5Loch-Leibinger-Titanplatte. Ab dem fünften post-operativen Tag erfolgte die horizontale Ganzkörpervibration für fünfzehn Minuten täglich über dreißig Tage für vier der ovarektomierten Gruppen. Jede der vorgenannten Gruppen wurde mit einer gruppenspezifischen Frequenz von 30, 50, 70 oder $90 \mathrm{~Hz}$ bei einer Amplitude von 0,5 mm horizontal vibriert. Nach Abschluss der Behandlung wurde die mechanische Stabilität der Tibia in einem biomechanischen Kompressionstest untersucht. Es folgte die Analyse der Dichtewerte von Kortikalis, Kallus und Gesamtknochen mittels Mikrocomputertomographie sowie die histomorphometrische Untersuchung der Knochen- und Kallusstrukturen. Der zeitliche Verlauf der Frakturheilung wurde durch eine polychrome Sequenzmarkierung beurteilt.

Die Auswertung der Ergebnisse bestätigte eine herabgesetzte mechanische Stabilität, eine reduzierte Dichte des Kallus und eine verzögerte Knochenneubildung an der osteopenen Rattentibia. Dieser negative Einfluss des Östrogendefizits konnte durch die horizontale Ganzkörpervibration nicht ausgeglichen werden. Es wurde darüber hinaus eine 
verminderte Kortikalisbreite bei Frequenzen unterhalb $90 \mathrm{~Hz}$ und eine herabgesetzte Kallusdichte bei einer Frequenz von $30 \mathrm{~Hz}$ auffällig. Durch eine verminderte Kallusbildung bei einer horizontalen Vibration mit Frequenzen von $70 \mathrm{~Hz}$ und $90 \mathrm{~Hz}$ kann eine verschlechterte Frakturheilung angenommen werden. Die Frequenz $50 \mathrm{~Hz}$ hat zumindest keinen negativen Effekt auf die osteoporotische Frakturheilung im Vergleich zum Gesunden. Insgesamt zeigte die horizontale Ganzkörpervibration jedoch eher negative Wirkungen auf die Knochenstrukturen und die Frakturheilung. Im Gegensatz dazu konnte in anderen Arbeiten ein positiver Einfluss auf die Frakturheilung für eine vertikale Ganzkörpervibration festgestellt werden. Gründe hierfür könnten im Einfluss der dabei wirkenden axialen Kräfte gesehen werden, wie sie auch bei natürlichen Bewegungen auftreten. Aufgrund dessen ist in weiterführenden Untersuchungen eine vertikale Vibration empfehlenswert, um ein optimales Vibrationsregime $\mathrm{zu}$ finden, das anschließend am Großtier und im Verlauf in klinischen Studien untersucht werden kann. 


\section{$6 \quad$ Literaturverzeichnis}

Aspray TJ (2013): New horizons in fracture risk assessment. Age Ageing 42, 548-554

Babu S, Sandiford NA, Vrahas M (2015): Use of Teriparatide to improve fracture healing: What is the evidence? World J Orthop $\underline{6}, 457-461$

Baron R, Ferrari S, Russell RGG (2011): Denosumab and bisphosphonates: different mechanisms of action and effects. Bone $\underline{48}, 677-692$

Bartl R: Osteoporose: Prävention, Diagnostik, Therapie. 4., vollst. überarb. und erw. Auflage; Thieme, Stuttgart 2011

Bellido T (2014): Osteocyte-driven bone remodeling. Calcifi Tissue Int 94, 25-34

Berg BN, Harmison CR (1957): Growth, disease, and aging in the rat. J Gerontol 12, 370377

Brandi ML (2012): Drugs for bone healing. Expert Opin Investig Drugs 21, 1169-1176

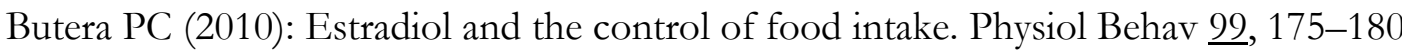

Butezloff MM, Zamarioli A, Leoni GB, Sousa-Neto MD, Volpon JB (2015): Whole-body

vibration improves fracture healing and bone quality in rats with ovariectomy-induced osteoporosis. Acta Cir Bras $\underline{30}, 727-735$

Christiansen C, Lindsay R (1990): Estrogens, bone loss and preservation. Osteoporos Int 1 , $7-13$

Claes L, Reusch M, Wolfram U, Göckelmann M, Ignatius A (2011): Modelle der metaphysären Frakturheilung. Osteologie 20, 29-33

Cummings SR, San Martin J, McClung MR, Siris ES, Eastell R, Reid IR, Delmas P, Zoog HB, Austin M, Wang A (2009): Denosumab for prevention of fractures in postmenopausal women with osteoporosis. New Engl J Med $\underline{361}$, 756-765

Daub F: Kurzzeiteffekte von Estradiol, Raloxifen, Phytohormonen und Parathormon auf die metaphysäre Frakturheilung des manifest osteoporotischen Knochens der Ratte. Med. Diss. Göttingen 2010

Dobnig H, Turner RT (1997): The effects of programmed administration of human parathyroid hormone fragment (1-34) on bone histomorphometry and serum chemistry in rats. Endocrinology 138, 4607-4612

Döll CJ: Einfluss der vertikalen Ganzkörpervibration unterschiedlicher Frequenz auf den osteoporotischen Lendenwirbelkörper der Ratte. Med Diss. Göttingen 2011

Edwards MH, Dennison EM, Aihie Sayer A, Fielding R, Cooper C (2015): Osteoporosis and sarcopenia in older age. Bone $\underline{80}, 126-130$ 
Engelke K, Karolczak M, Lutz A, Seibert U, Schaller S, Kalender W (1999): Micro-CT:

Technologie und Applikationen zur Erfassung von Knochenstruktur. Radiologe 39, 203212

Flieger J, Karachalios T, Khaldi L, Raptou P, Lyritis G (1998): Mechanical stimulation in the form of vibration prevents postmenopausal bone loss in ovariectomized rats. Calcif Tissue Int $\underline{63}, 510-514$

Florencio-Silva R, Sasso, Gisela Rodrigues da Silva, Sasso-Cerri E, Simões MJ, Cerri PS (2015): Biology of Bone Tissue: Structure, Function, and Factors That Influence Bone Cells. Biomed Res Int 2015, 421746

Frost HM, Jee WS (1992): On the rat model of human osteopenias and osteoporoses. Bone Miner $\underline{18}, 227-236$

Goldhahn J, Féron JM, Kanis J, Papapoulos S, Reginster JY, Rizzoli R, Dere W, Mitlak B, Tsouderos Y, Boonen S (2012): Implications for fracture healing of current and new osteoporosis treatments: an ESCEO consensus paper. Calcif Tissue Int 90, 343-353

Grifka J, Hower K: Skeletterkrankungen des Erwachsenen. In: Grifka J, Kuster M (Hrsg.): Orthopädie und Unfallchirurgie: Für Praxis, Klinik und Facharztprüfung. Springer, Berlin 2011, 164-181

Gruber R (2010): Osteoporosetherapie und Frakturheilung. J Miner Stoffwechs 17(1), 6-10 Gruber R, Koch H, Doll BA, Tegtmeier F, Einhorn TA, Hollinger JO (2006): Fracture healing in the elderly patient. Exp Gerontol 41, 1080-1093

Hao YJ, Zhang G, Wang YS, Qin L, Hung WY, Leung K, Pei FX (2007): Changes of microstructure and mineralized tissue in the middle and late phase of osteoporotic fracture healing in rats. Bone $\underline{41}, 631-638$

Hartke J (1998): Non-primate models of osteoporosis. Lab Anim Sci 4ㄹ, 623-629

Herold G: Innere Medizin 2016: Gerd Herold (Verlag), Köln 2015

Huang TW, Chuang PY, Lin SJ, Lee CY, Huang KC, Shih HN, Lee MS, Hsu RW, Shen WJ (2016): Teriparatide Improves Fracture Healing and Early Functional Recovery in Treatment of Osteoporotic Intertrochanteric Fractures. Medicine (Baltimore) 95, e3626 Iwamoto J, Sato Y, Takeda T, Matsumoto H (2012): Whole body vibration exercise improves body balance and walking velocity in postmenopausal osteoporotic women treated with alendronate: Galileo and Alendronate Intervention Trail (GAIT). J Musculoskelet Neuronal Interact 12, 136-143

Jakob F, Felsenberg D (2013): Grundlagen des Knochenstoffwechsels und pharmakologische Daten. MKG Chir $\underline{6}, 72-79$

Jee WS, Yao W (2001): Overview: animal models of osteopenia and osteoporosis. J Musculoskelet Neuronal Interact 1, 193-207 
Johnson JT, Hansen MS, Wu I, Healy LJ, Johnson CR, Jones GM, Capecchi MR, Keller C (2006): Virtual histology of transgenic mouse embryos for high-throughput phenotyping. PLoS Genet 2 , e61

Judex S, Lei X, Han D, Rubin C (2007): Low-magnitude mechanical signals that stimulate bone formation in the ovariectomized rat are dependent on the applied frequency but not on the strain magnitude. J Biomech $\underline{40}, 1333-1339$

Kalu DN (1991): The ovariectomized rat model of postmenopausal bone loss. Bone Miner $\underline{15}, 175-191$

Kanis JA, McCloskey EV, Johansson H, Cooper C, Rizzoli R, Reginster JY (2013):

European guidance for the diagnosis and management of osteoporosis in postmenopausal women. Osteoporos Int 24, 23-57

Kasturi G, Adler RA (2011): Mechanical means to improve bone strength: ultrasound and vibration. Curr Rheumatol Rep $\underline{13}$, 251-256

Kohn D, Pape D: Stoffwechselerkrankungen der Haltungs- und Bewegungsorgane. In: Scharf HP, Rüter A, Pohlemann T, Marzi I, Kohn D, Günther KP (Hrsg.): Orthopädie und Unfallchirurgie: Facharztwissen nach der neuen Weiterbildungsordnung. 2., korrigierte Auflage; Elsevier Urban \& Fischer, München 2011, 415-425

Komori T (2015): Animal models for osteoporosis. Eur J Pharmacol 포, 287-294

Komrakova M, Werner C, Wicke M, Nguyen BT, Sehmisch S, Tezval M, Stuermer KM, Stuermer EK (2009): Effect of daidzein, 4-methylbenzylidene camphor or estrogen on gastrocnemius muscle of osteoporotic rats undergoing tibia healing period. J Endocrinol 201, 253-262

Komrakova M, Stuermer EK, Werner C, Wicke M, Kolios L, Sehmisch S, Tezval M, Daub F, Martens T, Witzenhausen P (2010): Effect of human parathyroid hormone hPTH (1-34) applied at different regimes on fracture healing and muscle in ovariectomized and healthy rats. Bone $\underline{47}, 480-492$

Komrakova M, Sehmisch S, Tezval M, Schmelz U, Frauendorf H, Grueger T, Wessling T, Klein C, Birth M, Stuermer KM (2011): Impact of 4-methylbenzylidene camphor, daidzein, and estrogen on intact and osteotomized bone in osteopenic rats. J Endocrinol 211, 157168

Komrakova M, Sehmisch S, Tezval M, Ammon J, Lieberwirth P, Sauerhoff C, Trautmann L, Wicke M, Dullin C, Stuermer KM (2013): Identification of a vibration regime favorable

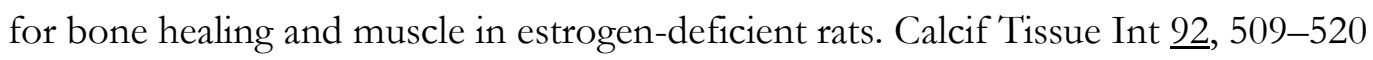

Komrakova M, Stuermer EK, Tezval M, Stuermer KM, Dullin C, Schmelz U, Doell C, Durkaya-Burchhardt N, Fuerst B, Genotte T (2014): Evaluation of twelve vibration regimes applied to improve spine properties in ovariectomized rats. Bone Rep 
Komrakova M, Weidemann A, Dullin C, Ebert J, Tezval M, Stuermer KM, Sehmisch S (2015): The Impact of Strontium Ranelate on Metaphyseal Bone Healing in Ovariectomized Rats. Calcif Tissue Int 97, 391-401

Komrakova M, Hoffmann DB, Nuehnen V, Stueber H, Wassmann M, Wicke M, Tezval M, Stuermer KM, Sehmisch S (2016): The Effect of Vibration Treatments Combined with Teriparatide or Strontium Ranelate on Bone Healing and Muscle in Ovariectomized Rats. Calcif Tissue Int $\underline{99}, 408-422$

Kubo T, Shiga T, Hashimoto J, Yoshioka M, Honjo H, Urabe M, Kitajima I, Semba I, Hirasawa Y (1999): Osteoporosis influences the late period of fracture healing in a rat model prepared by ovariectomy and low calcium diet. Journal Steroid Biochem Mol Biol $\underline{68}, 197-202$

Lauritzen C (2005): Knochendichtebestimmung in der Menopause. Gynäkologe $\underline{38}$, 255273

Leung KS, Shi HF, Cheung WH, Qin L, Ng WK, Tam KF, Tang N (2009): Lowmagnitude high-frequency vibration accelerates callus formation, mineralization, and fracture healing in rats. Journal Orthop Res $\underline{27}$, 458-465

Marsell R, Einhorn TA (2011): The biology of fracture healing. Injury $\underline{42}$, 551-555

McClung MR, Grauer A, Boonen S, Bolognese MA, Brown JP, Diez-Perez A, Langdahl BL, Reginster JY, Zanchetta JR, Wasserman SM (2014): Romosozumab in postmenopausal women with low bone mineral density. N Engl J Med $\underline{370}$, 412-420

McClung MR (2015): Emerging Therapies for Osteoporosis. Endocrinol Metab (Seoul) $\underline{30}$, 429-435

McElroy JF, Wade GN (1987): Short- and long-term effects of ovariectomy on food intake, body weight, carcass composition, and brown adipose tissue in rats. Physiol Behav $\underline{39}$, 361-365

McNamara LM, Prendergast PJ, Schaffler MB (2005): Bone tissue material properties are altered during osteoporosis. J Musculoskelet Neuronal Interact $\underline{5}, 342-343$

Mikosch P, Gosch M (2013): Osteoporose - Therapie und sektorenübergreifendes Management. Wien Med Wochenschr (2013) 163, 455-461

Miwa M, Sibonga JD, Sarkar G, Bronk JT, Mizuno K, Turner RT, Bolander ME (1999): Estrogen defenciency causes delayed fracture repair. Trans Orthop Res Soc 24, 482 Moreira LDF, Oliveira MLd, Lirani-Galvão AP, Marin-Mio RV, Santos RNd, LazarettiCastro M (2014): Physical exercise and osteoporosis: Effects of different types of exercises on bone and physical function of postmenopausal women. Arq Bras Endocrinol Metab $\underline{58}$, $514-522$ 
Namkung-Matthai H, Appleyard R, Jansen J, Hao Lin J, Maastricht S, Swain M, Mason RS, Murrell GA, Diwan AD, Diamond T (2001): Osteoporosis influences the early period of fracture healing in a rat osteoporotic model. Bone $\underline{28}, 80-86$

Niethard FU, Pfeil J, Biberthaler P: Osteoporose. In: Niethard FU, Pfeil J, Biberthaler P (Hrsg.): Duale Reihe Orthopädie und Unfallchirurgie. 6., vollst. überarb. und erw. Auflage; Thieme, Stuttgart 2009, 144-150

NIH (2001): Osteoporosis prevention, diagnosis, and therapy. JAMA $\underline{285}$, 785-795

Noor Z, Kania N, Setiawan B (2014): Tibia bone properties at different time course of ovariectomized rats. J Metab Diabetes Disord $\underline{13}, 91$

Oxlund B, Ørtoft G, Andreassen T, Oxlund H (2003): Low-intensity, high-frequency vibration appears to prevent the decrease in strength of the femur and tibia associated with ovariectomy of adult rats. Bone $\underline{32}, 69-77$

Pasqualini M, Lavet C, Elbadaoui M, Vanden-Bossche A, Laroche N, Gnyubkin V, Vico L (2013): Skeletal site-specific effects of whole body vibration in mature rats: from deleterious to beneficial frequency-dependent effects. Bone $\underline{55}, 69-77$

Pschyrembel W: Pschyrembel klinisches Wörterbuch. 259., neu bearb. Auflage; de Gruyter, Berlin 2002

Rahn BA: Die polychrome Sequenzmarkierung des Knochens. In Matzen PF (Hrsg.): Callus. Nova Acta Leopoldina Neue Folge 223, Band 44. Barth, Leipzig 1976, 249-255

Rubin C, Turner AS, Mallinckrodt C, Jerome C, McLeod K, Bain S (2002a): Mechanical strain, induced noninvasively in the high-frequency domain, is anabolic to cancellous bone, but not cortical bone. Bone $\underline{30}$, 445-452

Rubin C, Turner AS, Müller R, Mittra E, McLeod K, Lin W, Qin Y-X (2002b): Quantity and quality of trabecular bone in the femur are enhanced by a strongly anabolic, noninvasive mechanical intervention. J Bone Miner Res 17, 349-357

Rubin C, Judex S, Qin YX (2006): Low-level mechanical signals and their potential as a non-pharmacological intervention for osteoporosis. Age Ageing $\underline{35 \text { Suppl 2 }}$, ii32-ii36

Rubinacci A, Marenzana M, Cavani F, Colasante F, Villa I, Willnecker J, Moro GL, Spreafico LP, Ferretti M, Guidobono F (2008): Ovariectomy sensitizes rat cortical bone to whole-body vibration. Calcif Tissue Int $\underline{82}, 316-326$

Schindeler A, McDonald MM, Bokko P, Little DG (2008): Bone remodeling during fracture repair: The cellular picture. Semin Cell Dev Biol 19 , 459-466

Schmidt W: Bewegungssystem-Grundlagen. In: Aumüller D, Aust G, Doll A, Engele J, Kirsch J, Mense S, Reißig D, Salvetter J, Schmidt W, Schmitz F et al.: Duale Reihe Anatomie. 2.überarb. Auflage; Thieme, Stuttgart 2010, 183-207 
Schulte HM (1997): Osteoporose: Diagnose, Therapie und Prophylaxe. Gynäkologe $\underline{30}$, 352

Sehmisch S, Galal R, Kolios L, Tezval M, Dullin C, Zimmer S, Stuermer KM, Stuermer EK (2009): Effects of low-magnitude, high-frequency mechanical stimulation in the rat osteopenia model. Osteoporos Int 20, 1999-2008

Shi HF, Cheung WH, Qin L, Leung AHC, Leung KS (2010): Low-magnitude highfrequency vibration treatment augments fracture healing in ovariectomy-induced osteoporotic bone. Bone 46, 1299-1305

Slatkovska L, Alibhai SMH, Beyene J, Cheung AM (2010): Effect of whole-body vibration on BMD: a systematic review and meta-analysis. Osteoporos Int 21, 1969-1980

Slatkovska L, Alibhai SMH, Beyene J, Hu H, Demaras A, Cheung AM (2011): Effect of 12 months of whole-body vibration therapy on bone density and structure in postmenopausal women: a randomized trial. Ann Intern Med 155, 668

Sobotta Lehrbuch Histologie: Zytologie, Histologie, mikroskopische Anatomie. Hrsg. v. Welsch U. Elsevier Urban \& Fischer, München 2003

Stengel S von, Kemmler W, Bebenek M, Engelke K, Kalender WA (2011): Effects of whole-body vibration training on different devices on bone mineral density. Med Sci Sport Exerc 43, 1071-1079

Stuermer EK, Seidlova-Wuttke D, Sehmisch S, Rack T, Wille J, Frosch KH, Wuttke W, Sturmer KM (2006): Standardized bending and breaking test for the normal and osteoporotic metaphyseal tibias of the rat: effect of estradiol, testosterone, and raloxifene. J Bone Miner Res 21, 89-96

Stuermer EK, Komrakova M, Werner C, Wicke M, Kolios L, Sehmisch S, Tezval M, Utesch C, Mangal O, Zimmer S (2010a): Musculoskeletal response to whole-body vibration during fracture healing in intact and ovariectomized rats. Calcif Tissue Int $\underline{87}, 168-180$ Stuermer EK, Sehmisch S, Rack T, Wenda E, Seidlova-Wuttke D, Tezval M, Wuttke W, Frosch KH, Stuermer KM (2010b): Estrogen and raloxifene improve metaphyseal fracture healing in the early phase of osteoporosis. A new fracture-healing model at the tibia in rat. Langenbeck Arch Surg $\underline{395}, 163-172$

Stuermer EK, Komrakova M, Sehmisch S, Tezval M, Dullin C, Schaefer N, Hallecker J, Stuermer KM (2014): Whole body vibration during fracture healing intensifies the effects of estradiol and raloxifene in estrogen-deficient rats. Bone $\underline{64}, 187-194$

Tezval M, Biblis M, Sehmisch S, Schmelz U, Kolios L, Rack T, Stuermer KM, Stuermer EK (2011): Improvement of femoral bone quality after low-magnitude, high-frequency mechanical stimulation in the ovariectomized rat as an osteopenia model. Calcif Tissue Int $\underline{88}, 33-40$ 
Toth MJ, Poehlman ET, Matthews DE, Tchernof A, MacCoss MJ (2001): Effects of estradiol and progesterone on body composition, protein synthesis, and lipoprotein lipase in rats. Am J Physiol Endocrinol Metab 280, 501

Trautmann LM: Einfluss der vertikalen Ganzkörpervibration verschiedener Frequenzen auf die Frakturheilung der osteoporotischen Ratte. Med. Diss. Göttingen 2014

Turner AS (2001): Animal models of osteoporosis--necessity and limitations. Eur Cell Mater $1,66-81$

Utesch CM: Einfluss der vertikalen Ganzkörpervibration auf die metaphysäre Frakturheilung der gesunden und osteoporotischen Tibia im Ratten-Tiermodell. Med. Diss. Göttingen 2015 van der Jagt OP, van der Linden, JC, Verhaar J, Weinans H (2012): Low-magnitude whole body vibration does not affect bone mass but does affect weight in ovariectomized rats. J Bone Miner Metab $\underline{30}, 40-46$

Wade SW, Strader C, Fitzpatrick LA, Anthony MS, O'Malley CD (2014): Estimating prevalence of osteoporosis: examples from industrialized countries. Arch Osteoporo $\underline{9}, 182$ Weber-Rajek M, Mieszkowski J, Niespodzinski B, Ciechanowska K (2015): Whole-body vibration exercise in postmenopausal osteoporosis. Prz Menopauzalny $\underline{14}, 41-47$

Wehrle E, Wehner T, Heilmann A, Bindl R, Claes L, Jakob F, Amling M, Ignatius A (2014): Distinct frequency dependent effects of whole-body vibration on non-fractured bone and fracture healing in mice. J Orthop Res $\underline{32}$, 1006-1013

Weidemann A: Der Einfluss von Strontiumranelat auf die Frakturheilung osteopener Ratten. Med. Diss. Göttingen 2014

Wessler S (1989): The issue of animal models of thrombosis. Ann N Y Acad Sci $\underline{566}, 366-$ 370

Wolff J: Das Gesetz der Transformation der Knochen. Hirschwald, Berlin 1892

Wronski TJ, Lowry PL, Walsh CC, Ignaszewski LA (1985): Skeletal alterations in ovariectomized rats. Calcif Tissue Int $\underline{37}$, 324-328

Wronski TJ, Cintron M, Dann LM (1988a): Temporal relationship between bone loss and increased bone turnover in ovariectomized rats. Calcif Tissue Int $\underline{43}, 179-183$

Wronski TJ, Cintrón M, Doherty AL, Dann LM (1988b): Estrogen treatment prevents osteopenia and depresses bone turnover in ovariectomized rats. Endocrinology 123, 681686

Kluba T, Rehart S, Reize P, Roetman B, Rudert M: Metabolische Knochen- und Gelenkerkrankungen. In: Wülker N (Hrsg.): Taschenlehrbuch Orthopädie und Unfallchirurgie. 2. Auflage; Thieme, Stuttgart 2010, 487-506 
Wysocki A, Butler M, Shamliyan T, Kane RL (2011): Whole-body vibration therapy for osteoporosis: state of the science. Ann Intern Med 155, 680-6, W206-13

Xie L, Jacobson JM, Choi ES, Busa B, Donahue LR, Miller LM, Rubin CT, Judex S (2006): Low-level mechanical vibrations can influence bone resorption and bone formation in the growing skeleton. Bone $\underline{39}, 1059-1066$

Xiong J, Piemontese M, Onal M, Campbell J, Goellner JJ, Dusevich V, Bonewald L, Manolagas SC, O’Brien CA, Heymann D (2015): Osteocytes, not Osteoblasts or Lining Cells, are the Main Source of the RANKL Required for Osteoclast Formation in Remodeling Bone. PLoS ONE 10, 1-19 


\section{Danksagung}

Ich danke ganz herzlich Frau Prof. Dr. med. Ewa Stürmer. Von ihr stammt die Anregung zur Bearbeitung dieses Themas. Sie stand mir jederzeit mit hilfreichen Anregungen und konstruktiver Kritik zur Seite. Besonders bedanken möchte ich mich für die schnelle Korrektur, welche mich immer motiviert hat.

Ebenfalls möchte ich meinen besonderen Dank an Frau Dr. rer. nat. Marina Komrakova zum Ausdruck bringen. Sie war für mich eine verlässliche Ansprechpartnerin bei Fragen, insbesondere im Rahmen der Auswertung, und unterstützte mich immer mit ihren Ratschlägen während der gesamten Arbeit.

Mein Dank gilt auch den Mitarbeiterinnen des Labors Frau Annette Witt und Frau Ramona Castro-Machgut. Sie haben mich warmherzig im Labor willkommen geheißen und mich durch viele Tipps unterstützt. Insbesondere ihren motivierenden Worten verdanke ich die Fertigstellung dieser Arbeit.

Weiterhin möchte ich mich bei Herrn Christian Dullin für die Einarbeitung am Mikro-CT und in die dazugehörige Software sowie bei Herrn Fritz Kauer für die Einweisung zur Durchführung des biomechanischen Kompressionstests bedanken.

Die Studie wurde von der Deutschen Forschungsgemeinschaft (DGF, STU 478/3-2) gefördert. 


\section{Lebenslauf}

Ich, Peggy Lieberwirth, wurde am 18.09.1982 in Karl-Marx-Stadt, jetzt Chemnitz, geboren.

Im Rahmen meines schulischen Werdegangs konnte ich im Jahr 1999 die Mittlere Reife an der Annenschule in Chemnitz erlangen. Im Anschluss setzte ich meinen Bildungsweg am Beruflichen Schulzentrum für Wirtschaft II in Chemnitz fort und schloss im Juni 2002 meine schulische Ausbildung mit der Allgemeinen Hochschulreife ab. Aufgrund des Negativbescheides für einen Studienplatz für Humanmedizin arbeitete ich im Anschluss bis Oktober 2003 als geringfügig Angestellte bei der Tageszeitung „Freie Presse“ in Chemnitz und für die Praktiker Bau- und Heimwerkermärkte AG. Danach absolvierte ich von August 2003 bis Juli 2004 eine Vollzeitausbildung zur Rettungsassistentin an der Rettungsdienstschule Neidel in Werdau. Parallel engagierte ich mich im Sanitätszug des Katastrophenschutzes im Landesverband des Mittleren Erzgebirgskreises. Die weiteren Wartesemester überbrückte ich von September 2004 bis August 2005 als gewerbliche Mitarbeiterin im Rotationssystem bei der Willy Dany Restaurantbetriebsgesellschaft mbH \& Co. Service KG angestellt.

Um meinen Bildungsweg fortzusetzen, nahm ich im Oktober 2005 das Studium der Biologie (B.sc.) an der Carl von Ossietzky Universität in Oldenburg auf. Parallel bewarb ich mich weiterhin für einen Studienplatz für Humanmedizin.

Dieses konnte ich zum Wintersemester 2006 nach Erhalt eines Studienplatzes über das hochschuleigene Auswahlverfahren an der Georg-August-Universität in Göttingen beginnen. Den vorklinischen Studienabschnitt schloss ich am 29.09.2008 mit dem 1. Staatsexamen ab. Während des klinischen Studienabschnittes konnte ich in meinen Famulaturen erste Einblicke in die Bereiche der Inneren Medizin (Februar bis März 2009, Klinikum Chemnitz), der Anästhesie und Intensivmedizin (Juli bis August 2009, Klinikum Chemnitz), der Radiologie (März 2010, Gemeinschaftspraxis für Radiologie und Nuklearmedizin am Zeisigwaldklinikum Bethanien Chemnitz), der Frauenheilkunde und Geburtshilfe (Juli bis August 2010, Klinikum Chemnitz) und in der Pathologie (September bis Oktober 2010, Johannes Orth Institut für Pathologie und Neuropathologie in Göttingen) gewinnen.

Das Praktische Jahr absolvierte ich am Universitätsklinikum Göttingen. Im 1. Tertial arbeitete ich in den Abteilungen der Kardiologie und Pneumologie sowie Nephrologie und Rheumatologie im Bereich der Inneren Medizin (August bis Dezember 2011). Darauf 
folgte mein Wahltertial in der Abteilung für Anästhesiologie, Rettungs- und Intensivmedizin (Dezember 2011 bis April 2012). Das chirurgische Tertial absolvierte ich in der Abteilung für Unfallchirurgie, Plastische und Wiederherstellungschirurgie sowie in der Abteilung für Allgemein- und Viszeralchirurgie (April bis Juli 2012). Am 08.11.2012 konnte ich das Studium der Humanmedizin erfolgreich mit dem 2. Staatsexamen abschließen.

Während meines Studiums engagierte ich mich als Umwelttutorin und Wohnheimsprecherin des Studentendorfes Göttingen. Zudem arbeitete ich von April 2010 bis Juli 2011 als studentische Hilfskraft in der Abteilung für Allgemeinmedizin. Neben meinen sehr guten Englischkenntnissen und Grundkenntnissen in Französisch erwarb ich parallel zum Studium an der „Zentralen Einrichtung für Sprachen und Schlüsselqualifikationen“ der Universität Göttingen Grundkenntnisse in Spanisch.

Meine Promotion begann ich im Jahre 2010 in der Abteilung für Unfallchirurgie, Plastische und Wiederherstellungschirurgie der Universitätsmedizin Göttingen unter der Betreuung von Frau Prof. Dr. med. Ewa Stürmer.

Seit März 2013 arbeite ich als Assistenzärztin in der Inneren Medizin am Ernst von Bergmann-Klinikum in Potsdam. 